\title{
ASSESS THE KNOWLEDGE AND PRACTICES OF NURSES REGARDING THE PREVENTION OF INFECTION IN BURN PATIENT IN TERTIARY CARE HOSPITAL LAHORE
}

\author{
Rukhsana Manzoor, Reg \# PBSNO2183004 \\ Lahore School of Nursing \\ The University of Lahore \\ Lahore, Pakistan \\ barbydollmano786@gmail.com \\ Kousar Parveen, Assistant Professor \\ Lahore School of Nursing \\ The University of Lahore \\ Lahore, Pakistan \\ Kousar.parveen@uol.lsn.edu.pk \\ Muhammad Hussain, Assistant Professor \\ Lahore School of Nursing \\ The University of Lahore \\ Lahore, Pakistan \\ mhussainsial@gmail.com \\ Muhammad Afzal, associate professor \\ Lahore School of Nursing \\ The University of Lahore \\ Lahore, Pakistan \\ mafzalaku@gmail.com \\ Prof. Dr. Syed Amir Gilani \\ Lahore School of Nursing \\ The University of Lahore \\ Lahore, Pakistan \\ profgilani@gmail.com
}

\begin{abstract}
Introduction: Burn wound infection are one of the most significant and possibly genuine complications that happen in the intense period following injury. Roughly 180,000 expiries happen due to burn each year evaluated by world health organization in 2018. Reducing the spread of disease and human care services related burn infection in the burn unit of public hospital. WHO has revealed a lot higher occurrence in Pakistan roughly $1388 / 100000$ yearly when contrasted with worldwide frequency of 110/100000 for every annum Implementation of rules will lessen the rate pace of burn wound contamination in the burn unit. Methodology: quantitative observational descriptive study design was used to assess the nurses' knowledge and practices regarding prevention of infection in burn patient. In order to assess nurses practiced, data was collected through the standardized checklist and questionnaire regarding prevention of infection in burn patient. The checklist and questionnaire consist of 55 items. Results: The findings of this study revealed that there are poor knowledge and practices of nurses regarding prevention of infection in burn patient. Conclusion: Based on the findings of the study, it is concluded that nurses working in burn units of hospital of Lahore, Punjab region have low knowledge and practices regarding prevention of Infections among burn patients. Therefore, hospitals are required to organize adequate trainings and to develop unit specific clinical infection control guidelines and protocols
\end{abstract}

Key words: Infection, Practice, Knowledge, Burn, Patient. 
DOI: 10.7176/JHMN/74-11

Publication date:May $31^{\text {st }} 2020$

\section{CHAPTER - I}

\section{Introduction}

Background: Burn wound infection are one of the most significant and possibly genuine complications that happen in the intense period following injury. Roughly 180,000 expiries happen due to burn each year evaluated by world health organization in 2018 (John Manning, 2018). WHO has revealed a lot higher occurrence in Pakistan roughly 1388/100000 yearly when contrasted with worldwide frequency of 110/100000 for every annum Implementation of rules will lessen the rate pace of burn wound contamination in the burn unit (Othman \& Kendrick, 2010).

Reducing the spread of disease and human care services related burn infection in the burn unit of public hospital (El-Maghawry, El Nem, Sherif, \& Hagag, 2016). Burn infection are viewed as the major and basic healthcare services issues in most social insurance settings all things considered of developing nations (AL-Salih, Muhbes, \& Hindi, 2018). Contamination is one of the primary difficulties among burned patients. Medical team specially nurses working with such patients must have skills and information so as to guarantee conveyance of nature of care. Despite the fact that the burnt patients at high danger of creating dangerous issues as infection (El-Sayed, Gomaa, \& Abdel-Aziz, 2015).

Infection in burn patients has become a significant segment of the national and global development to upgrade client/patient security. Burn wound contamination is the most widely recognized reason for death among burnt patients following the burn injury itself. Nurses as a caretakers are at the focal point of patient consideration and are the health care experts destined to catch mistakes and prevent damage to patients (Eldeen, Abd-Elaziz, Moghazy, Shahin, \& El-Ata, 2016).

Nurses as medical caretakers are at more serious danger of getting and transmitting health care acquired infections over the span of conveying nursing care; measures to decrease the transmissions are consequently a noteworthy center nursing care. Aseptic Technique among attendants in disease control during the board of burns assumes an imperative job in decreasing their spread of infection and mortality and thus cost of wound management at individual and national level. Thusly, contamination is the most genuine entanglement of burn wound with sepsis being the fundamental cause of death. Adherence to the standard working methodology on burn patient care the executives help with decrease infection spread (JEROTICH, 2016). There is a significance importance of proper use, cleanliness and disposal of patients related items as follow,

Despite the presence of formal rules for the intense healthcare setup, nurse's adherence to prescribed utilization of facial defensive equipment to prevent hospital related transmission of transmittable respiratory pathogenic remains imperfect. In addition to individual factors, for example, information and instruction, group factors, for example, shared impression of hierarchical help for security may impact adherence (Rozenbojm, Nichol, Spielmann, \& Holness, 2015). 
Hospital obtained contaminations, one of the main sources of, morbidity and mortality, are basic in developing nations. Methicillin-safe staphylococcus aureus, commonest reason for disease, has been disconnected from the hands of the greater part of healthcare services laborers. Practice of hand cleanliness may help in the control of nosocomial diseases (Adegboye, Zakari, Ahmed, \& Olufemi, 2018).

Proof keeps on mounting demonstrating that the clinical consideration condition is a key part in empowering or encouraging transmission of pathogens. At the point when contacted, polluted ecological things and surfaces bring about tainting of the hands of medical caretakers and other health care worker. They, thus, can move microorganisms to patients, different surfaces or things, and even themselves. Surfaces, furniture, and hardware in tolerant rooms must be normally cleaned and purified utilizing specialists that are endorsed by the Environmental Protection Agency for use in healthcare services settings (Carrico, Garrett, Balcom, \& Glowicz, 2018).

Aseptic methods, which includes disease counteraction activities intended to shield patients from contamination while experiencing intrusive clinical strategies, is generally endorsed by rule creators as a basic competency in the avoidance of contaminations. Be that as it may, no significant clarification of what aseptic system is or how it is to be applied to guarantee understanding wellbeing is given inside any of the rules. The Aseptic Non-Touch Technique began by Rowley in the late 1990s, was intended to help address variable aseptic system measures of training and give a supported, contemporary, proof based structure to institutionalize this basic competency and help improve norms of training (Rowley \& Clare, 2019).

Around the world, an expected 16 billion injuries are address each year. Not all needles and syringes are discarded securely, making a danger of injury and disease and open doors for reuse (Unicomb et al., 2018). In 2015, a joint WHO/UNICEF appraisal found that simply over half (58\%) of inspected offices from 24 nations had satisfactory frameworks set up for the protected removal of medicinal services squander (Organization, 2015).

Healthcare services materials and individual defensive equipment are known to harbor various microorganisms. Most remarkably, there is an expanded worry that methicillin safe staphylococcus aureus and vancomycin-safe enterococcus can make due for a considerable length of time on cloths. There is further worry that these defiled cloths at that point become a potential wellspring of cross-tainting (Tarvadi, 2018).

All hospital visitors must follow the "Regulatory Policy". People with transmittable disease ought not visit patients. Attendants are checked by the Burn Center nursing staff and avoided if there is proof of a transferable disease. Visitors are told by nursing work force to perform hand cleanliness with an antimicrobial operator before entering and leaving tolerant consideration zones. In the event that the patient requires disengagement, the nursing staff educates guests to wear the suitable individual defensive hardware (Cancio et al., 2017).

The focal venous catheter is a gadget utilized for some, capacities, including observing hemodynamic markers and overseeing intravenous meds, liquids, blood items and parenteral sustenance. In any case, as a remote article, it is defenseless to colonization by micro-organisms, which may prompt catheter-related circulatory system disease and thusly, expanded mortality, morbidities and health insurance costs (Lai et al., 2016).

Chlorhexidine gluconate bathing of hospitalized patients may have advantage in lessening clinic obtained circulatory system contaminations. Be that as it may, the extent of impact, execution constancy, and patient- 
focused results are misty. Right now, we analyzed the impact of chlorhexidine gluconate bathing on counteraction of clinic procured circulatory system diseases and surveyed constancy to execution of this conduct mediation (Musuuza et al., 2019).

There is expanding enthusiasm for the job of cleaning for overseeing hospital obtained contaminations. Pathogens, for example, vancomycin-safe enterococci, methicillin safe Staphylococcus aureus, multi safe Gram-negative bacilli, norovirus, and Clostridium difficile persevere in the health care services condition for a considerable length of time. Both cleanser and disinfectant-based cleaning can help control these pathogens, in spite of the fact that challenges with estimating neatness have undermined the nature of distributed proof. Conventional cleaning techniques are famously wasteful for sterilization, and new methodologies have been proposed, including disinfectants, steam, mechanized dispersal frameworks, and antimicrobial surfaces (Dancer, 2014).

Medical attendants share obligation with other health care services work force for infection chance decrease in patients across whole continuum of care and assume imperative job in diminishing dangers for disease through an assortment of direct consideration exercises (Abukhelaif, 2019). Use and proper disposal of personal protective equipment, solid hospital waste management, environmental sanitation and properly cleanliness of equipment, surfaces play an important role in infection control among burnt patients. So, it is need to assess the nurse's knowledge and practices regarding the prevention of infection among burnt patients.

\section{Problem statement:}

Burn wounds are possibly hazardous conditions and burn patients request excellent consideration. Infection management during care of burnt patients at burnt units are essential for the wellbeing of patients and health care worker. Nurses are play as an important role during care of burnt patient. This care should be given by knowledgeable and competent nurses following specific guideline or protocols that will reduce the occurrence of infection and complications.

Thus, there is proof that administration and care of patient with burn injury need a one of a unique information and abilities from a mindful multidisciplinary colleague particularly the medical health worker such as nurse, and explicit contamination control rules ought to be produced for decreasing diseases particularly clinic procured disease. The actual need to do the study is to assess the knowledge and practice of nurses regarding prevention of infection among burnt patient. In the context of above mention research problem, the answer will give for bellow mentioned questions through this study.

Purpose of the study: the purpose of the study is to assess the nurses' knowledge and practice for prevention of infection in burn patients in tertiary care hospital Lahore

\section{Research questions:}

- What is the knowledge of nurses regarding Prevention of Infection in Burn Patients?

- What are the practices of nurses regarding Prevention of Infection in Burn Patients?

\section{Hypothesis}

\section{Alternative hypothesis:}

- Nurses knowledge may have positive effect in control of infection among burnt patient.

- Nurses practices may have positive effect in control of infection among burnt patient. 


\section{Null hypotheses:}

- Nurses knowledge may have no effect in control of infection among burnt patient.

- Nurses practices may have no effect in control of infection among burnt patient.

\section{Theoretical framework:}

An applied model by Quirke has been adjusted and utilized to investigate factors impacting arrangement of nursing care to hospitalized consume patients. The first model was gotten from an idea examination of problematic consideration of the intensely sick ward patients in articles distributed somewhere in the range of 1990 and 2009. This altered calculated model comprises of three segments that add to nursing care and anticipation of contamination to consume patients: association of work (staffing, patients, inspiration, and strategy), accessibility of hardware/supplies (material, for example, individual defensive gear's and prescription) and clinical nursing fitness

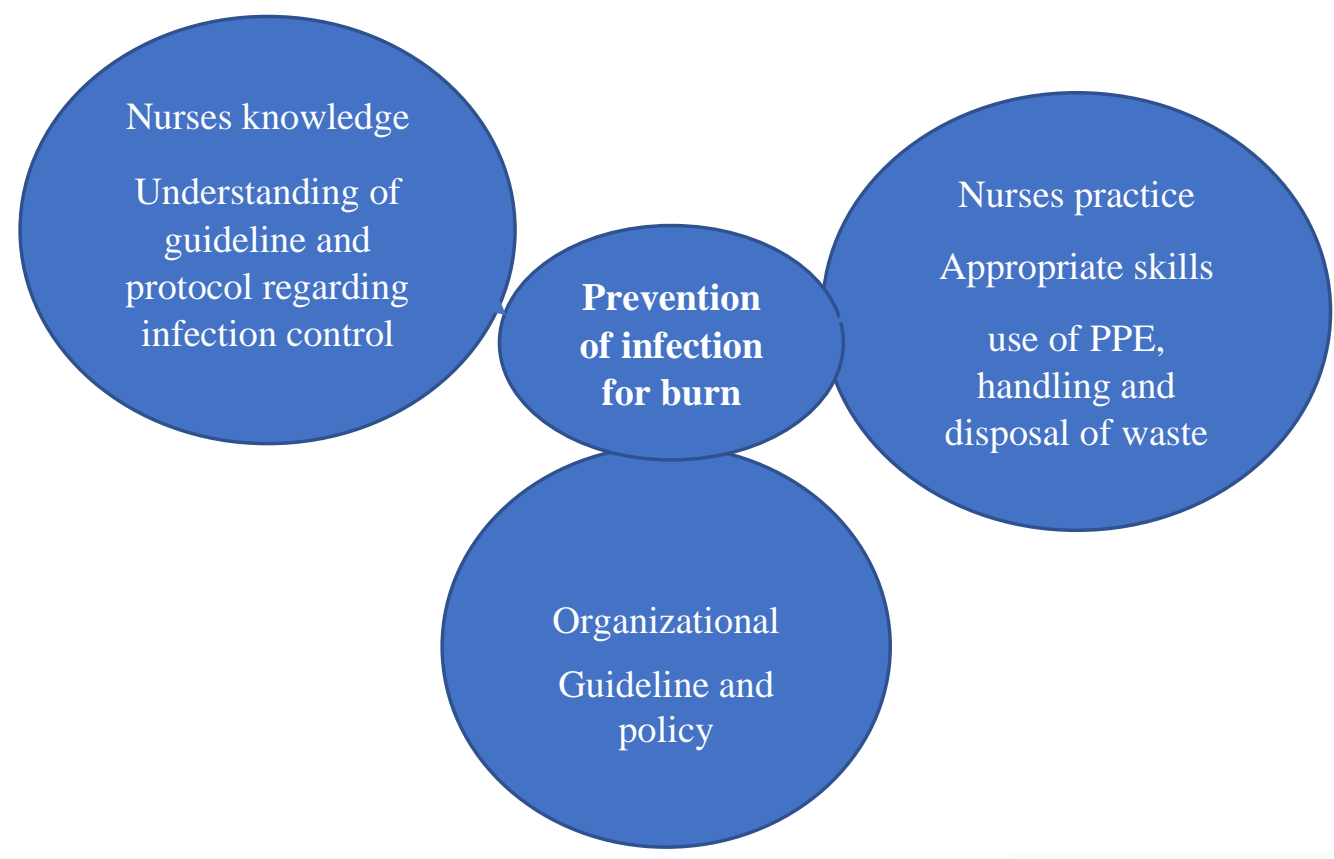

(Quirke, Coombs, \& McEldowney, 2011).

\section{Conceptual definition}

Knowledge: "'Knowledge' is characterized as what we know: information includes the psychological procedures of appreciation, comprehension and discovering that go on in the brain and just in the psyche, anyway much they include communication with the world outside the brain, and collaboration with others" (Davies et al., 2002).

Practices: "The application of rules and knowledge that leads to action"(Badran, 1995)

Infection: The attack and augmentation of microorganisms, for example, microscopic organisms, bacteria, and parasites that are not typically present inside the body (Calandra \& Cohen, 2005).

\section{Operational definition}

Knowledge: Awareness and understanding of nurses regarding infection prevention of burnt patient in tertiary care hospital Lahore.

Practices: standard guidelines and personal protective equipment follow/use by nurses working in burn unit of tertiary care hospital Lahore. 
Infection: The intrusion and duplication of microorganisms, for example, microscopic organisms, viruses, and parasites in consume quiet conceded in burn unit that are not regularly present inside the body.

\section{Variables of Study:}

\section{Independent variable;}

- Knowledge

- $\quad$ Practices

\section{Dependent variable;}

- Infection

\section{Limitation/ Scope of the study}

- Investigation discoveries will be restricted and can't be summed up on the generalized that the little example and chose from one land region in Pakistan.

- The extent of the examination will be additionally restricted not utilized control group

- $\quad$ The scope of the study will be also limited not used control group.

\section{CHAPTER - II}

\section{Review of Literature}

Roughly 180,000 deaths happen by burn each year assessed by world health organization in 2018 (Jennifer Manning, 2018). WHO has revealed a lot higher occurrence in Pakistan roughly 1388/100000 yearly when contrasted with worldwide frequency of 110/100000 for each annum Implementation of rules will decrease the rate pace of consume twisted disease in the consume unit (Othman \& Kendrick, 2010). Different studies show that the how patient related items, nurse knowledge and practices have importance in prevention of infection in burnt patients.

A study recently conducted in Pakistan regarding the assessment of Knowledge regarding infection control was received by $89 \%$ of nurses but their source of information was practice not in-service educational programs. Subsequently, they had inadmissible degree of information and practices showed by information and practice score under $75 \%$. The discoveries of the present examination uncovered medical attendants' low degree of information and practices. Thus, health care settings are required to compose propelled instructional courses and to create unit explicit clinical rules and conventions (Buksh, Ghani, Amir, Asmat, \& Ashraf, 2019).

Another study conducted in 2018 to assess the knowledge of nurses regarding prevention of infection among burn patients and results revealed that that the majority $69.8 \%$ of nurses had passed score of knowledge regarding nosocomial infection in burns' units at middle Euphrates teaching hospitals.in addition, the present study pointed out there was a significant relationship between nurse knowledge and number of training courses about nosocomial infection (AL-Salih et al., 2018).

In 2017 authors proposes in their investigations with respect to nurse's information about contamination and a large portion of the nurses $87 \%$ had a reasonable degree of information, while just $4 \%$ of them had a decent degree 
of information on preventive proportions of nosocomial diseases among burnt patients. The outcomes additionally uncovered that most of the nurses $71 \%$ had reasonable practices about nosocomial diseases while $26 \%$ of them had great practices and just $3 \%$ of them had poor practices. The holes in information and works on with respect to disease control measures show the need to build up a related medicinal services arrangement in regards to contamination (Alrubaiee, Baharom, Shahar, Daud, \& Basaleem, 2017).

In Nigeria a study conducted to assess the knowledge and practices of nurses regarding infection control and results revealed that the sixty nine out of the 80 respondents had great information that a hand is the most widely recognized vehicle of transmission of contamination. Be that as it may, 53.8\% and $32.5 \%$ of the respondents knew about development of hand cleanliness and rehearsed six stages of the hand washing procedure separately (Adegboye et al., 2018).

Hand washing: In 2016 a study conducted regarding aseptic technique such as hand washing in association with infection spread among burn patient and results revealed that the $42.9 \% 42.9 \%$ of the members didn't wash their hands appropriately previously, during and after the dressing methodology while $88.1 \%$ had great information on aseptic system; anyway $14.6 \%$ of the members kept up the aseptic system practice all through the technique while $85.4 \%$ didn't. Measurable criticalness was found between hindrances to aseptic system and satisfactory water supply in the taps and cleanser at $\mathrm{P}=0.038$. $70.7 \%$ of the rooms needed standard working methods on disease counteraction (JEROTICH, 2016).

Gloves: A study conducted in 2019 regarding gloves as a powerful hindrance for contamination control and results uncovered that there is solid proof of positive connection between familiarity with the respondents with gloves as a viable boundary for disease control, hand interceded transmission and catheter care rehearses with a large portion of the attendant's segment qualities anyway there was no relationship between the age and wearing of gloves (Abukhelaif, 2019).

Aseptic technique: Prevention of burn wound contamination includes evaluation of the injury at each dressing change for changes in the character, scent or measure of twisted seepage, with prompt warning of the doctor if any crumbling happens. Exacting aseptic procedure ought to be utilized when taking care of the open injury and dressing materials just as recurrence of dressing ought to be founded on the appraisal of the injury condition. In the event that the injury has necrotic material present, a debriding dressing ought to be picked while a defensive dressing is best for perfect, mending wounds (Norbury et al., 2016).

Needle stick injury: Injections with tainted needles and syringes in low-and center pay nations have diminished significantly as of late, incompletely because of endeavors to decrease reuse of infusion gadgets. Regardless of this advancement, in 2010, hazardous infusions were as yet liable for upwards of 33800 new HIV contaminations, 1.7 million hepatitis B diseases and 315000 hepatitis C diseases .An individual who encounters one needle stick injury from a needle utilized on a tainted source quiet has dangers of 30\%, 1.8\%, and $0.3 \%$ separately of getting contaminated with HBV, HCV and HIV (Pepin, Chakra, Pepin, Nault, \& Valiquette, 2014). 
Solid waste and PPE: the aggregate sum of waste created by human services exercises, about $85 \%$ is general, non-dangerous waste. The staying $15 \%$ is viewed as perilous material that might be irresistible, dangerous or radioactive. Measures to guarantee the safe and ecologically stable administration of social insurance squanders can keep unfriendly wellbeing and natural effects from such waste including the unintended arrival of substance or organic risks, including drug-safe microorganisms, into the earth subsequently ensuring the strength of patients, wellbeing laborers, and the overall population (Tarvadi, 2018).

Venous catheter insertion: An examination analyzed the impact of purging versus no purifying, and results uncovered that the Chlorhexidine arrangement may diminish blood diseases related with the catheter contrasted and povidone-iodine arrangement (lessening the contamination rate from 64 cases for each 1000 patients with povidone iodine to 41 instances of disease for every 1000 with chlorhexidine. This makes an interpretation of into the need to get 44 individuals maintain a strategic distance from one extra circulatory system contamination. Chlorhexidine arrangement may (contrasted and povidone iodine arrangement) additionally decrease the nearness of irresistible life forms inside the catheter diminished from 240 tainted catheters for every 1000 individuals to 189 contaminated catheters for every 1000 individuals (Lai et al., 2016).

Chlorhexidine bath: Patient bathing with chlorhexidine gluconate essentially decreased the rate of clinic gained circulation system diseases. Numerous examinations didn't report constancy to the intercession or patient-focused results. For maintainability and replicability fundamental for compelling execution, loyalty appraisal that goes past whether a patient got a mediation or not ought to be standard practice especially for complex social intercessions, for example, chlorhexidine gluconate bathing (Musuuza et al., 2019).

Environmental cleaning: Environmental cleaning is a piece of standard Precautions, which ought to be applied to all patients in all health care services setup. It is significant that ecological cleaning programs be executed inside the structure of office level projects. Where conceivable during staff preparing and instruction, for instance consider producing collaborations and featuring the connection between ecological cleaning and hand cleanliness exercises in forestalling natural transmission of emergency clinic procured disease (Ling, Apisarnthanarak, Villanueva, Pandjaitan, \& Yusof, 2015).

\section{Objectives}

\section{General objective:}

- To assess the Nurses' knowledge and practices for prevention of infection in burn patients in tertiary care hospital Lahore.

\section{Specific objectives}

- To assess the Nurses' knowledge for prevention of infection in burn patients in tertiary care hospital Lahore.

- To assess the Nurses' practices for prevention of infection in burn patients in tertiary care hospital Lahore. 


\section{Significance of the study}

Patient: who conceded burn unit for the most part is profoundly helpless to disease. Along these lines, the use of widespread precautionary measures secured staff, patients and condition from contamination it is limited uses in burn unit to advance patient wellbeing and reduction chance.

Nurse: in this manner, evaluation level of attendants' information and practice about disease control procedure is crucial activity to control contamination in the burn unit. In this way nurses will comprehend their weakness and attempted to receive standard rule in results their insight and abilities will be improved.

Organization: The Finding of the examination may be useful for the association to build up the methodologies to control superfluous infection through instructional meeting, workshop, and class in result at last this will improve the workplace and nature of care. It will be appropriate for the administration to find a way to locate the powerless components. In results the quality of care will be improved.

Policy maker: This mindfulness will help the strategy creator to plan methodologies and set in motion to improve the workplace.

Future researcher: The aftereffect of this investigation will provide guidance to the future analyst to use this examination as a writing and direction. Moreover, study will assist them with identifying the investigation hole. The discoveries of the examination can be utilized as optional information for future research researchers.

\section{CHAPTER - III}

\section{Material and Methods}

\section{Study Design:}

Observational quantitative cross-sectional investigation study design was use

\section{Study site:}

The study was conducted in Jinnah hospital located at Lahore, Pakistan.

\section{Study Setting:}

The study was conducted in burn-unit of Jinnah hospital.

\section{Study duration:}

The Study duration was 4 months from February, 2020 to May, 2010.

\section{Study population:}

The study population was all charge nurses working in burn units of Jinnah hospital.

\section{Inclusion Criteria:}

- All charge nurses working in burn units working at least for six months before the start of data collection.

- Willing to participate

\section{Exclusion Criteria:}

- Nurses working in burn care units, who were not involved in direct patient care e.g. Head nurses, Clinical Instructors and Nurse Managers and nurses who have worked for less than six months in the Burns Unit.

- $\quad$ Not willing to participate

\section{Sampling Technique:}


Data was collected by convenient sampling technique from selected sample.

\section{Sample Size:}

Sample size was calculated by using "Selvin's formula".

$\mathrm{n}=\mathrm{N} / 1+(\mathrm{N})(\mathrm{E})^{2}$

The total population is 300 .

$\mathrm{N}=$ Population, $\mathrm{n}=$ Sample size, $\mathrm{E}=5 \%$ Margin of error $\quad$ Confidence interval $95 \%$

$$
\begin{aligned}
& \mathrm{n}=\mathrm{N} / 1+(\mathrm{N})(\mathrm{E})^{2} \\
& \mathrm{n}=300 / 1+(300)(0.05)^{2} \\
& \mathrm{n}=300 / 1+(300)(0.0025) \\
& \mathrm{n}=300 / 1+.75 \\
& \mathrm{n}=300 / 1.75 \\
& \mathrm{n}=171
\end{aligned}
$$

The sample size for this study will be 171 .

\section{Ethical Consideration;}

Composed consent was taken from the Ethical board of University of Lahore. Authorization was taken from the Nursing manager of, Jinnah hospital, to lead investigate study. All members were educated about the motivation behind the examination. All data and gathered information were kept secret by head examiner printed copy in lock. Secrecy of delicate duplicate was kept up by a coding. The subject was educated that there are no hindrances or hazard on the strategies of the investigation.

\section{Data collection procedure:}

After endorsement poll was circulated the nurses to survey the information and watch the nurse's practices over a time of 02 months beginning from walk 2020 to April 2020. The chose burn units were visited on consistent schedule and nurses were drawn closer during morning, night and night shifts.

\section{Data Collection Instrument and Tools:}

A well-adapted questionnaire was to measure the knowledge in this study from nurses' point of view it consists of two sections.

Section A: section A consists of demographic data such as age, educational status, experience, information received regarding infection control and protocol availability regarding infection control.

Section B: section "B" consists of 27 items. It was used in 2018 to assess the knowledge of nurses regarding prevention of infection among burnt patient. It was calculated as with internal consistency of 0.685 which indicated that the instrument was reliable for data collection. The nurses will require indicating their opinions.

Section C: section "C" is a checklist including, use of personal protective equipment's and its disposal, fumigation, disinfectant of medical equipment, appropriate waste management of burn unit waste, aseptic techniques, hand 
washing techniques, Chlorhexidine bath, aseptic techniques of skin preparation. Check list will use to assess the practices of nurses working in burn units.

\section{Data Analysis Method:}

The study was analyzing the data by SPSS version 16. Statistical analysis of the study was descriptive. The study sample will be characterized by using a measure of central tendency (mean, median, and mode).

\section{CHAPTER - IV}

\section{Results}

This study is conducted at Jinnah hospital to assess the knowledge and practices of nurses regarding the prevention of infection in burn patient. The result of this study distributed into two sections, first section is statistics of demographic factors of nurse working in hospital regarding the prevention of infection in burn patient and second is frequency and statistics of 27 items regarding nursing knowledge assessment and Checklist regarding prevention of infection in burn patients.

Section A: Table 1 shows that the frequency of demographics includes age, qualification experience, Protocol availability regarding infection control and Information received regarding infection control of the 171 participants and the results revealed that the age of participants was found minimum 21 to highest 52, participant's age group 21-28 years frequency was $31(18.1 \%)$, majority $64(37.4 \%)$ participants were belong to age group 37-44 years and moderately 53 (31\%) were fall in age group 29- 36 years and only 23 (13.5\%) were 45-52 year old. Only 32 (18.3\%) participants have experience 10-12 years, majority of nurses 62 (36.7\%) have 7-9 years job experience, $38(22.2 \%)$ have 4-6 years' experience and 39 (22.8\%) nurses have 1-3 years' experience. Participants' response regarding Protocol availability regarding infection control as only $56(32.7 \%)$ go with there is no proper availability of protocol and majority $115(67.3 \%)$ respond as yes there is availability of protocols as needed. The Information received regarding infection control was found as majority $106(62 \%)$ were not received information and only 65 $(38 \%)$ were Information received regarding infection control. The qualification of the participants was $16(9.4 \%)$ having diploma in midwifery, majority 109 (63.7\%) have diploma in general nursing, $36(21.1 \%)$ have bachelor of science in nursing (Post RN) and only 10 (5.8\%) were hold a degree of Bachelor of science in nursing (Generic).

\section{Demographics}

\begin{tabular}{|c|c|c|c|}
\hline \multicolumn{2}{|c|}{ Demographic Variable } & Frequency & Valid Percent \\
\hline Age: & $\begin{array}{l}21-28 \text { years } \\
29-36 \text { years } \\
37-44 \text { years } \\
45-52 \text { years } \\
\text { Total }\end{array}$ & $\begin{array}{c}31 \\
53 \\
64 \\
23 \\
\mathbf{1 7 1}\end{array}$ & $\begin{array}{c}18.1 \% \\
31 \% \\
37.4 \% \\
13.5 \% \\
\mathbf{1 0 0 . 0} \%\end{array}$ \\
\hline Qualification: & $\begin{array}{l}\text { Diploma in midwifery } \\
\text { Diploma in general nursing } \\
\text { Bachelor of science in nursing (Post RN) } \\
\text { Bachelor of science in nursing (Generic) } \\
\text { Total }\end{array}$ & $\begin{array}{c}16 \\
109 \\
36 \\
10 \\
\mathbf{1 7 1}\end{array}$ & $\begin{array}{c}9.4 \% \\
63.7 \% \\
21.1 \% \\
5.8 \% \\
\mathbf{1 0 0 . 0} \%\end{array}$ \\
\hline Experience: & $\begin{array}{l}1-3 \text { year } \\
4-6 \text { year } \\
7-9 \text { year } \\
10-12 \text { year }\end{array}$ & $\begin{array}{l}39 \\
38 \\
62 \\
32\end{array}$ & $\begin{array}{l}22.8 \% \\
22.2 \% \\
36.7 \% \\
18.3 \%\end{array}$ \\
\hline
\end{tabular}




\begin{tabular}{|c|c|c|c|}
\hline & Total & 171 & $100.0 \%$ \\
\hline $\begin{array}{lr}\begin{array}{l}\text { Protocol } \\
\text { regarding }\end{array} & \begin{array}{r}\text { availability } \\
\text { infection } \\
\text { control }\end{array} \\
\end{array}$ & $\begin{array}{l}\text { Yes } \\
\text { No } \\
\text { Total }\end{array}$ & $\begin{array}{c}115 \\
56 \\
\mathbf{1 7 1}\end{array}$ & $\begin{array}{c}67.3 \% \\
32.7 \% \\
\mathbf{1 0 0 . 0 \%}\end{array}$ \\
\hline $\begin{array}{ll}\begin{array}{l}\text { Information } \\
\text { regarding } \\
\text { control }\end{array} & \begin{array}{r}\text { received } \\
\text { infection }\end{array} \\
\end{array}$ & $\begin{array}{l}\text { Yes } \\
\text { No } \\
\text { Total } \\
\end{array}$ & $\begin{array}{c}106 \\
65 \\
\mathbf{1 7 1}\end{array}$ & $\begin{array}{c}62 \% \\
38 \% \\
\mathbf{1 0 0 . 0} \%\end{array}$ \\
\hline
\end{tabular}

Table 1

Table 2 shows the mean, median, mode and standard deviation of demographic variable the highest mean 2.60 for age, then 2.51 for qualification and 2.23 for Experience and the Protocol availability regarding infection lowest mean was 1.33 . The Std. Deviation is $(.941,1.042,1.697, .471,487)$ were respectively for, age, Qualification, experience, Protocol availability regarding infection and Information received regarding infection. The highest mode and median value is 3 .

\section{Demographics Statistics}

\begin{tabular}{|l|c|c|c|c|c|}
\hline \multicolumn{1}{|c|}{ Variable } & N & Mean & Median & Mode & $\begin{array}{c}\text { Std. } \\
\text { Deviation }\end{array}$ \\
\hline Age: & 171 & 2.6 & 3.00 & 3 & .941 \\
\hline Qualification: & 171 & 2.51 & 3.00 & 2 & 1.042 \\
\hline Experience: & 171 & 2.23 & 2.00 & 2 & 1.697 \\
\hline Protocol availability regarding infection & 171 & 1.33 & 1.00 & 1 & .471 \\
\hline Information received regarding infection & 171 & 1.38 & 1.00 & 1 & .487 \\
\hline
\end{tabular}

Table 2

Figure 1 shows that the age of participants was found minimum 21 to highest 52, participant's age group 21-28 years frequency was $31(18.1 \%)$, majority $64(37.4 \%)$ participants were belong to age group 37-44 years and moderately 53 (31\%) were fall in age group 29- 36 years and only 23 (13.5\%) were 45-52 year old.
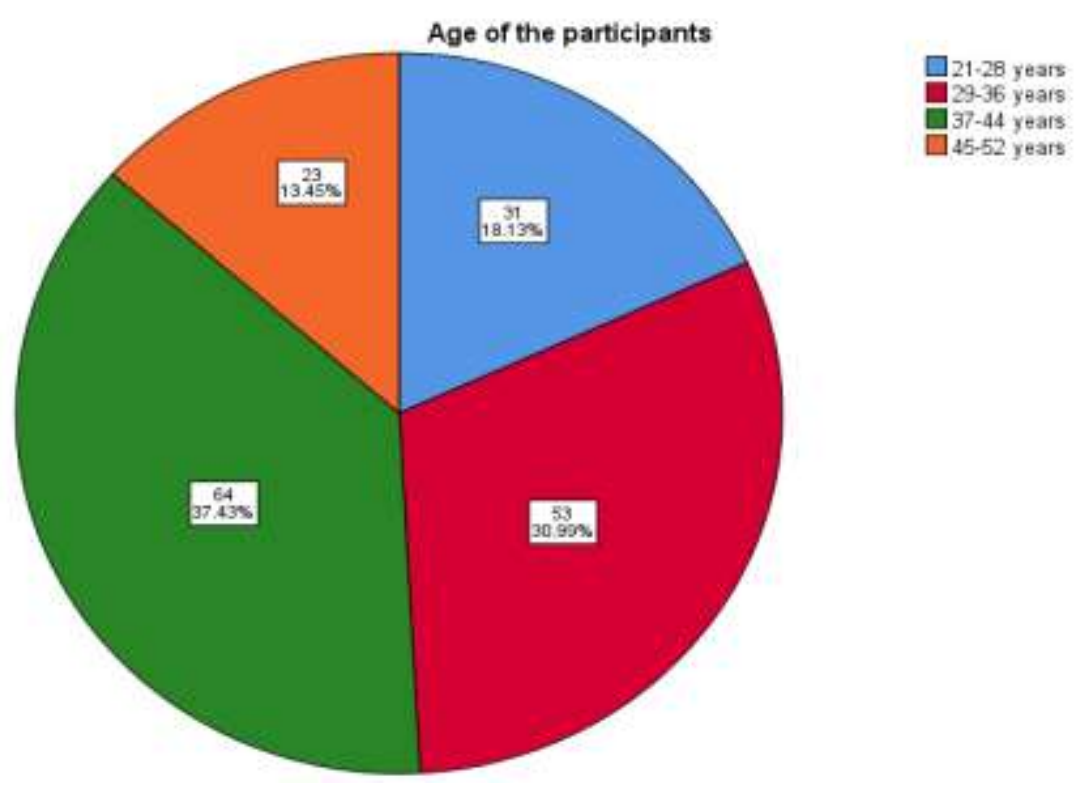

Figure 1 
Figure 2 shows that the only $32(18.3 \%)$ participants have experience $10-12$ years, majority of nurses $62(36.7 \%)$ have 7-9 years job experience, 38 (22.2\%) have 4-6 years' experience and 39 (22.8\%) nurses have 1-3 years' experience.

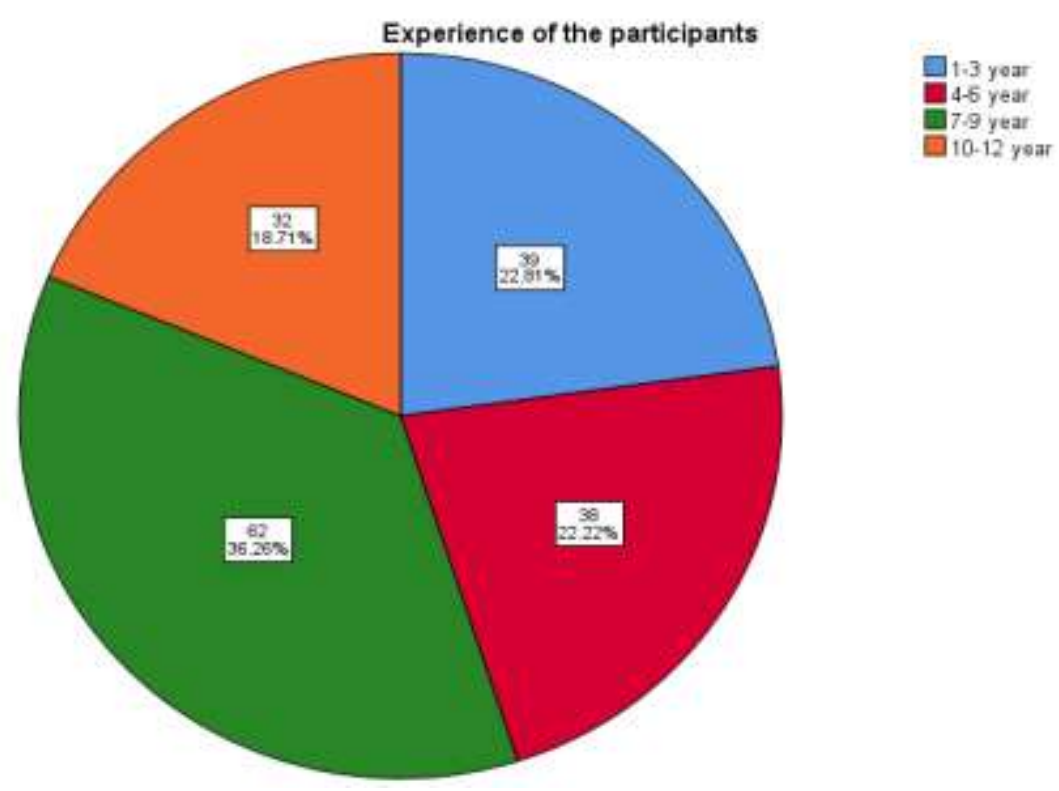

Figure 2

Figure 3 shows that The qualification of the participants was $16(9.4 \%)$ having diploma in midwifery, majority $109(63.7 \%)$ have diploma in general nursing, 36 (21.1\%) have bachelor of science in nursing (Post RN) and only $10(5.8 \%)$ were hold a degree of Bachelor of science in nursing (Generic).
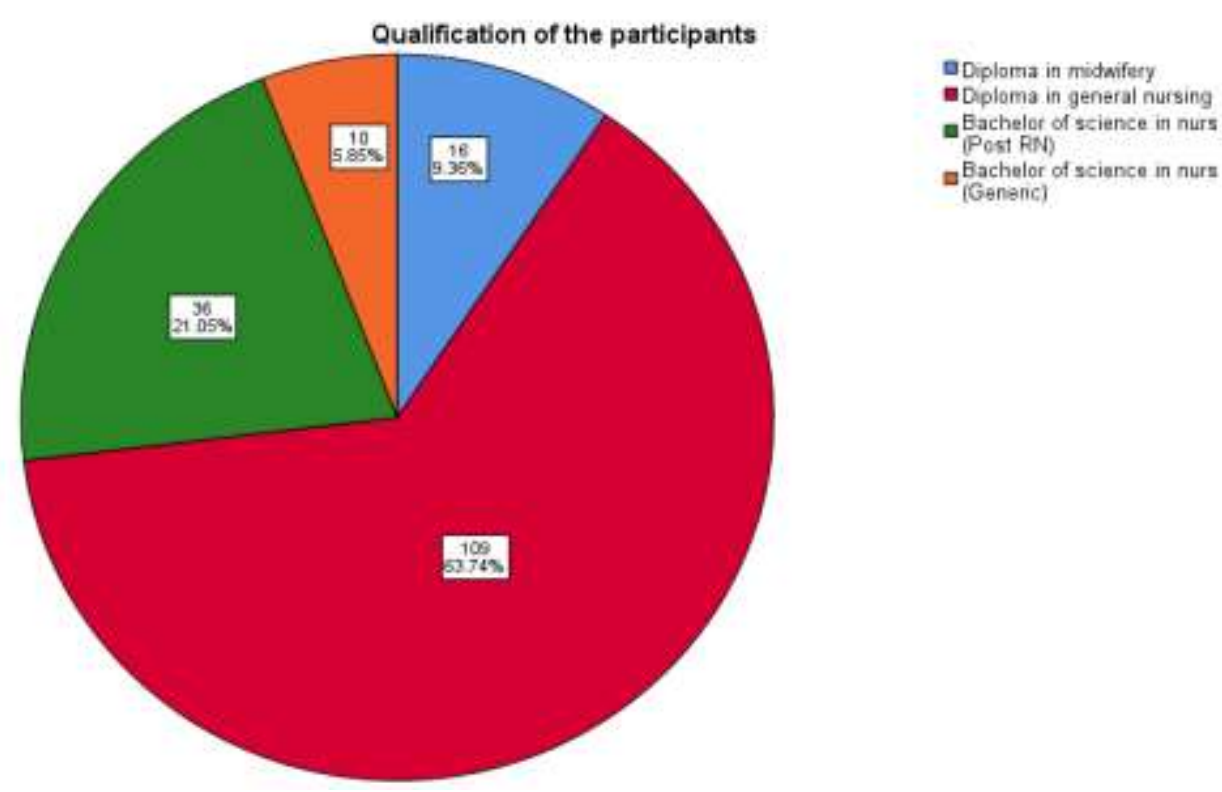

Figure 3

Figure 4 shows that the participants' response regarding Protocol availability regarding infection control as only $56(32.7 \%)$ go with there is no proper availability of protocol and majority $115(67.3 \%)$ respond as yes there is availability of protocols as needed. 


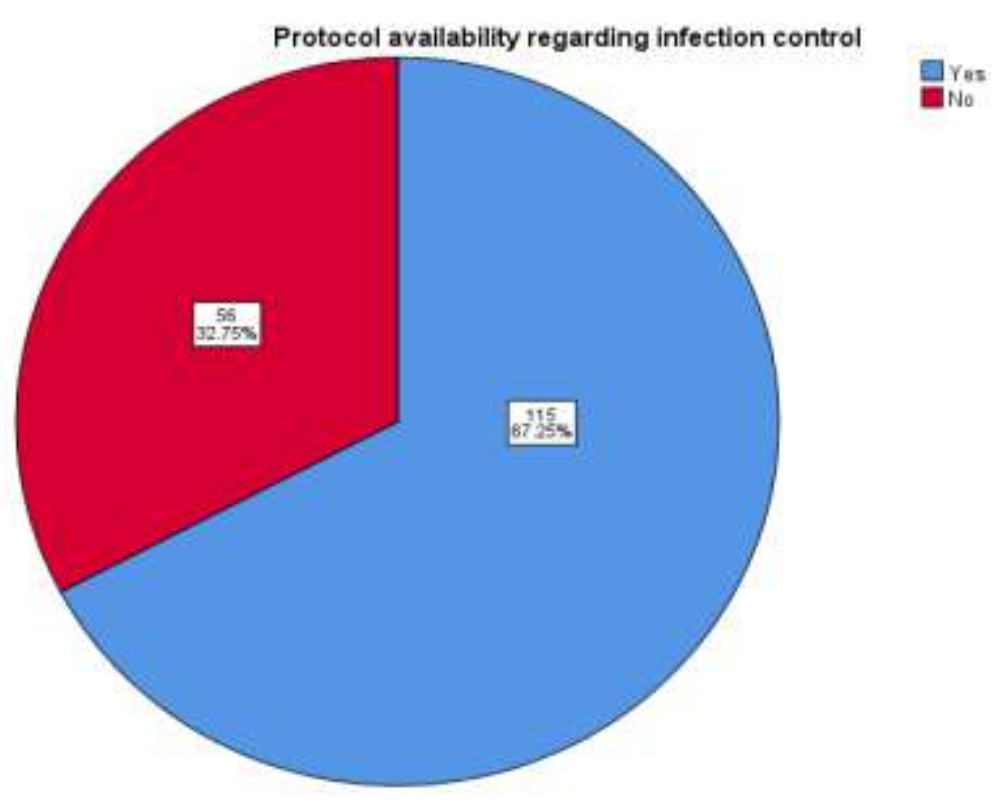

Figure 4

Figure 5 shows that the participants respond regarding information received regarding infection control and results revealed that the majority 106 (62\%) were not received information and only $65(38 \%)$ were Information received regarding infection control.

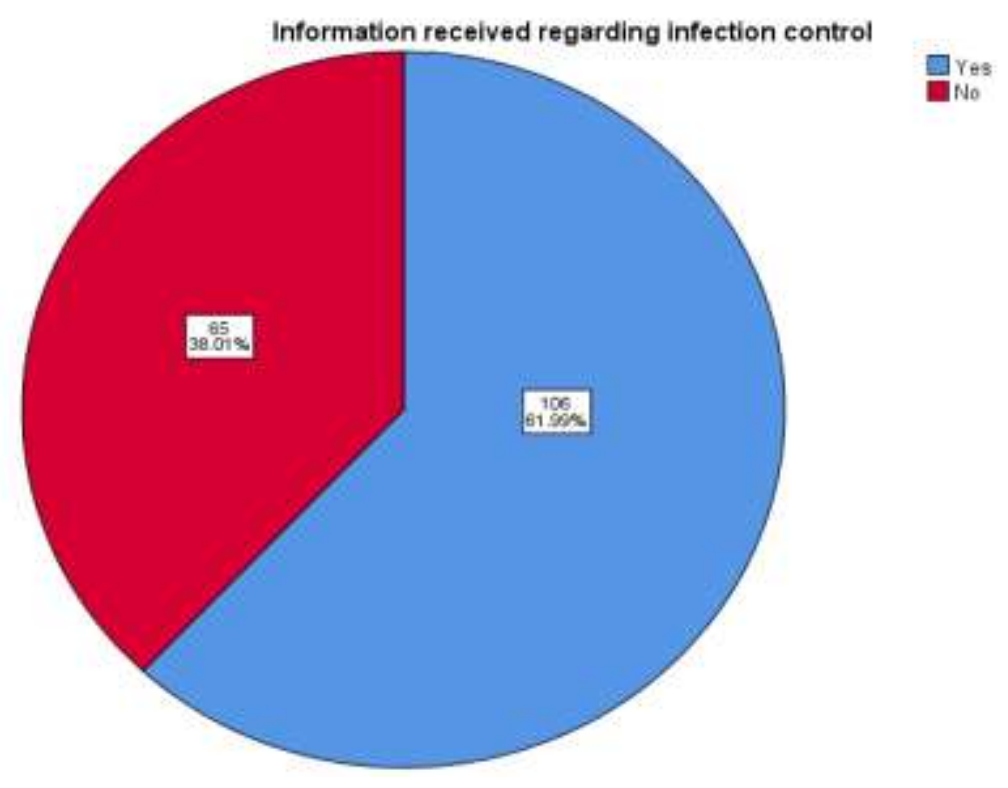

Figure 5

Section B: Section 2 consist of questionnaire and checklist regarding the prevention of infection in burn patient consisting 54 items further divided into 2 parts, and each part consists 27 items.

Table 3 shows the frequency percentage of 27 items of questionnaire regarding knowledge assessment of nurses for the prevention of infection in burn patient. and results revealed that mostly above $50 \%$ nurses have good knowledge. Item one is "Burn patients are unique due to propensity to disperse microbes" and results revealed that the majority $108(63.2 \%)$ respond as yes and only $63(36 \%)$ respond as "No". The participant responds as 95 (55.4\%) know and 76 (44.6\%) did not know the referral criteria of American Burn Association. Item three is "Zone 
is located in the center of burn wound" and participants respond as majority 101 (69.1\%) were go with "Yes" and $70(40.9 \%)$ were responds as "No". The participants response regarding item four which is "Treat it with a skin care product like antibiotic ointment" and results revealed that the only $80(46.2 \%)$ were do this and majority 91 (53.8) did not do this. The participants response regarding item five and results revealed that majority 103 (60.2\%) know that and 68 (39.8\%) did not know that the major burn infection is burn wound cellulitis. Item six is "Common cause of fever in burn patients is systemic inflammatory" and majority 119 (69.4\%) go with yes and 52 (30.6\%) respond as "No". Item seven is "Burn wound cellulitis is most common infection in burn patients" and results revealed that the majority $110(64.7 \%)$ respond as yes and only 61 (35.3\%) respond as "No". The participant responds as 104 (60.2\%) know and 67 (39.8\%) did not know the Burn wounds initially colonized with grampositive organisms. Item nine is "Sepsis syndrome manifested by, bloodstream infection, Fluid loss" and participants respond as majority 91 (53.2\%) were go with "Yes" and 80 (46.8\%) were responds as "No". The participants response regarding item ten which is "Exogenous microorganisms resistant as compared to endogenous" and results revealed that the only 120 (70.2\%) were do this and 51 (29.8) did not do this. The participants response regarding item eleven and results revealed that majority $114(66.8 \%)$ know that and 57 $(33.3 \%)$ did not know that the principle causative agent of cellulitis gram positive organisms. Item twelve is "Routine surveillance cultures should be taken after 3 months" and majority 108 (63.2\%) go with yes and 63 $(36.8 \%)$ respond as "No". Item thirteen is "Quantitative swab culture provide information about the presence of microorganisms on the external catheter surface" and results revealed that the only $71(41.5 \%)$ respond as yes and $100(58.5 \%)$ respond as "No". The participant responds as $99(57.1 \%)$ know and $72(42.9 \%)$ did not know the contact precautions are most effective than other precautions. Item fifteen is "plants and flowers harbor resistant organisms that's why these are not allowed in burn unit" and participants respond as majority 100 (58.5\%) were go with "Yes" and $71(41.5 \%)$ were responds as "No". The participants response regarding item sixteen which is "According to Spaulding classification of medical devices, which come in contact with mucous membranes or nonintact skin require high level of disinfection as semi critical item" and results revealed that the only $100(58.5 \%)$ were go with "Yes" and 71 (41.5\%) were responds as "No". The participants response regarding item seventeen and results revealed that majority $103(60.2 \%)$ know that and 68 (39.8\%) did not know that the CDC guidelines of disinfection, Immersion time of equipment for high level disinfection (HLD) with $2.4 \%$ glutaraldehyde. Item eighteen is "high touch surface areas must be clean and disinfect" and majority 105 (61.4\%) go with yes and 66 (38.6\%) respond as "No". Item nineteen is "chlorhexidine bath and its suggested frequency in burn patients for prevention of infection in burn patients" and results revealed that the only $96(55.4 \%)$ respond as yes and 76 (44.6\%) respond as "No". The participant responds as 93 (54.7\%) know and 78 (45.3\%) did not know the factor including high antibiotic pressures, high colonization pressures, need for intensive medical and surgical therapy, and a vulnerable, immunocompromised patient leads to acquisition of antibiotic resistant organism in burn patients. Item twenty-one is "preparation of the isolation room or area, ensure that appropriate handwashing facilities and hand-hygiene supplies are available" and participants respond as majority 105 (61.4\%) were go with "Yes" and 66 (38.2\%) were responds as "No". The participants response regarding item twenty two which is "precautions such as hand washing and barrier nursing, efficient cleaning and decontamination of hospital equipment, are most important for prevention of MRSA in burn patients" and results revealed that the only 99 (57.2\%) were go with "Yes" and 71 (41.5\%) were responds as "No". The participants response regarding item twenty-three and results revealed that majority $105(61.4 \%)$ know that and 66 (38.6\%) did not know that the burn Patients require additional 
infection control precautions. Item twenty-four is "nasal decolonization of MRSA patients done by mupirocin" and majority $99(57.9 \%)$ go with yes and 72 (42.1\%) respond as "No". The participants response regarding item twenty-five which is "Aquatic environment of hydrotherapy room is difficult to decontaminate" and results revealed that the only $126(73.5 \%)$ were go with "Yes" and 45 (26.7\%) were responds as "No". The participants response regarding item twenty-six and results revealed that majority $81(47.4 \%)$ know that and $90(52.6 \%)$ did not know that the specific antiseptic such as Chlorhexidine gluconate recommended for hand washing. Item twenty-seven is "Did you that the Important step during removal of personal protective equipment" and majority $90(52.6 \%)$ go with yes and $81(47.4 \%)$ respond as "No".

\section{Assessment regarding nursing knowledge}

\begin{tabular}{|c|c|c|c|c|}
\hline Item regarding knowledge & $\begin{array}{c}\text { Yes } \\
\text { F }\end{array}$ & F \% & $\begin{array}{c}\text { No } \\
F\end{array}$ & F \% \\
\hline Burn patients are unique due to propensity to disperse microbes & 108 & $63.2 \%$ & 63 & $36 \%$ \\
\hline Referral criteria of American Burn Association & 95 & $55.4 \%$ & 76 & $44.6 \%$ \\
\hline Zone is located in the center of burn wound & 101 & $69.1 \%$ & 70 & $40.9 \%$ \\
\hline Treat it with a skin care product like antibiotic ointment & 80 & $46.2 \%$ & 91 & $53.8 \%$ \\
\hline Major burn infection is burn wound cellulitis & 103 & $60.2 \%$ & 68 & $39.8 \%$ \\
\hline Common cause of fever in burn patients is systemic inflammatory & 119 & $69.4 \%$ & 52 & $30.6 \%$ \\
\hline Burn wound cellulitis is most common infection in burn patients & 110 & $64.7 \%$ & 61 & $35.3 \%$ \\
\hline Burn wounds initially colonized with gram-positive organisms & 104 & $60.2 \%$ & 67 & $39.8 \%$ \\
\hline Sepsis syndrome manifested by, bloodstream infection, Fluid loss & 91 & $53.2 \%$ & 80 & $46.8 \%$ \\
\hline Exogenous microorganisms resistant as compared to endogenous & 120 & $70.2 \%$ & 51 & $29.8 \%$ \\
\hline Principle causative agent of cellulitis gram positive organisms & 114 & $66.8 \%$ & 57 & $33.3 \%$ \\
\hline Routine surveillance cultures should be taken after 3 months & 108 & $63.2 \%$ & 63 & $36.8 \%$ \\
\hline Semi Quantitative swab culture provide information....... & 71 & $41.5 \%$ & 100 & $58.5 \%$ \\
\hline Contact precautions are most effective than other precautions & 99 & $57.1 \%$ & 72 & $42.9 \%$ \\
\hline Plants and flowers harbor resistant organisms & 100 & $58.5 \%$ & 71 & $41.5 \%$ \\
\hline Medical devices, which come in contact with $\mathrm{m}$ & 100 & $58.5 \%$ & 71 & $41.5 \%$ \\
\hline $\begin{array}{l}\text { CDC guidelines of disinfection, Immersion time of equipment for high level } \\
\text { disinfection (HLD) with } 2.4 \% \text { glutaraldehyde. }\end{array}$ & 103 & $60.2 \%$ & 68 & $39.8 \%$ \\
\hline High touch surface areas must be clean and disinfect. & 105 & $61.4 \%$ & 66 & $38.6 \%$ \\
\hline Chlorhexidine bath and its suggested frequency in burn patients. & 95 & $55.4 \%$ & 76 & $44.6 \%$ \\
\hline Factor including high antibiotic pressures, high colonization.... & 93 & $54.7 \%$ & 78 & $45.3 \%$ \\
\hline Preparation of the isolation room or area, ensure that appropriate & 105 & $61.4 \%$ & 66 & $38.2 \%$ \\
\hline Precautions such as hand washing and barrier nursing, efficient... & 99 & $57.9 \%$ & 72 & $42.1 \%$ \\
\hline Burn Patients require additional infection control precautions? & 105 & $61.4 \%$ & 66 & $38.6 \%$ \\
\hline Nasal decolonization of MRSA patients done by mupirocin? & 99 & $57.9 \%$ & 72 & $42.1 \%$ \\
\hline Aquatic environment of hydrotherapy, difficult to decontaminate? & 126 & $73.3 \%$ & 45 & $26.7 \%$ \\
\hline Antiseptic such as chlorhexidine recommended for hand washing? & 81 & $47.4 \%$ & 90 & $52.6 \%$ \\
\hline Important step during removal of personal protective equipment? & 90 & $52.6 \%$ & 81 & $47.4 \%$ \\
\hline
\end{tabular}

Table 3

Table 4 shows that the statistics (mean, median, mode and standard deviation) of 27 items of checklist regarding knowledge assessment of nurses for the prevention of infection in burn patient and results revealed that the highest mean value is 1.58 of item thirteen which is "Semi Quantitative swab culture provide information about the presence of microorganisms on the external catheter surface" and comparatively lowest mean value is 1.26 for item twenty five which is "Aquatic environment of hydrotherapy room is difficult to decontaminate". The mean value for others item is between 1.26-1.58 respectively. Median and mode value of most of items is 1 and highest is 2 . Standard deviation value .501 is highest and comparatively .442 is low.

Assessment regarding nursing knowledge 


\begin{tabular}{|c|c|c|c|c|c|}
\hline Variable & $\mathbf{N}$ & Mean & Median & Mode & $\begin{array}{c}\text { Std. } \\
\text { D }\end{array}$ \\
\hline Burn patients are unique due to propensity to disperse microbes & 171 & 1.37 & 1.00 & 1 & .484 \\
\hline Referral criteria of American Burn Association & 171 & 1.44 & 1.00 & 1 & .498 \\
\hline zone is located in the center of burn wound & 171 & 1.41 & 1.00 & 1 & .493 \\
\hline Treat it with a skin care product like antibiotic ointment & 171 & 1.53 & 2.00 & 2 & .500 \\
\hline Major burn infection is burn wound cellulitis & 171 & 1.40 & 1.00 & 1 & .491 \\
\hline Common cause of fever in burn patients is systemic inflammatory & 171 & 1.30 & 1.00 & 1 & .461 \\
\hline Burn wound cellulitis is most common infection in burn patients & 171 & 1.36 & 1.00 & 1 & .480 \\
\hline Burn wounds initially colonized with gram-positive organisms & 171 & 1.39 & 1.00 & 1 & .490 \\
\hline Sepsis syndrome manifested by, bloodstream infection, Fluid loss & 171 & 1.47 & 1.00 & 1 & .500 \\
\hline Exogenous microorganisms resistant as compared to endogenous & 171 & 1.29 & 1.00 & 1 & .455 \\
\hline principle causative agent of cellulitis gram positive organisms & 171 & 1.33 & 1.00 & 1 & .482 \\
\hline Routine surveillance cultures should be taken after 3 months & 171 & 1.36 & 1.00 & 1 & .470 \\
\hline Semi Quantitative swab culture provide information....... & 171 & 1.58 & 2.00 & 1 & .495 \\
\hline Contact precautions are most effective than other precautions & 171 & 1.42 & 1.00 & 2 & .495 \\
\hline Plants and flowers harbor resistant organisms & 171 & 1.42 & 1.00 & 1 & .494 \\
\hline Medical devices, which come in contact with mucous membranes. & 171 & 1.42 & 1.00 & 1 & .494 \\
\hline $\begin{array}{l}\text { CDC guidelines of disinfection, Immersion time of equipment for high level } \\
\text { disinfection (HLD) with } 2.4 \% \text { glutaraldehyde. }\end{array}$ & 171 & 1.40 & 1.00 & 1 & .491 \\
\hline High touch surface areas must be clean and disinfect. & 171 & 139 & 1.00 & 1 & .488 \\
\hline Chlorhexidine bath and its suggested frequency in burn patients. & 171 & 1.44 & 1.00 & 1 & .498 \\
\hline Factor including high antibiotic pressures, high colonization..... & 171 & 1.46 & 1.00 & 1 & .500 \\
\hline Preparation of the isolation room or area, ensure that appropriate & 171 & 1.39 & 1.00 & 1 & .488 \\
\hline Precautions such as hand washing and barrier nursing, efficient... & 171 & 1.42 & 1.00 & 1 & .495 \\
\hline Burn Patients require additional infection control precautions? & 171 & 1.39 & 1.00 & 1 & .490 \\
\hline Nasal decolonization of MRSA patients done by mupirocin? & 171 & 1.42 & 1.00 & 1 & .495 \\
\hline Aquatic environment of hydrotherapy, difficult to decontaminate? & 171 & 1.26 & 2.00 & 2 & .442 \\
\hline Antiseptic such as chlorhexidine recommended for hand washing? & 171 & 1.53 & 1.00 & 1 & .501 \\
\hline Important step during removal of personal protective equipment? & 171 & 1.47 & 1.00 & 1 & .501 \\
\hline
\end{tabular}

\section{Table 4}

Figure 6 shows that the results regarding item one is "Burn patients are unique due to propensity to disperse microbes" and results revealed that the majority 108 (63.2\%) respond as yes and only 63 (36\%) respond as "No".

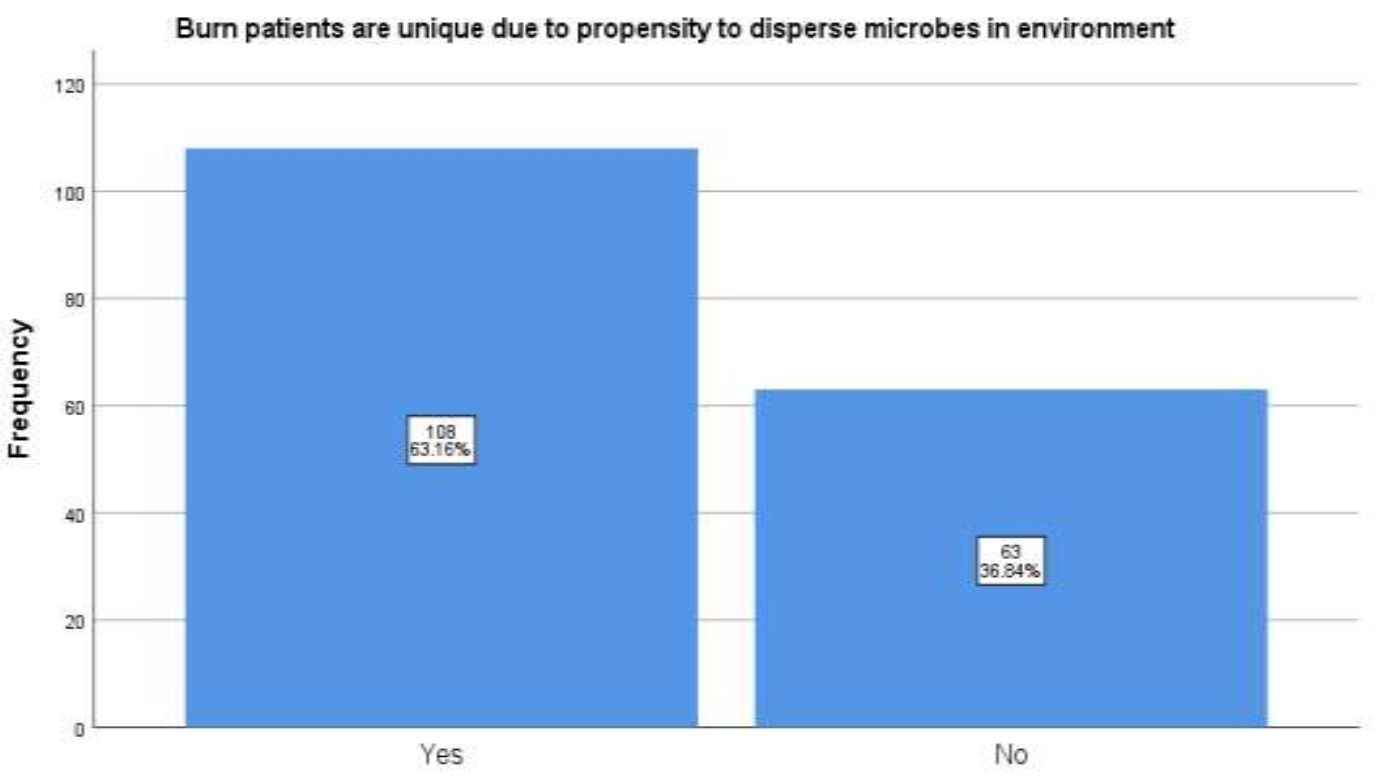

Burn patients are unique due to propensity to disperse microbes in environment 


\section{Figure 6}

Figure 7 shows that the results regarding item two and the participant responds as 95 (55.4\%) know and 76 (44.6\%) did not know the referral criteria of American Burn Association.

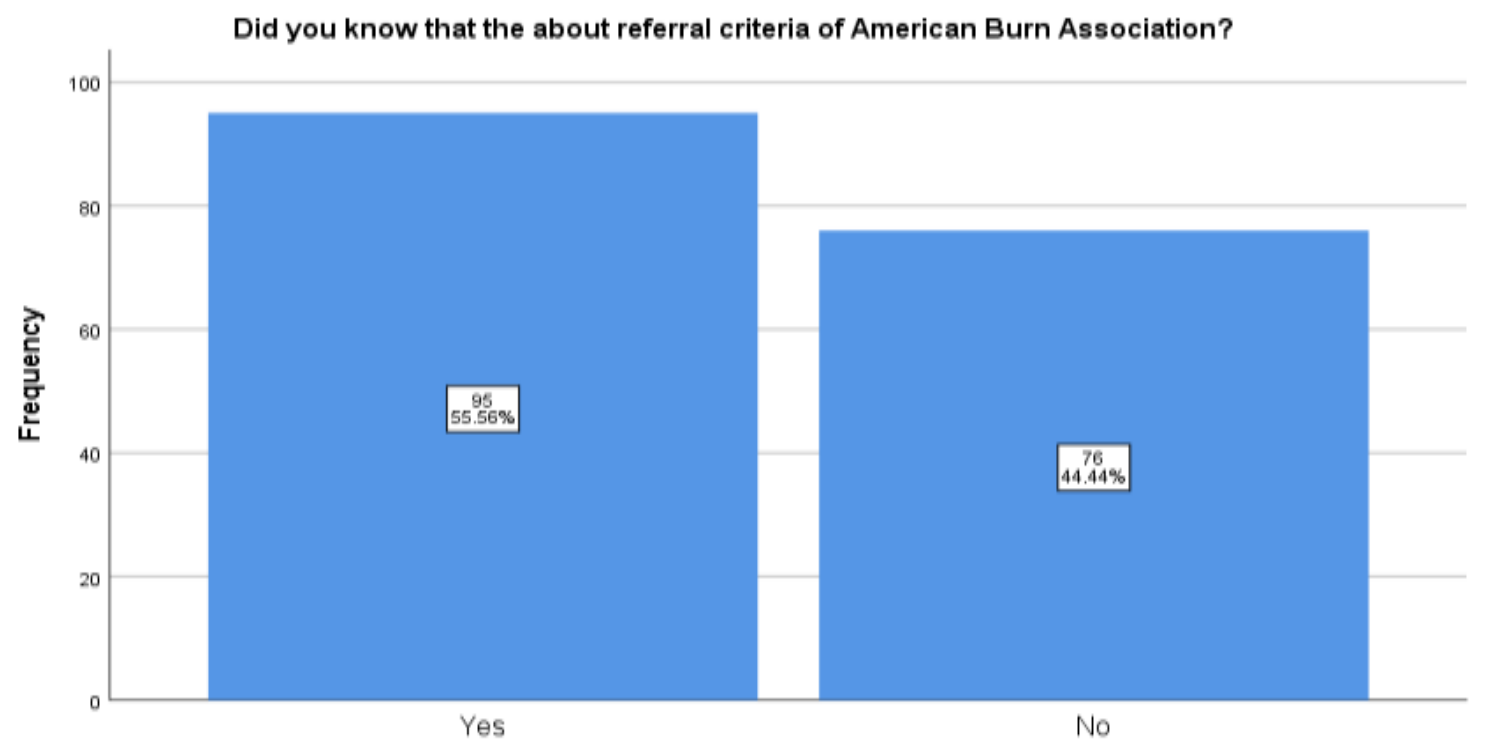

Did you know that the about referral criteria of American Burn Association?

Figure 7

Figure 8 shows that the results regarding item three is "Zone is located in the center of burn wound" and participants respond as majority 101 (69.1\%) were go with "Yes" and 70 (40.9\%) were responds as "No".

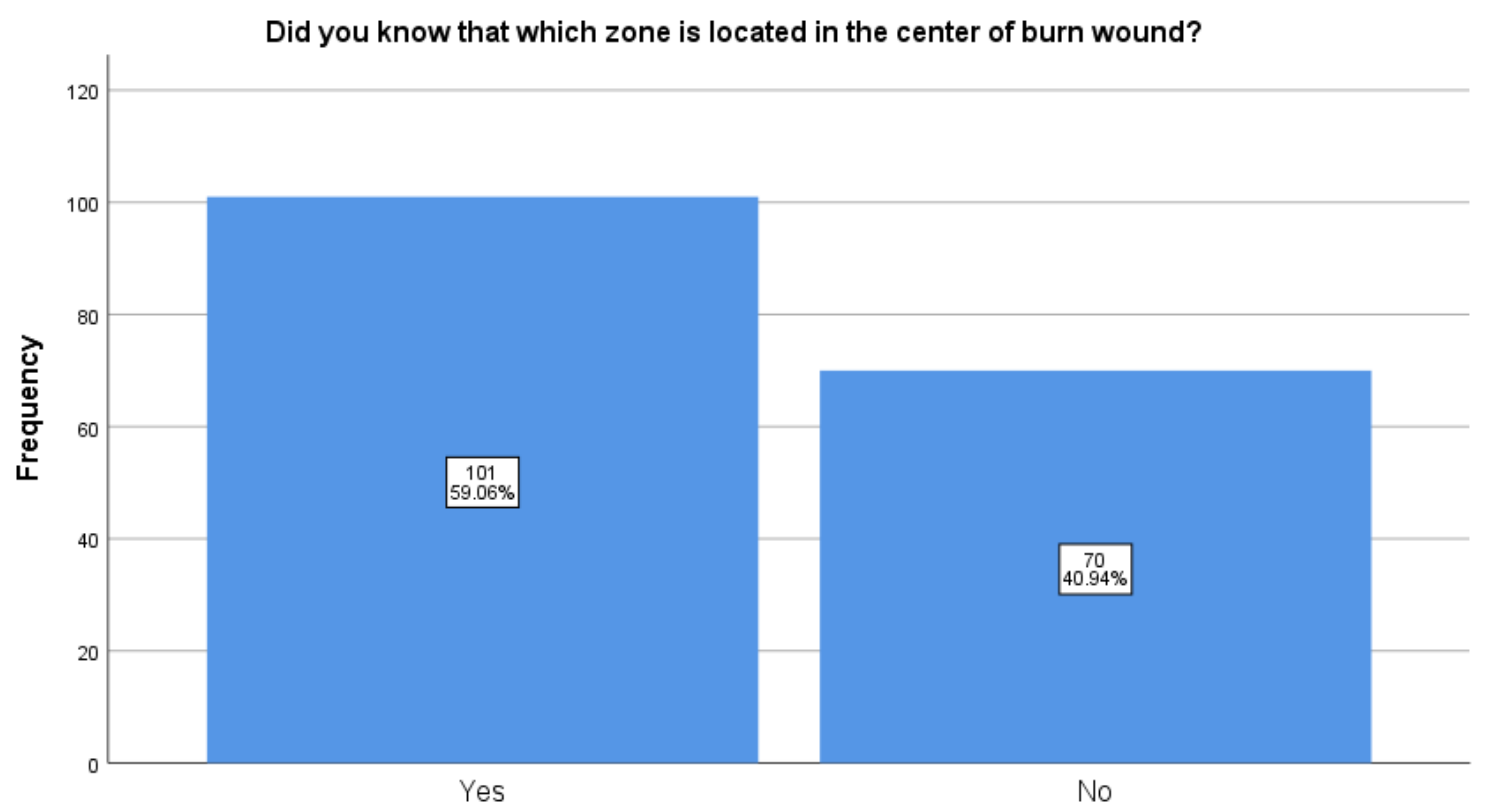

Did you know that which zone is located in the center of burn wound?

Figure 8 
Figure 9 shows that the results regarding item and the participants response regarding item four which is "Treat it with a skin care product like antibiotic ointment" and results revealed that the only $80(46.2 \%)$ were do this and majority 91 (53.8) did not do this.

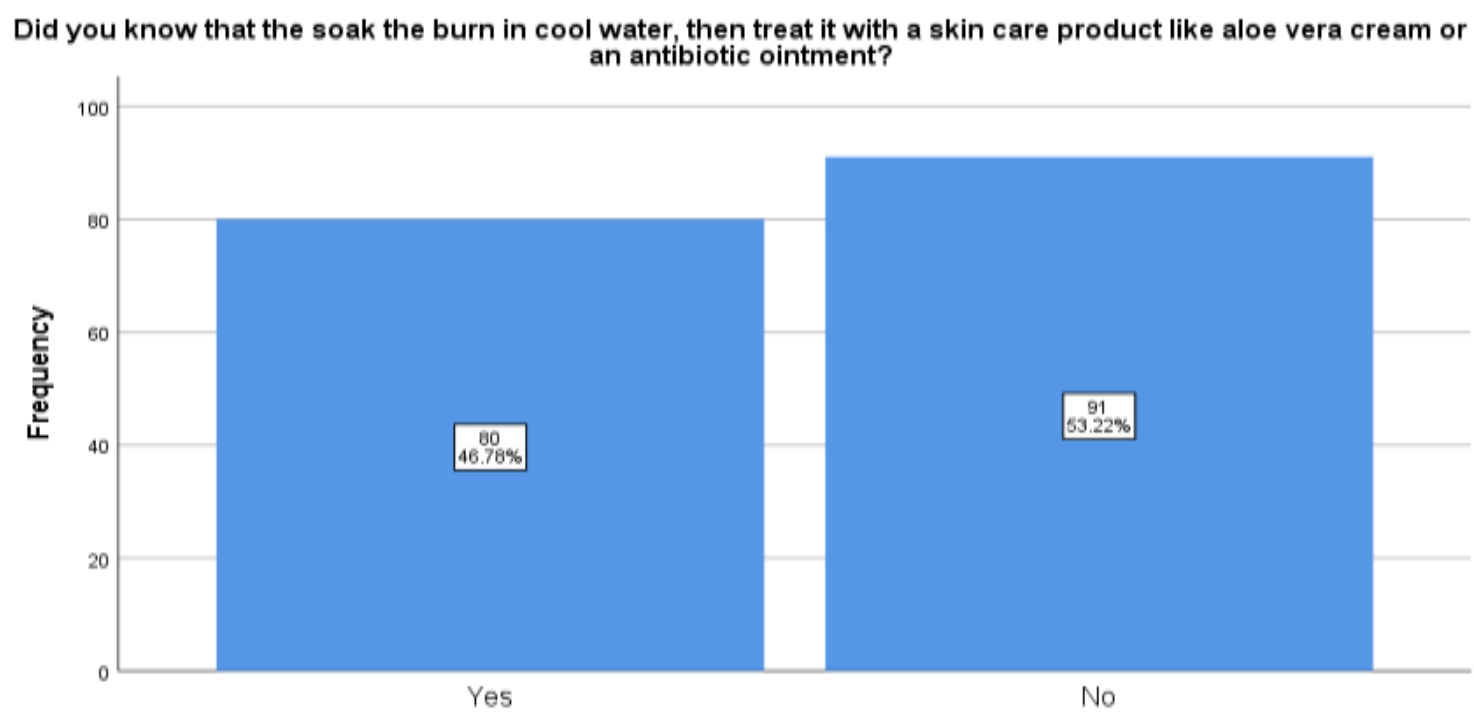

Did you know that the soak the burn in cool water, then treat it with a skin care product like aloe vera cream or an antibiotic ointment?

Figure 9

Figure 10 shows that the results regarding item and the participants response regarding item five and results revealed that majority $103(60.2 \%)$ know that and 68 (39.8\%) did not know that the major burn infection is burn wound cellulitis.

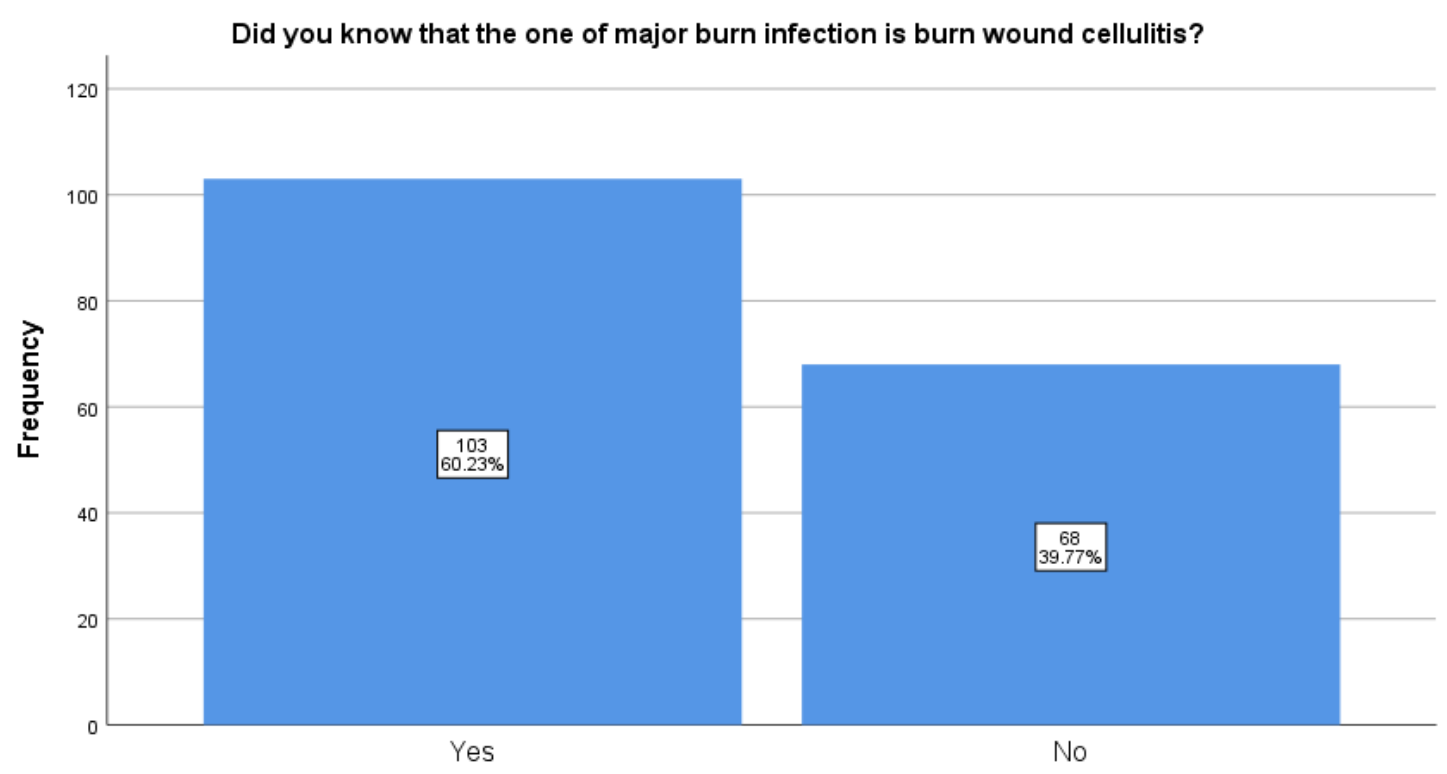

Did you know that the one of major burn infection is burn wound cellulitis?

Figure 10

Figure 11 shows that the results regarding item six is "Common cause of fever in burn patients is systemic inflammatory" and majority $119(69.4 \%)$ go with yes and 52 (30.6\%) respond as "No". 


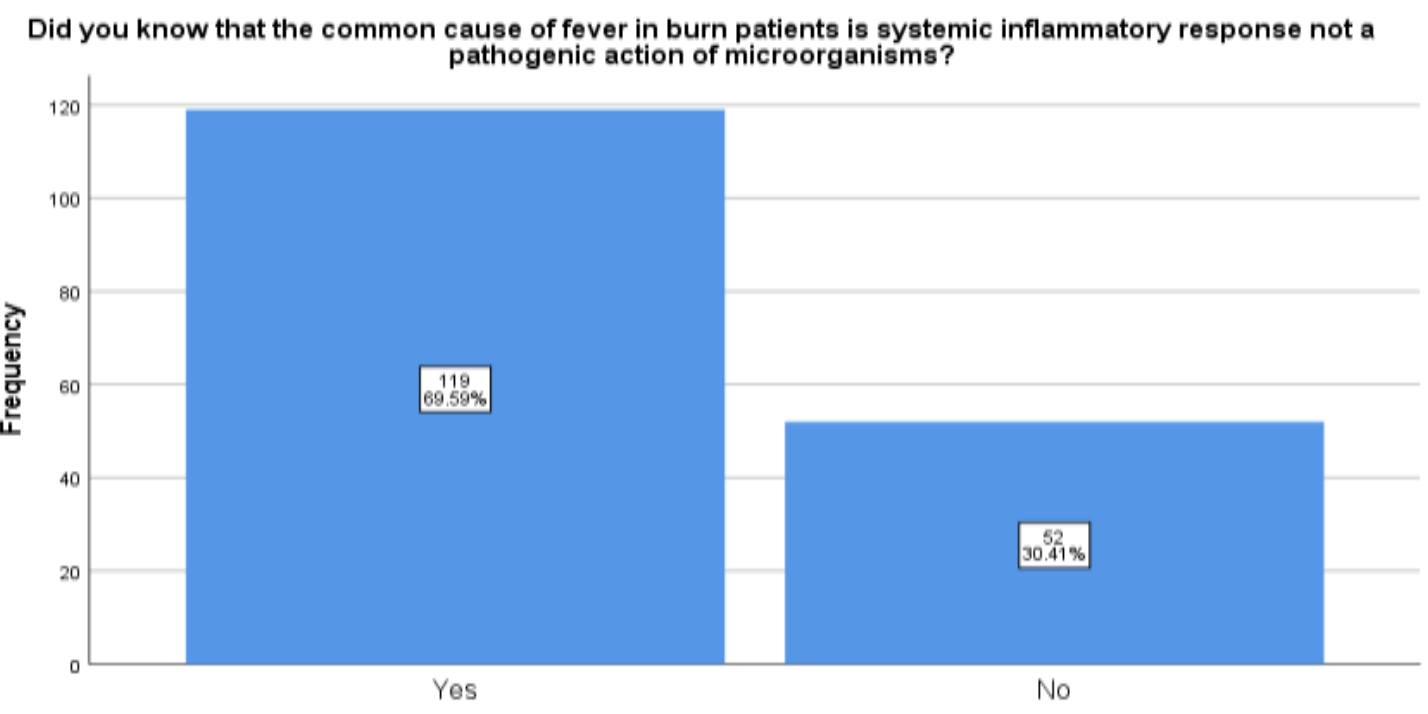

Did you know that the common cause of fever in burn patients is systemic inflammatory response not a pathogenic action of microorganisms?

Figure 11

Figure 12 shows that the results regarding item seven is "Burn wound cellulitis is most common infection in burn patients" and results revealed that the majority $110(64.7 \%)$ respond as yes and only $61(35.3 \%)$ respond as "No".

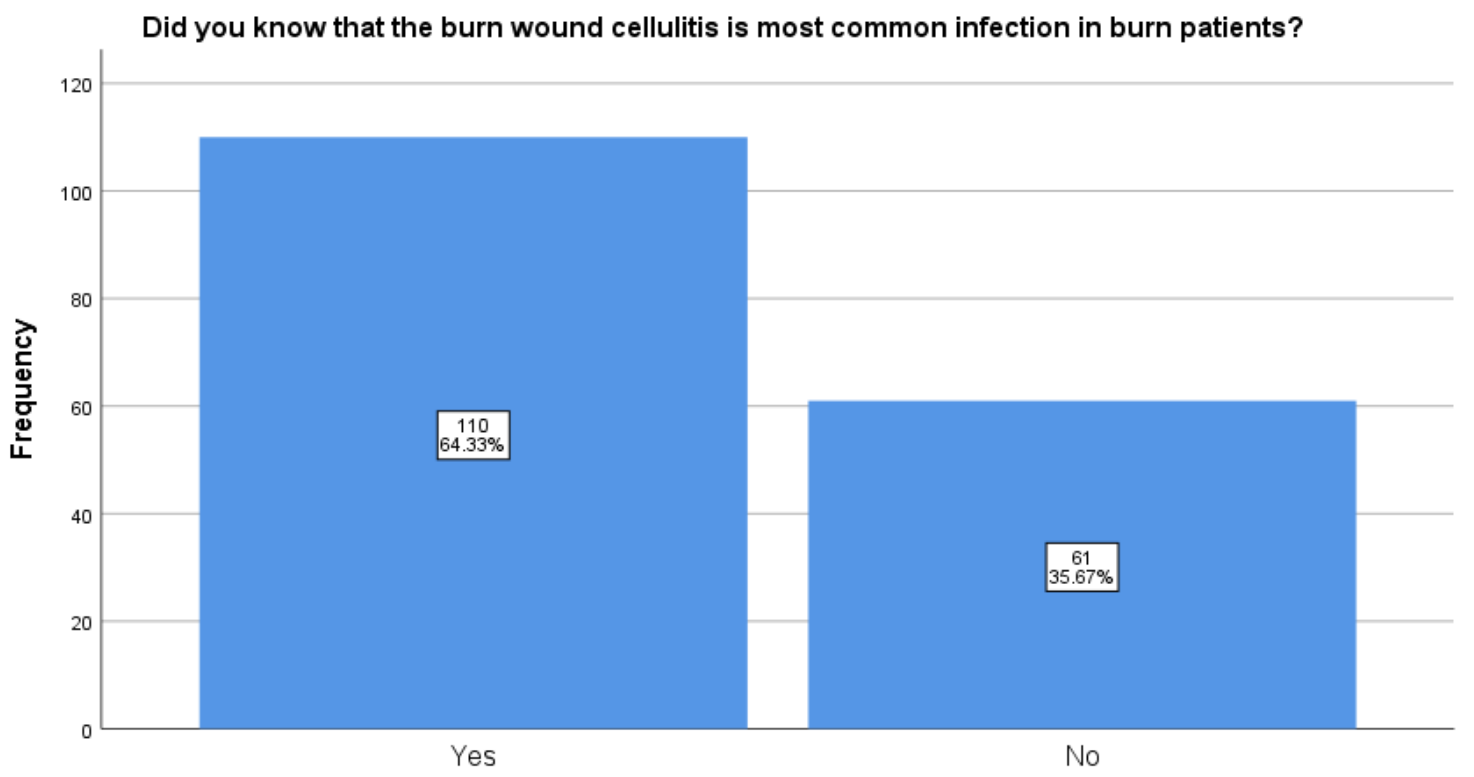

Did you know that the burn wound cellulitis is most common infection in burn patients?

Figure 12

Figure 13 shows that the results regarding item and the participant responds as 104 (60.2\%) know and 67 (39.8\%) did not know the Burn wounds initially colonized with gram-positive organisms. 


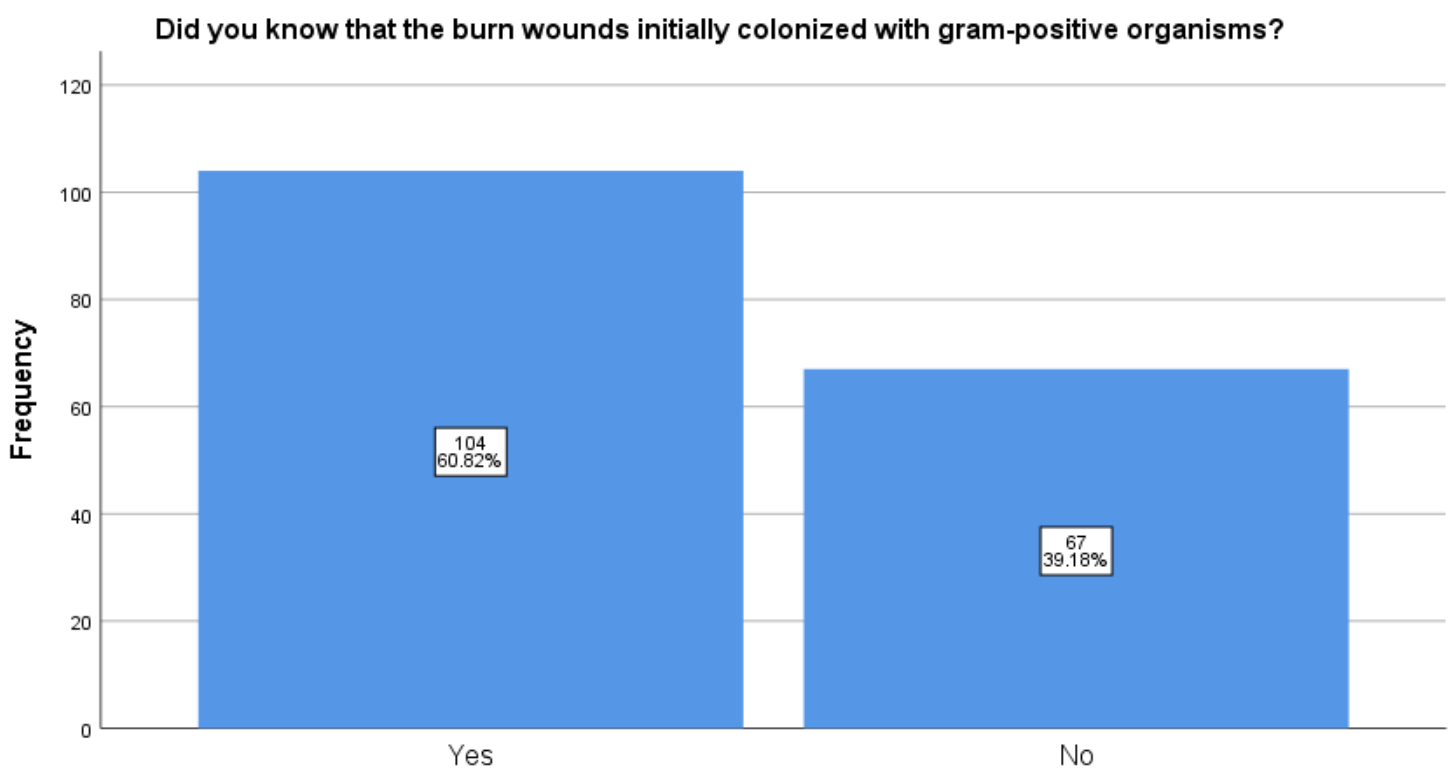

Did you know that the burn wounds initially colonized with gram-positive organisms?

Figure 13

Figure 14 shows that the results regarding item nine is "Sepsis syndrome manifested by, bloodstream infection, Fluid loss" and participants respond as majority $91(53.2 \%)$ were go with "Yes" and 80 (46.8\%) were responds as "No".

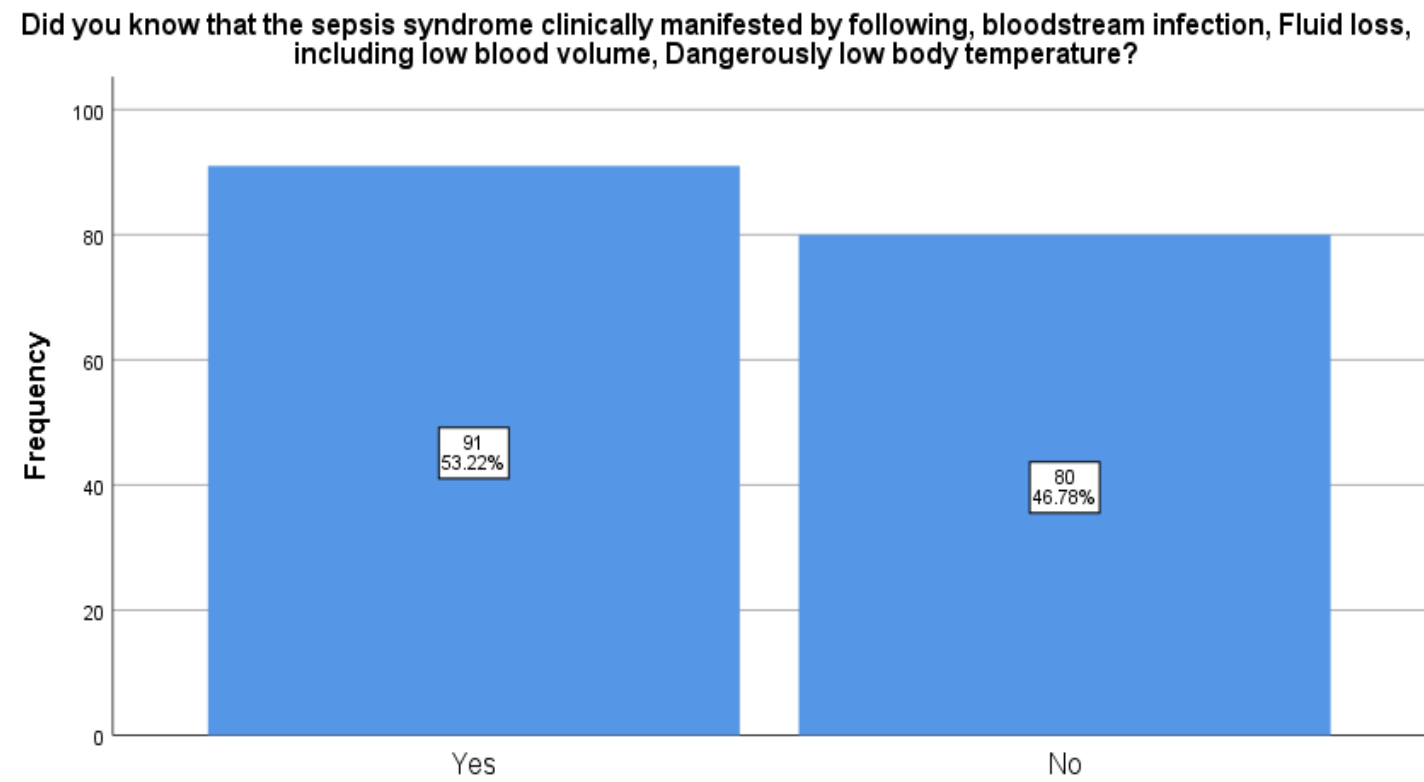

Did you know that the sepsis syndrome clinically manifested by following, bloodstream infection, Fluid loss, including low blood volume, Dangerously low body temperature?

\section{Figure 14}

Figure 15 shows that the results regarding item and the participants response regarding item ten which is "Exogenous microorganisms resistant as compared to endogenous" and results revealed that the only $120(70.2 \%)$ were do this and 51 (29.8) did not do this. 


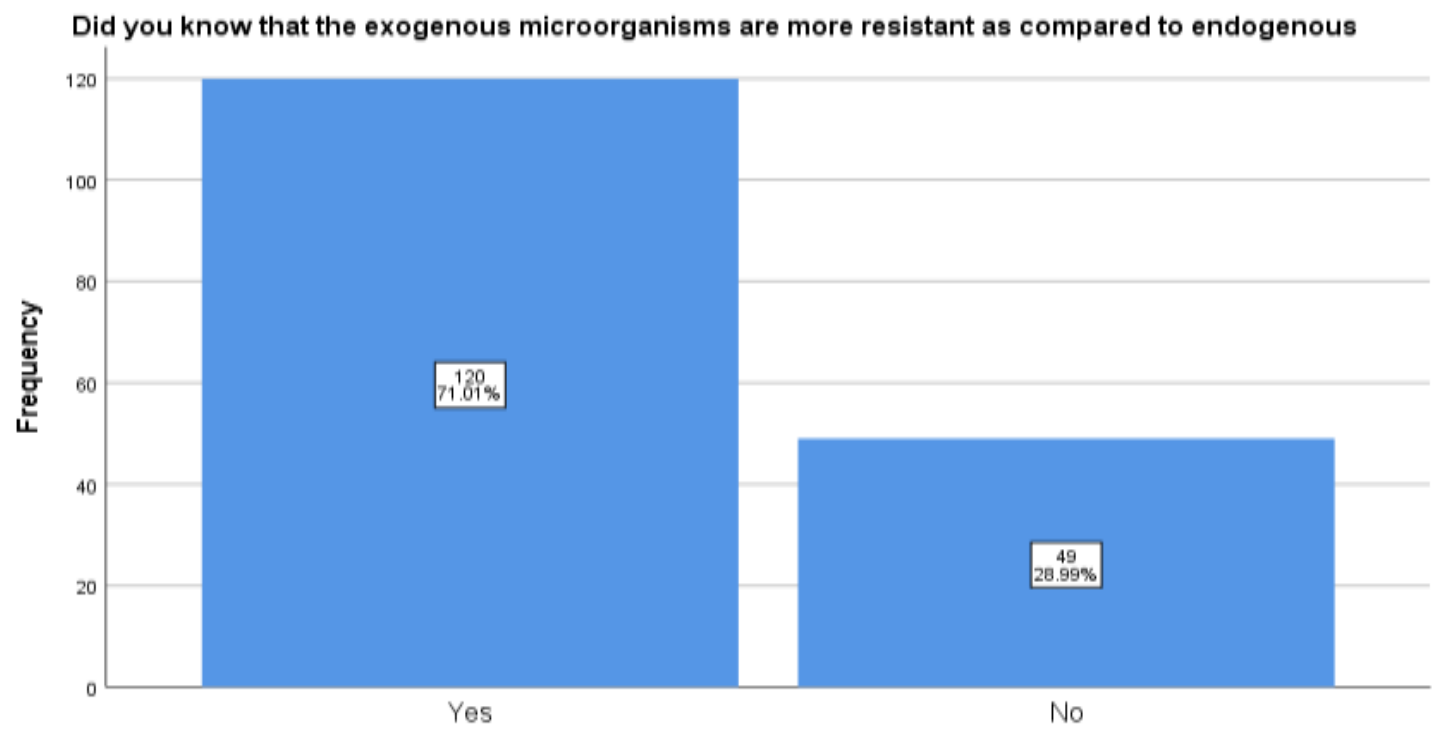

Did you know that the exogenous microorganisms are more resistant as compared to endogenous

Figure 15

Figure 16 shows that the results regarding item and the participants response regarding item eleven and results revealed that majority 114 (66.8\%) know that and 57 (33.3\%) did not know that the principle causative agent of cellulitis gram positive organisms.

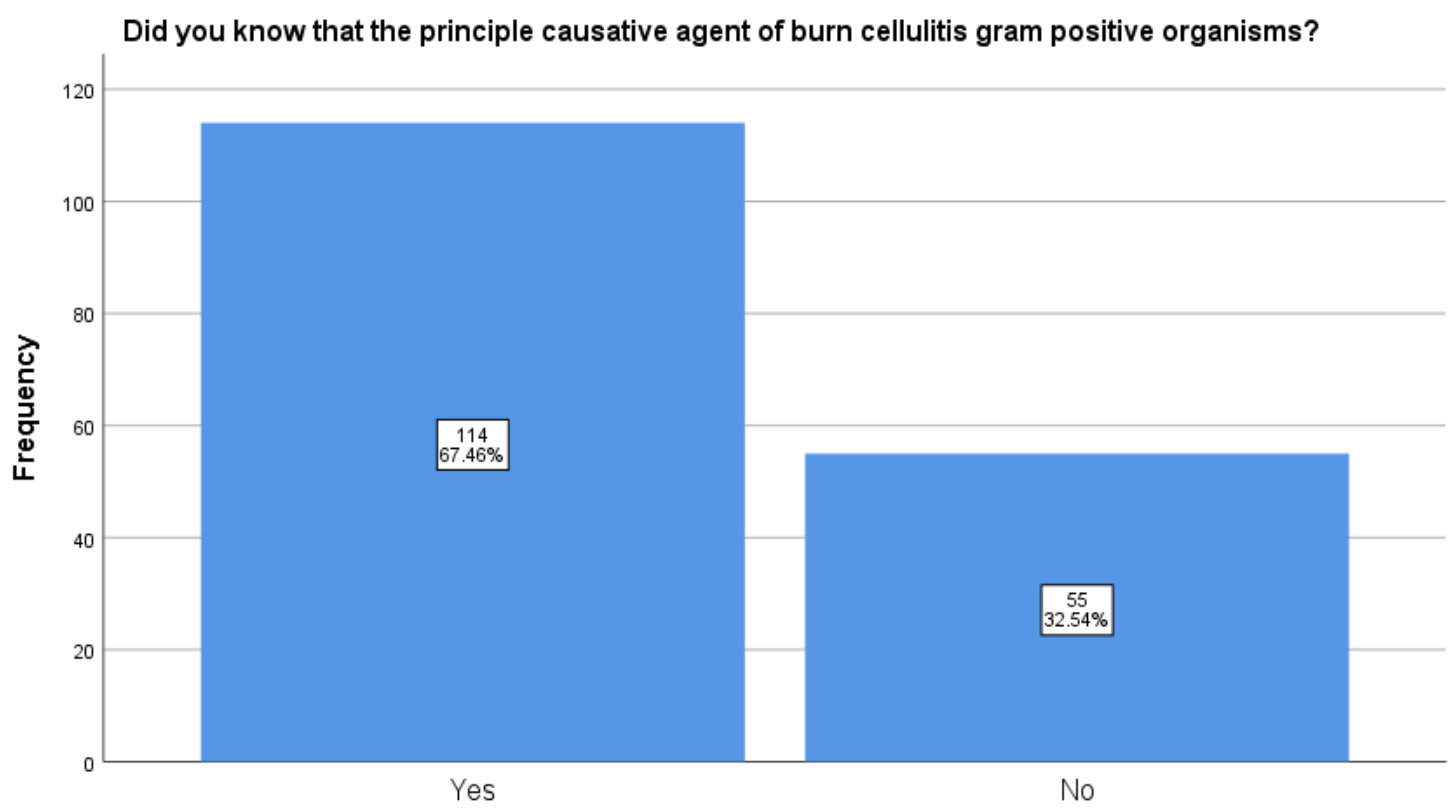

Did you know that the principle causative agent of burn cellulitis gram positive organisms?

Figure 16

Figure 17 shows that the results regarding item twelve is "Routine surveillance cultures should be taken after 3 months" and majority 108 (63.2\%) go with yes and $63(36.8 \%)$ respond as "No". 


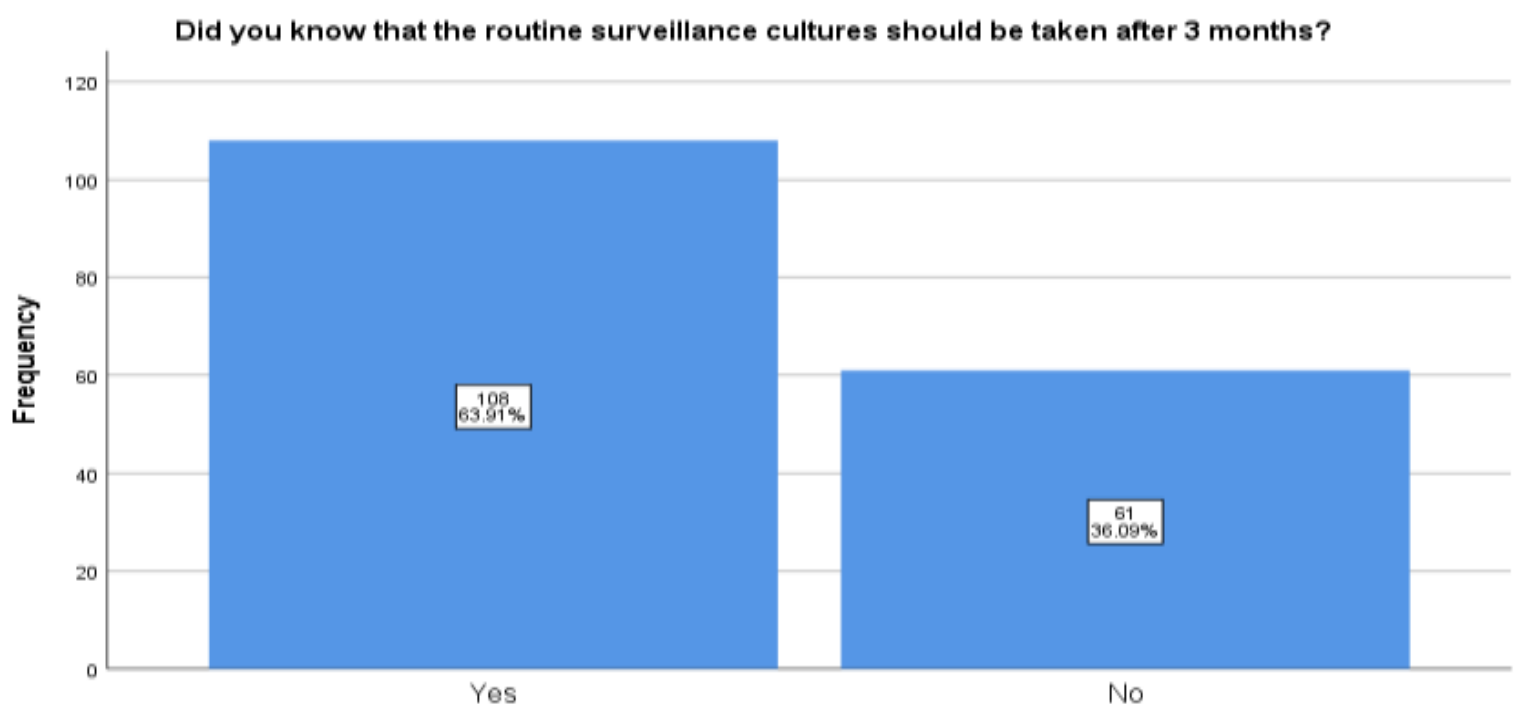

Did you know that the routine surveillance cultures should be taken after 3 months?

Figure 17

Figure 18 shows that the results regarding item thirteen is "Quantitative swab culture provide information about the presence of microorganisms on the external catheter surface" and results revealed that the only $71(41.5 \%)$ respond as yes and $100(58.5 \%)$ respond as "No".

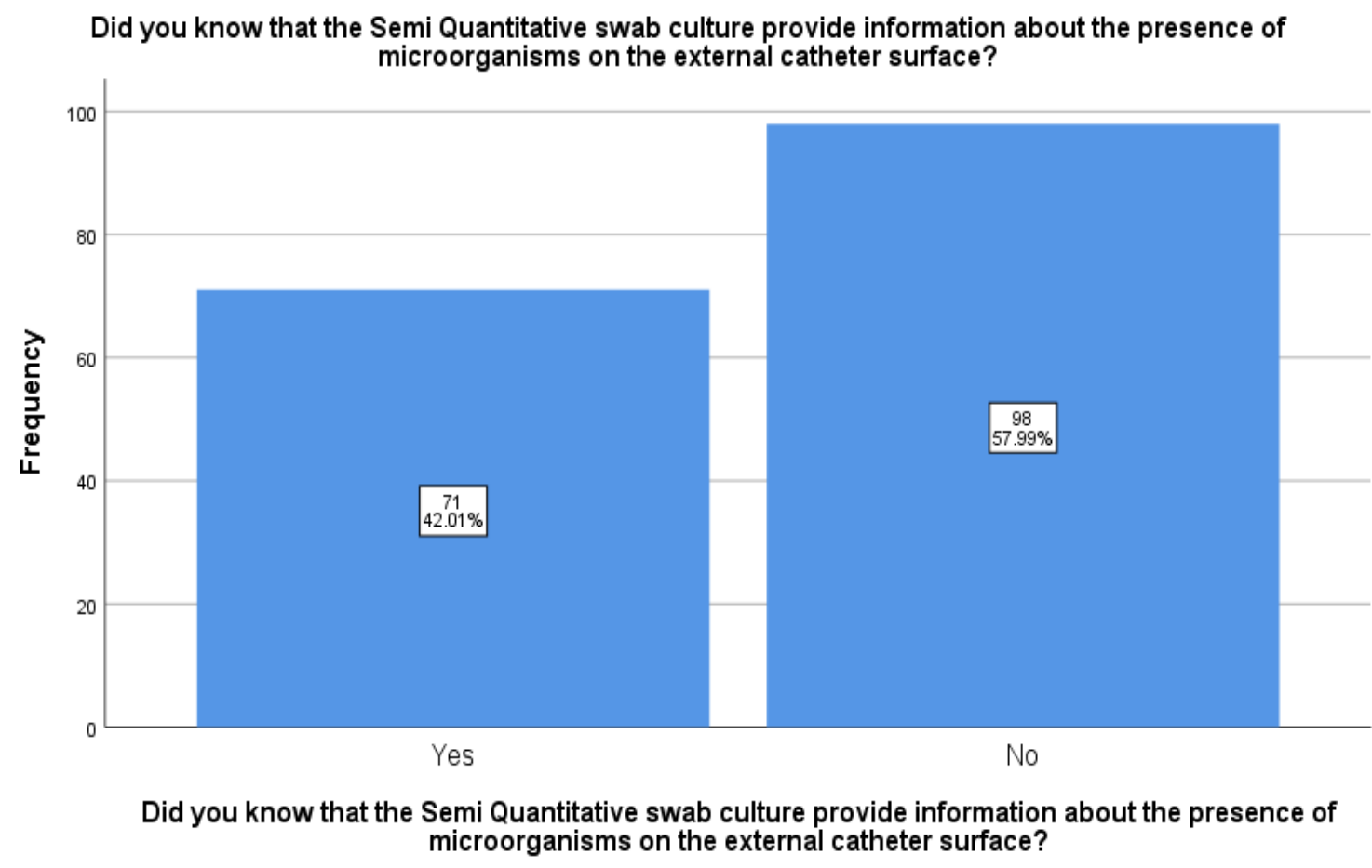

Figure 18

Figure 19 shows that the results regarding item and the participant responds as $99(57.1 \%)$ know and $72(42.9 \%)$ did not know the contact precautions are most effective than other precautions. 


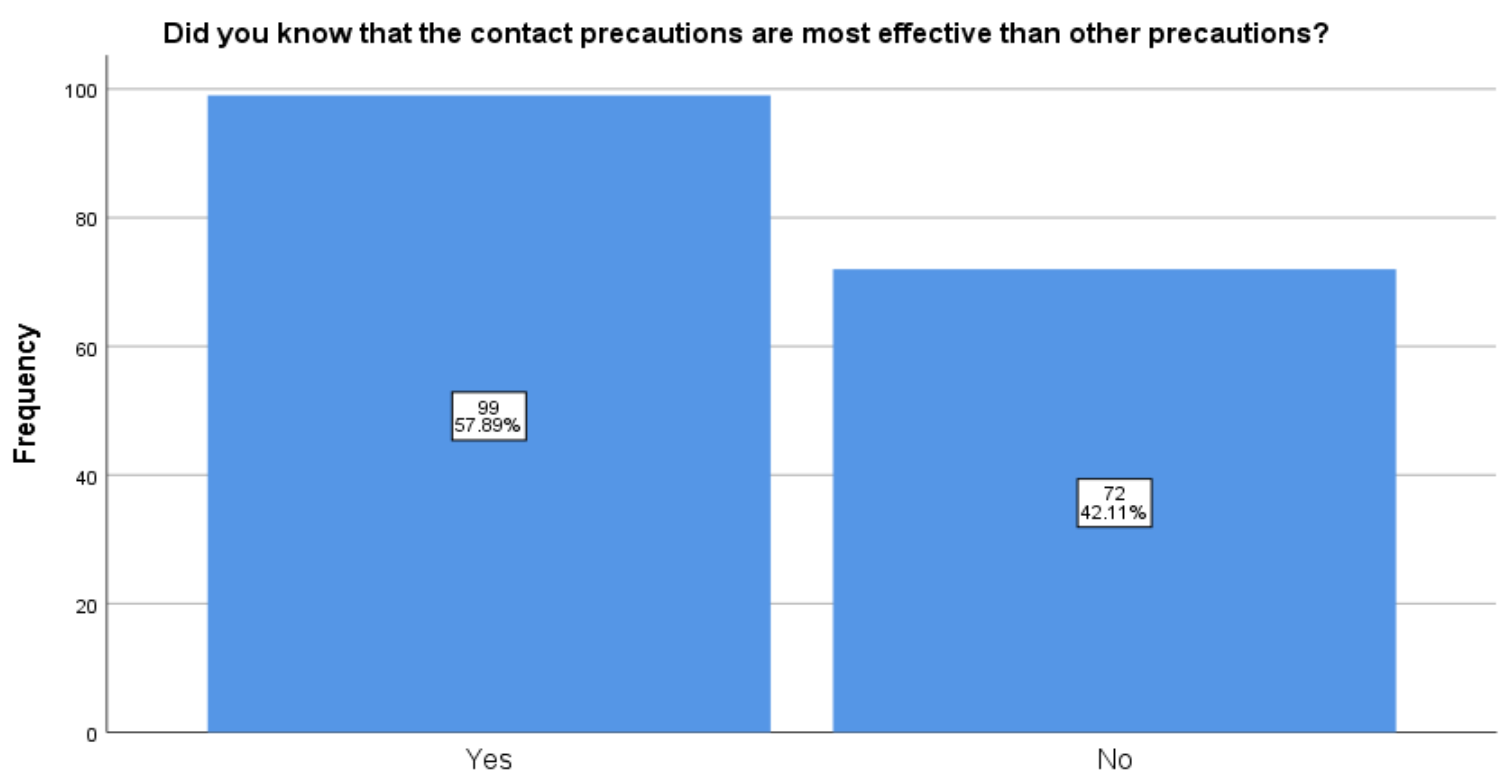

Did you know that the contact precautions are most effective than other precautions?

Figure 19

Figure 20 shows that the results regarding item fifteen is "plants and flowers harbor resistant organisms that's why these are not allowed in burn unit" and participants respond as majority 100 (58.5\%) were go with "Yes" and 71 (41.5\%) were responds as "No".

\section{Did you know that the plants and flowers harbor resistant organisms that's why these are not allowed in burn}

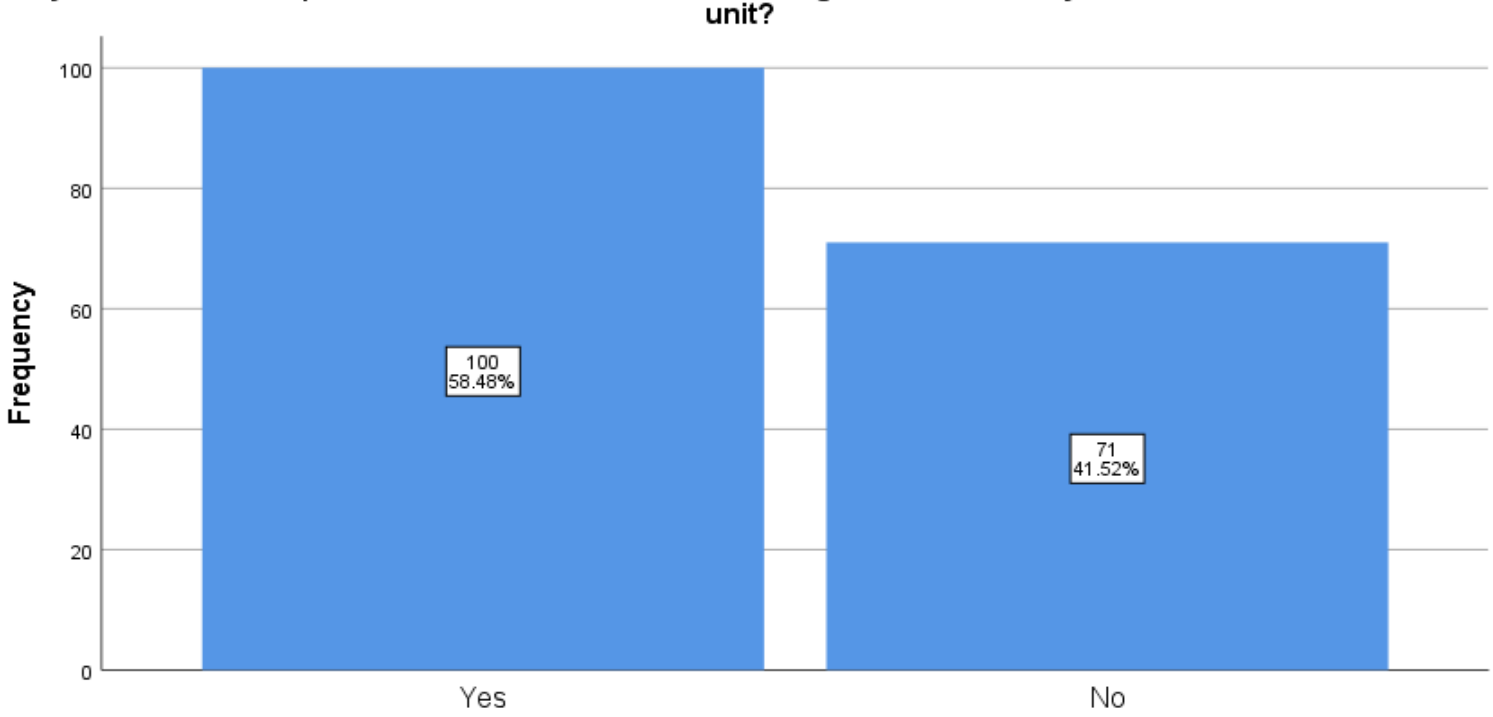

Did you know that the plants and flowers harbor resistant organisms that's why these are not allowed in burn unit?

Figure 20

Figure 21 shows that the results regarding item and the participants response regarding item sixteen which is "According to Spaulding classification of medical devices, which come in contact with mucous membranes or nonintact skin require high level of disinfection as semi critical item" and results revealed that the only $100(58.5 \%)$ were go with "Yes" and 71 (41.5\%) were responds as "No". 


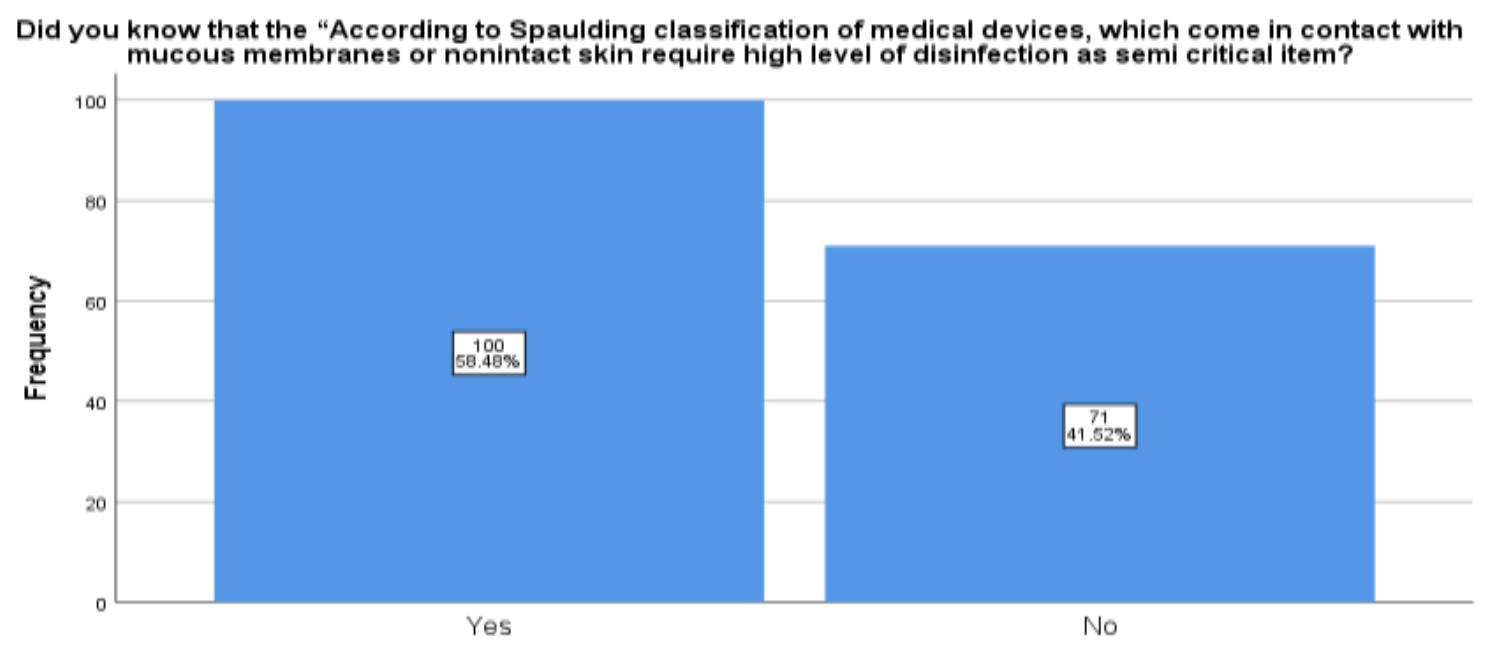

Did you know that the "According to Spaulding classification of medical devices, which come in contact with mucous membranes or nonintact skin require high level of disinfection as semi critical item?

Figure 21

Figure 22 shows that the results regarding item and the participants response regarding item seventeen and results revealed that majority 103 (60.2\%) know that and 68 (39.8\%) did not know that the CDC guidelines of disinfection, Immersion time of equipment for high level disinfection (HLD) with $2.4 \%$ glutaraldehyde.

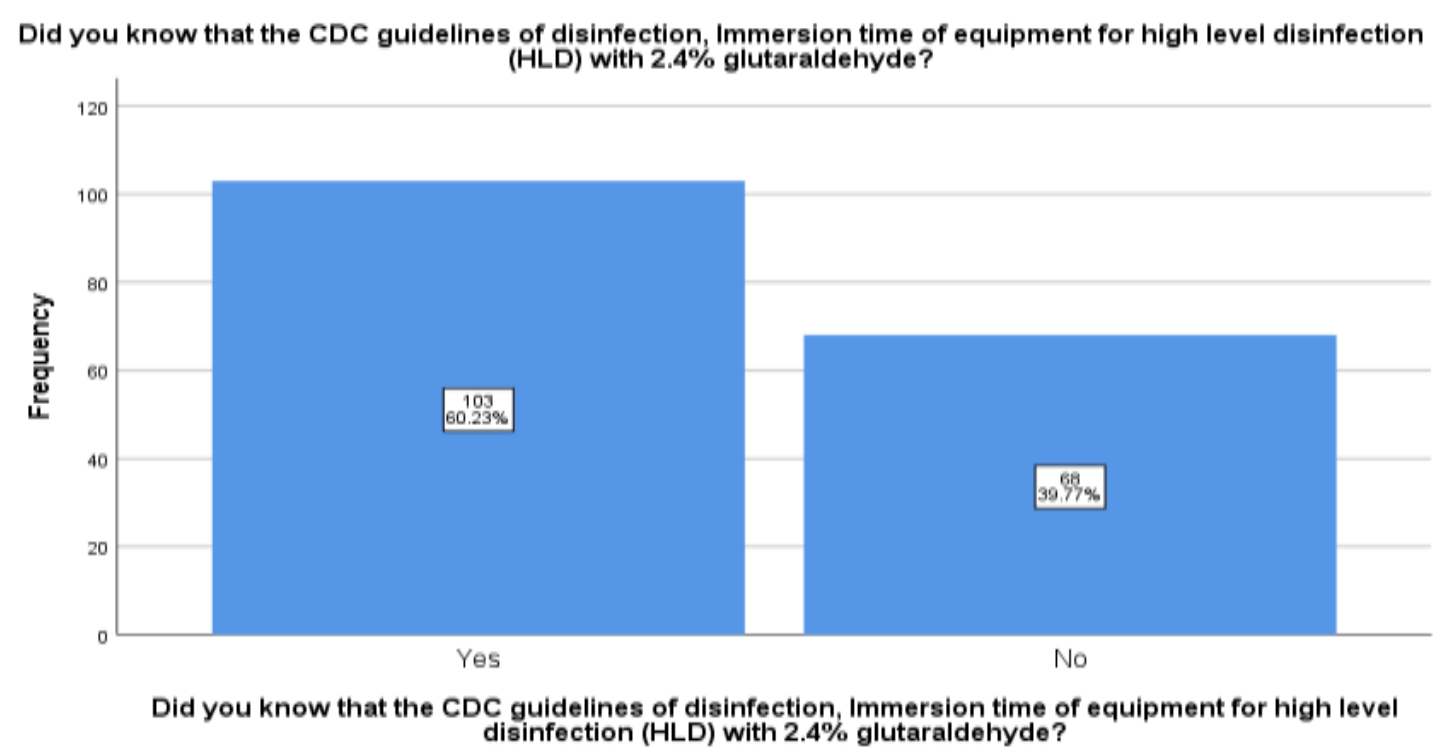

Figure 22

Figure 23 shows that the results regarding item eighteen is "high touch surface areas must be clean and disinfect" and majority 105 (61.4\%) go with yes and $66(38.6 \%)$ respond as "No". 


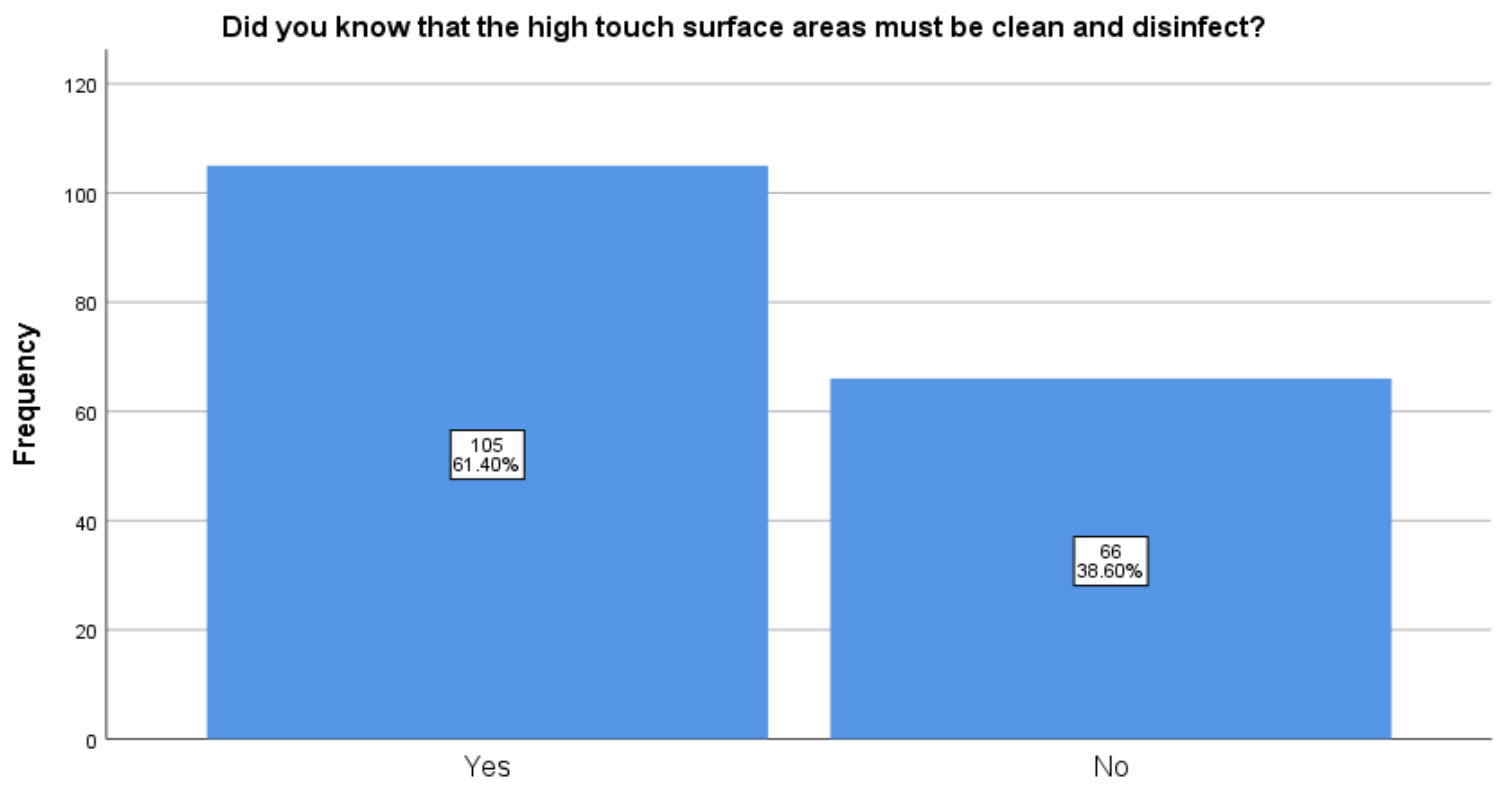

Did you know that the high touch surface areas must be clean and disinfect?

Figure 23

Figure 24 shows that the results regarding item nineteen is "chlorhexidine bath and its suggested frequency in burn patients for prevention of infection in burn patients" and results revealed that the only $96(55.4 \%)$ respond as yes and $76(44.6 \%)$ respond as "No".

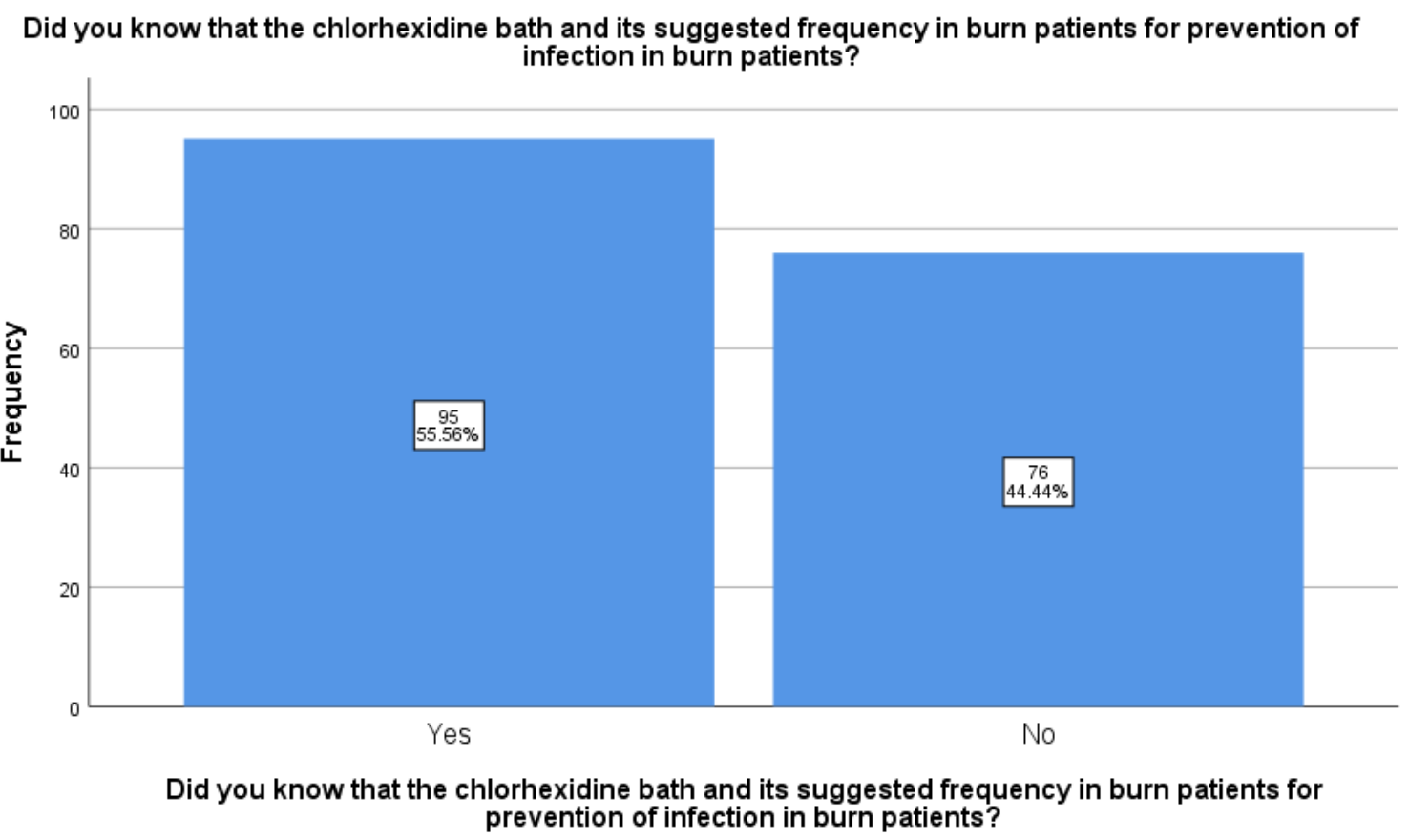

Figure 24

Figure 25 shows that the results regarding item and the participant responds as 93 (54.7\%) know and 78 (45.3\%) did not know the factor including high antibiotic pressures, high colonization pressures, need for intensive medical and surgical therapy, and a vulnerable, immunocompromised patient leads to acquisition of antibiotic resistant organism in burn patients. 
Did you know that the factor including high antibiotic pressures, high colonization pressures, need for intensive medical and surgical therapy, and a vulnerable, immunocompromised patient leads to acquisition of

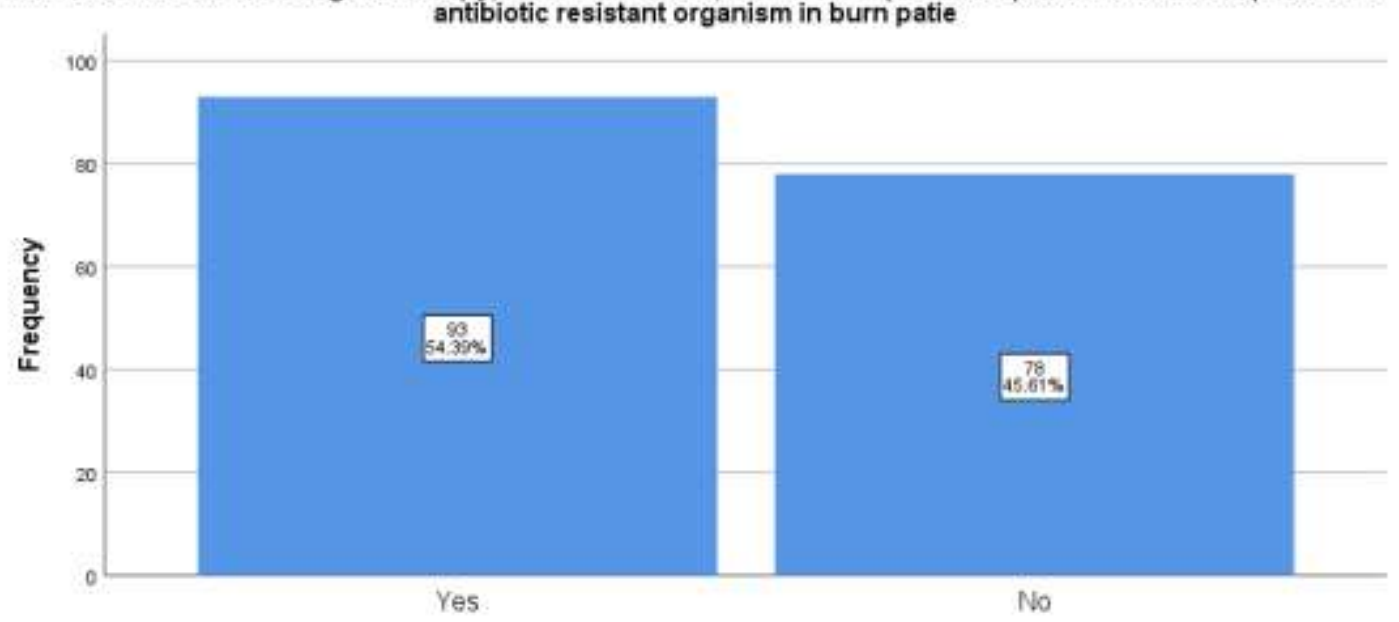

Did you know that the factor including high antibiotic pressures, high colonization pressures, need for intensive medical and surgical therapy, and a vulnerable, immunocompromised patient leads to acquisition of antibiotic resistant organism in burn patie

\section{Figure 25}

Figure 26 shows that the results regarding item twenty-one is "preparation of the isolation room or area, ensure that appropriate handwashing facilities and hand-hygiene supplies are available" and participants respond as majority 105 (61.4\%) were go with "Yes" and 66 (38.2\%) were responds as "No".

\section{Did you know that the preparation of the isolation room or area, ensure that appropriate handwashing facilities
and hand-hygiene supplies are available?}

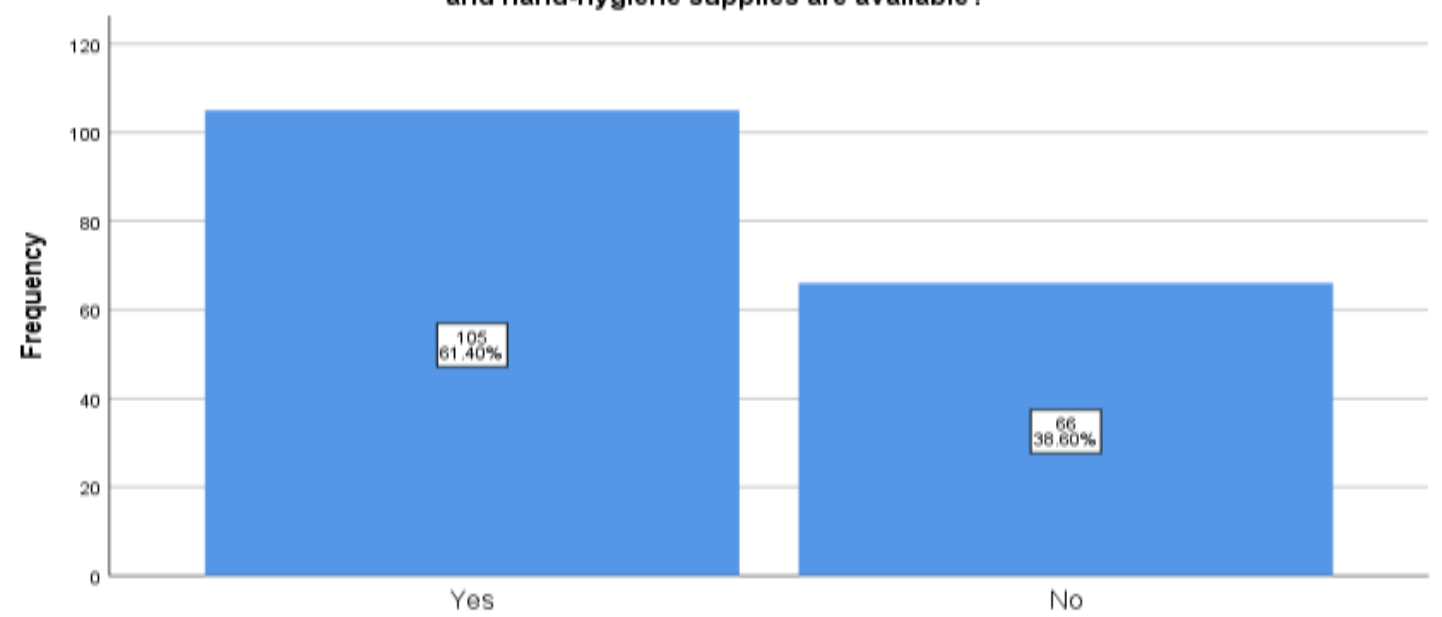

Did you know that the preparation of the isolation room or area, ensure that appropriate handwashing facilities and hand-hygiene supplies are available?

Figure 26

Figure 27 shows that the results regarding item and the participants response regarding item twenty two which is "precautions such as hand washing and barrier nursing, efficient cleaning and decontamination of hospital equipment, are most important for prevention of MRSA in burn patients" and results revealed that the only 99 (57.2\%) were go with "Yes" and 71 (41.5\%) were responds as "No". 


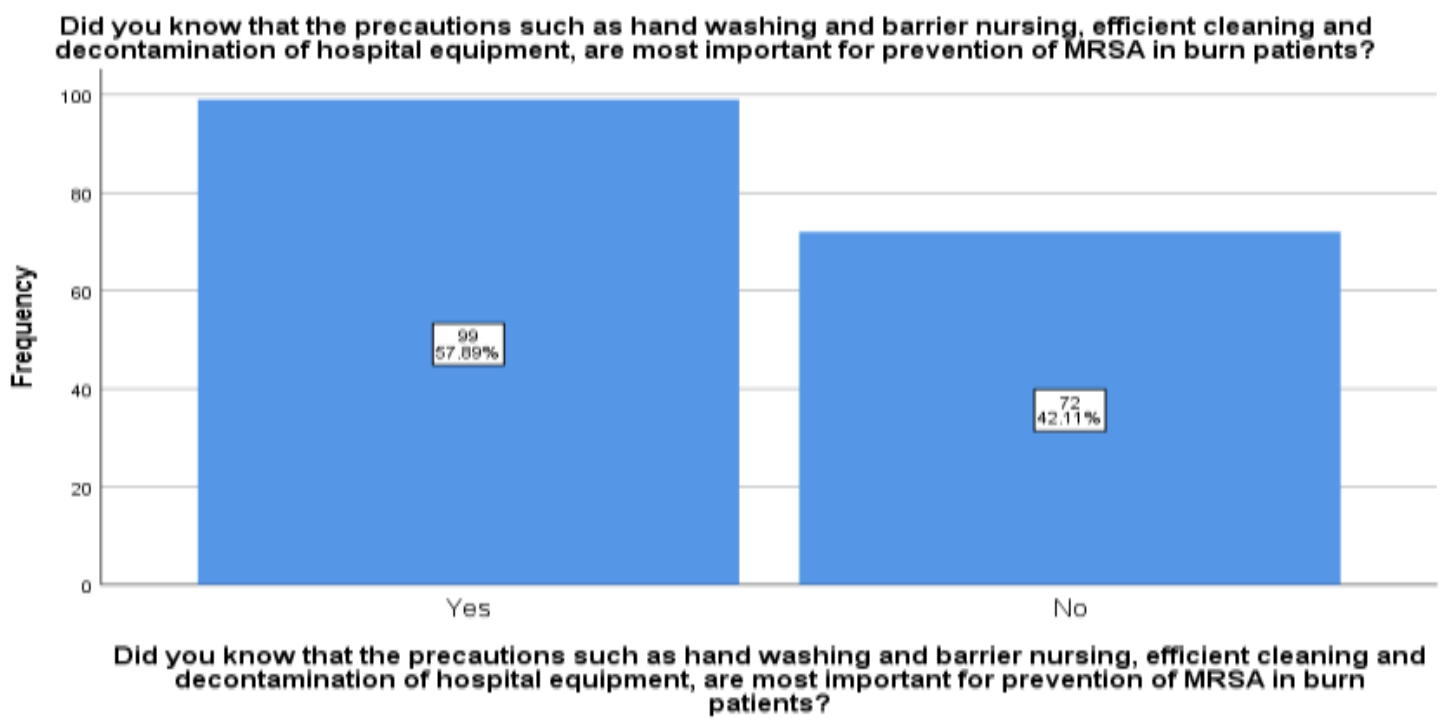

Figure 27

Figure 28 shows that the results regarding item and the participants response regarding item twenty-three and results revealed that majority $105(61.4 \%)$ know that and 66 (38.6\%) did not know that the burn Patients require additional infection control precautions.

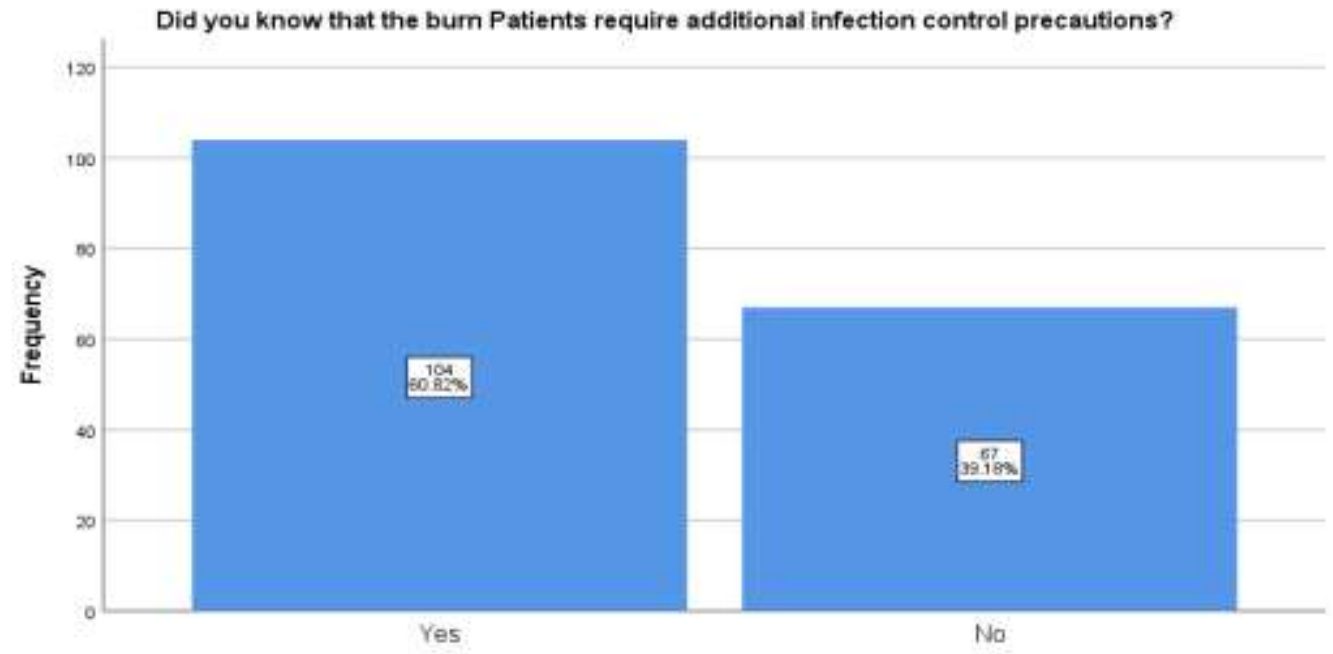

Did you know that the burn Patients require additional infection control precautions?

Figure 28

Figure 29 shows that the results regarding item twenty-four is "nasal decolonization of MRSA patients done by mupirocin" and majority 99 (57.9\%) go with yes and 72 (42.1\%) respond as "No". 


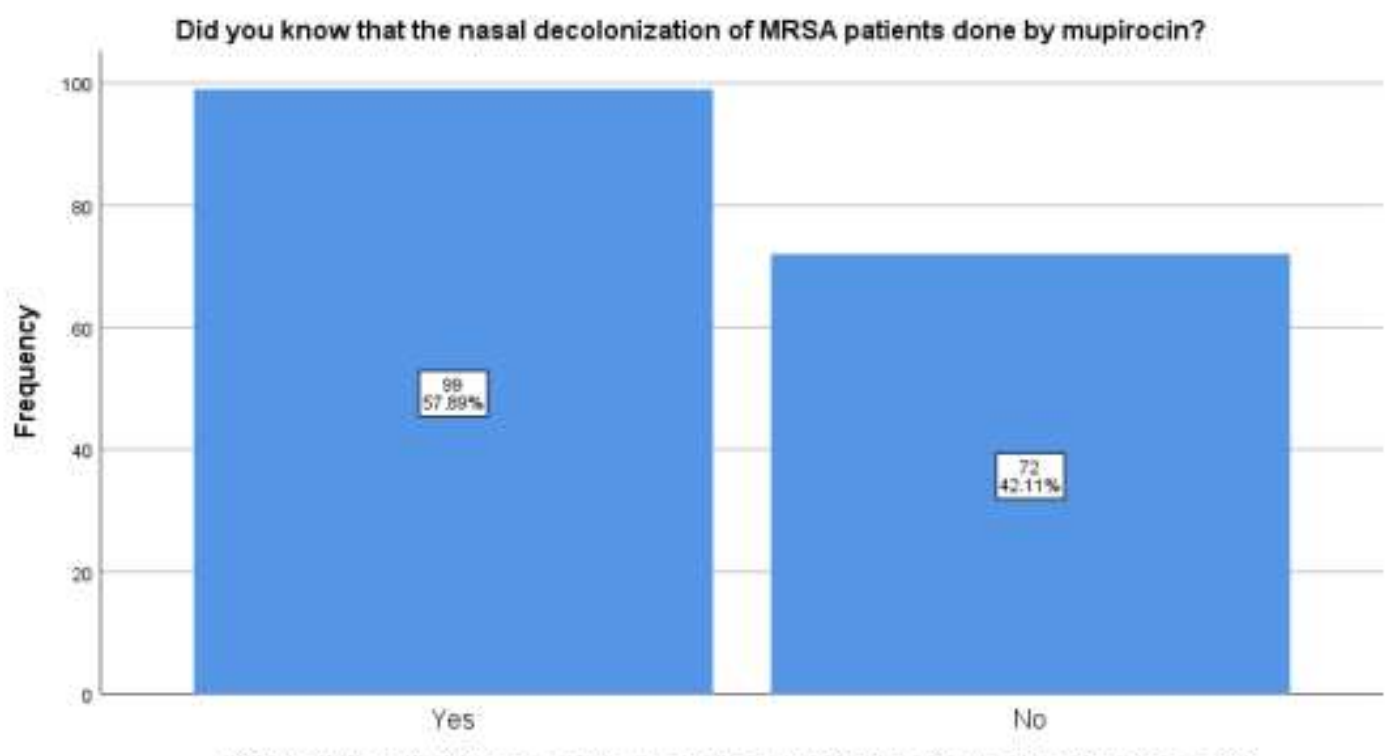

Did you know that the nasal decolonization of MRSA patients done by mupirocin?

Figure 29

Figure 30 shows that the results regarding item and the participants response regarding item twenty-five which is "Aquatic environment of hydrotherapy room is difficult to decontaminate" and results revealed that the only 126 (73.5\%) were go with "Yes" and 45 (26.7\%) were responds as "No".

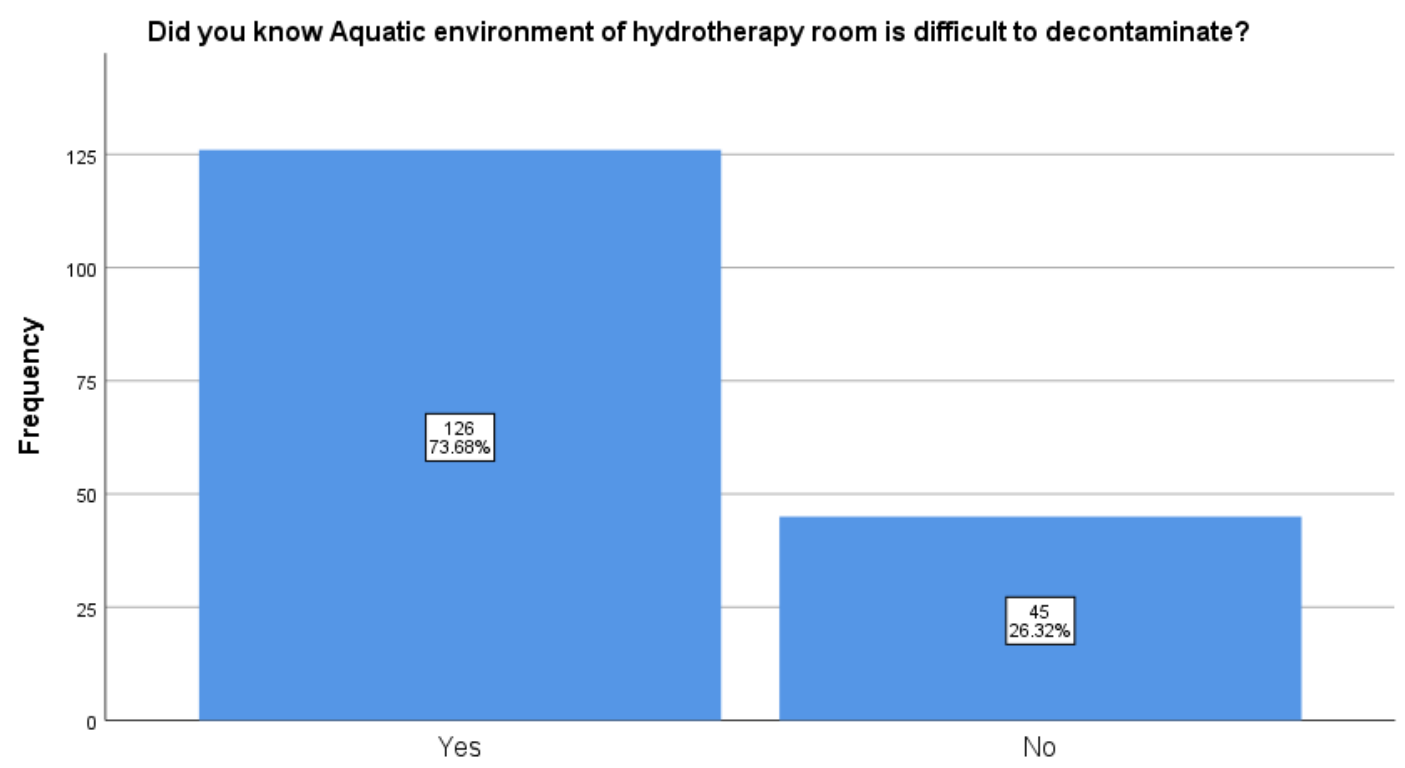

Did you know Aquatic environment of hydrotherapy room is difficult to decontaminate?

Figure 30

Figure 31 shows that the results regarding item and the participants response regarding item twenty-six and results revealed that majority $81(47.4 \%)$ know that and $90(52.6 \%)$ did not know that the specific antiseptic such as Chlorhexidine gluconate recommended for hand washing. 


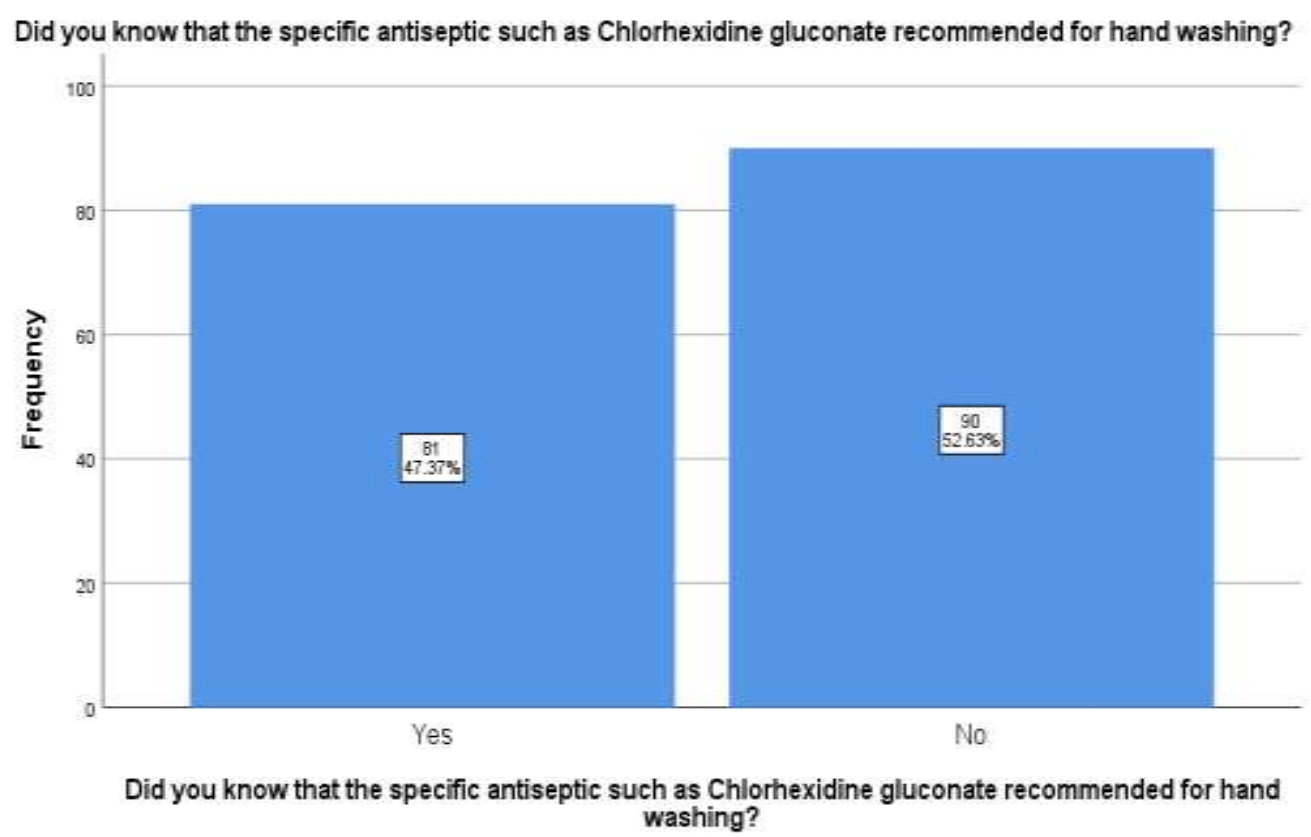

Figure 31

Figure 32 shows that the results regarding item twenty-seven is "Did you that the Important step during removal of personal protective equipment" and majority $90(52.6 \%)$ go with yes and $81(47.4 \%)$ respond as "No".

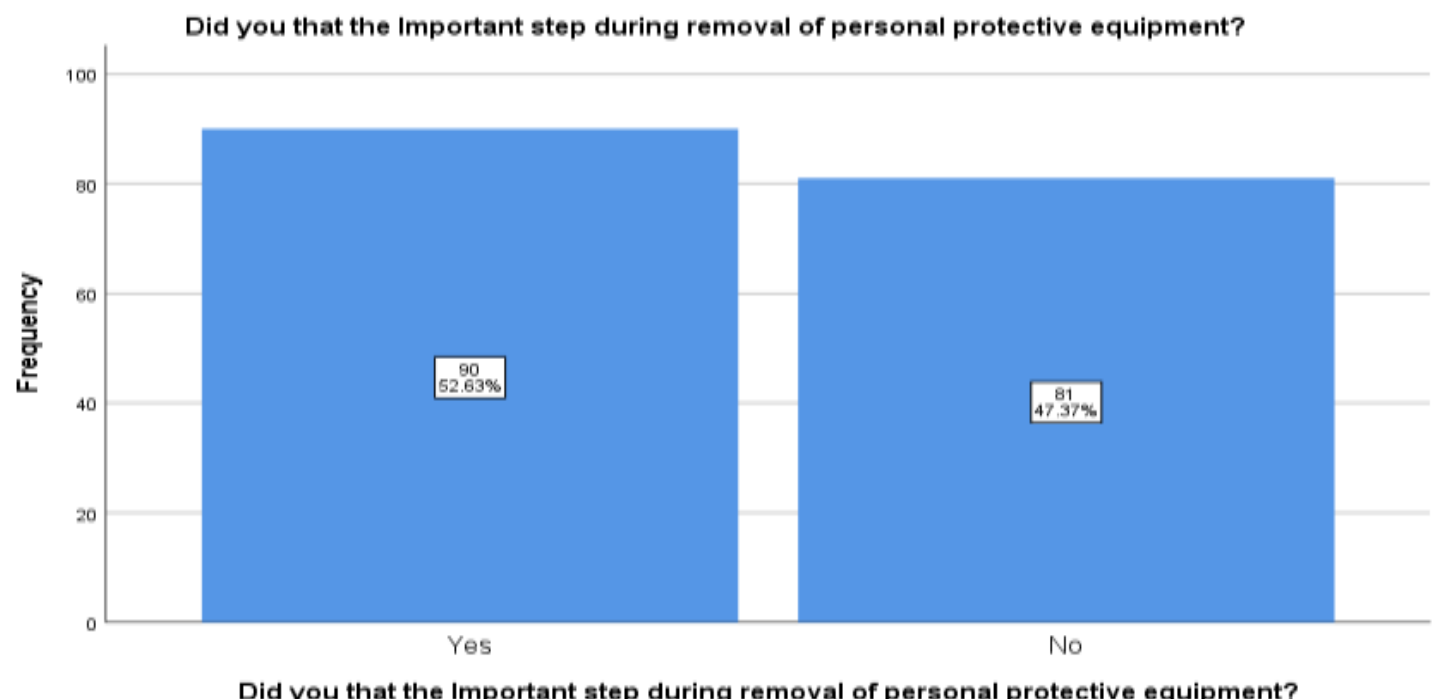

Figure 32

Table 5 shows the results of observation regarding nurses' practices for the prevention of infection in burn patient and results revealed that majority of participants 110 (64.3\%) observed as wash their hand 56 (32.7\%) did not wash their hand and only $5(2.9 \%)$ were not applicable at the time of patient care. Most of participants $81(47.4 \%)$ observed as wear mask, $90(52.6 \%)$ did not wear mask and only $0(0 \%)$ were not applicable at the time of patient care. Observation regarding item three was show that 78 (45.2\%) participants wear gown, 67 (39.2\%) did not wear gown and only $26(15.4 \%)$ were not applicable. Majority of participants $92(53.8 \%)$ observed as wear gloves 58 (33.7\%) did not wear gloves and only 21 (12.5\%) were not applicable at the time of patient care. Most of participants 86 (50.3\%) observed as to use no touch technique, 62 (36.3\%) did not use no touch technique and only 
$23(13.4 \%)$ were not applicable at the time of patient care. Observation regarding item six was show that 87 $(50.9 \%)$ participants were disinfect the devices, 61 (35.8\%) did not were disinfect the devices and only 23 (13.4\%) were not applicable at the time of patient care. Majority of participants 93 (54.4\%) observed as to disinfect the sphygmomanometer, $49(28.6 \%)$ did not disinfect the sphygmomanometer and only $29(17.6 \%)$ were not applicable at the time of patient care. Most of participants 111 (64.9\%) observed as to disinfect the stethoscope, $47(25.9 \%)$ did not disinfect the stethoscope and only 17 (9.2\%) were not applicable at the time of patient care. Observation regarding item nine was show that 95 (55.8\%) participants were monitor equipment, $66(38.8 \%)$ did not monitor equipment and only $10(5.4 \%)$ were not applicable at the time of patient care. Majority of participants $96(52.2 \%)$ observed as to dispose needle/sharp properly, 58 (33.9\%) did not dispose needle/sharp properly and only $17(9.9 \%)$ were not applicable at the time of patient care. Most of participants 133 (77.8\%) observed as to handle soiled linen properly, $31(18.1 \%)$ did not handle soiled linen properly and only 7 (4.1\%) were not applicable at the time of patient care. Observation regarding item twelve was show that $121(77.4 \%)$ participants were dispose PPE properly, $37(21.6 \%)$ did not dispose PPE properly and only $13(7.8 \%)$ were not applicable at the time of patient care. Majority of participants 131 (76.6\%) observed as to dispose clinical/waste properly, $27(15.6 \%)$ did not dispose clinical/waste properly and only $13(7.8 \%)$ were not applicable at the time of patient care. Most of participants 121 (70\%) observed as to wash hand after procedure, 41 (24.2\%) did not wash hand after procedure and only $9(5.8 \%)$ were not applicable at the time of patient care. Observation regarding item fifteen was show that $126(73.6 \%)$ participants were follow the patient visitor policy, $32(18.6 \%)$ did not follow the patient visitor policy and only $13(7.8 \%)$ were not applicable at the time of patient care. Majority of participants $125(76.6 \%)$ observed as to take specific precautions, $27(15.8 \%)$ did not take specific precautions and only $19(11.1 \%)$ were not applicable at the time of patient care. Most of participants $115(67.3 \%)$ observed as to wash hand before procedure, $44(25.7 \%)$ did not wash hand before procedure and only $11(7 \%)$ were not applicable at the time of patient care. Observation regarding item eighteen was show that $105(61.2 \%)$ participants were clean skin with antiseptic, 50 (29.6\%) did not clean skin with antiseptic and only 16 (9.2\%) were not applicable at the time of patient care. Majority of participants 80 (46.8\%) observed as to use A-septics technique while placing catheter, $73(42.7 \%)$ did not use A-septics technique while placing catheter and only 18 (10.5\%) were not applicable at the time of patient care.

Most of participants 102 (69.7\%) observed as to use standard application for dressing, 46 (25.3\%) did not use standard application for dressing and only $24(14 \%)$ were not applicable at the time of patient care. Observation regarding item twenty-one was show that 97 (56.3\%) participants were use Aseptic techniques during dressing, 65 (38\%) did use Aseptic techniques during dressing and only 9 (5.7\%) were not applicable at the time of patient care. Majority of participants $113(16.1 \%)$ observed as to know horizontal surfaces while cleaner clean the surface, 51 $(29.8 \%)$ did not to know horizontal surfaces while cleaner clean the surface and only 7 (4.1\%) were not applicable at the time of patient care. Most of participants 94 (55\%) observed as to ask the cleaner to clean walls, $60(35.1 \%)$ did not ask the cleaner to clean walls and only 17 (9.9\%) were not applicable at the time of patient care. Observation regarding item twenty-four was show that 87 (50.9\%) participants were disinfect the surfaces of furniture 79 $(46.2 \%)$ did not disinfect the surfaces of furniture and only $5(2.9 \%)$ were not applicable at the time of patient care. Majority of participants 109 (63.9\%) observed as to disinfect the monitor, 57 (32.2\%) did not disinfect the monitor and only $5(2.9 \%)$ were not applicable at the time of patient care. Most of participants $86(50.3 \%)$ observed as give 
chlorhexidine bath, $85(49.7 \%)$ did not give chlorhexidine bath and only $0(0 \%)$ were not applicable at the time of patient care. Observation regarding item twenty-seven was show that $85(49.7 \%)$ participants were prefer to fumigation. $71(41.5 \%)$ did not prefer to fumigation and only $15(8.7 \%)$ were not applicable at the time of patient care.

\section{Checklist regarding prevention of infection in burn patients}

\begin{tabular}{|c|c|c|c|c|c|c|}
\hline Checklist items & $\begin{array}{c}\text { Observed } \\
\text { F }\end{array}$ & $\begin{array}{c}\text { Valid } \\
\%\end{array}$ & $\begin{array}{c}\text { Not } \\
\text { observed } \\
\text { F } \\
\end{array}$ & $\begin{array}{c}\text { Valid } \\
\%\end{array}$ & $\begin{array}{c}\text { Not } \\
\text { applicable } \\
\text { F } \\
\end{array}$ & $\underset{\%}{\text { Valid }}$ \\
\hline Hand washing & 110 & $64.3 \%$ & 56 & $32.7 \%$ & 5 & $2.9 \%$ \\
\hline Mask & 81 & $47.4 \%$ & 90 & $52.6 \%$ & 0 & $0 \%$ \\
\hline Gown & 78 & $45.2 \%$ & 67 & $39.2 \%$ & 26 & $15.6 \%$ \\
\hline Gloves & 92 & $53.8 \%$ & 58 & $33.7 \%$ & 21 & $12.5 \%$ \\
\hline No Touch Technique & 86 & $50.3 \%$ & 62 & $36.3 \%$ & 23 & $13.4 \%$ \\
\hline Disinfection Devices & 87 & $50.9 \%$ & 61 & $35.8 \%$ & 23 & $13.4 \%$ \\
\hline Sphygmomanometer: & 93 & $54.4 \%$ & 49 & $28.6 \%$ & 29 & $17 \%$ \\
\hline Stethoscope & 111 & $64.9 \%$ & 47 & $25.9 \%$ & 17 & $9.2 \%$ \\
\hline Monitoring equipment & 95 & $55.8 \%$ & 66 & $38.8 \%$ & 10 & $5.4 \%$ \\
\hline Disposal Needle/Sharp & 96 & $56.2 \%$ & 58 & $33.9 \%$ & 17 & $9.9 \%$ \\
\hline Handling Soiled linen & 133 & $77.8 \%$ & 31 & $18.1 \%$ & 7 & $4.1 \%$ \\
\hline Disposal of PPE & 121 & $77.6 \%$ & 37 & $21.6 \%$ & 13 & $7.8 \%$ \\
\hline Disposal Clinical/Waste & 131 & $76.6 \%$ & 27 & $15.6 \%$ & 13 & $7.8 \%$ \\
\hline Hand washing after procedure & 121 & $70 \%$ & 41 & $24.2 \%$ & 9 & $5.8 \%$ \\
\hline Patient visitor policy & 126 & $73.6 \%$ & 32 & $18.6 \%$ & 13 & $7.8 \%$ \\
\hline Specific Precautions & 125 & $73.1 \%$ & 27 & $15.8 \%$ & 19 & $11.1 \%$ \\
\hline Hand Washing before procedure & 115 & $67.3 \%$ & 44 & $25.7 \%$ & 11 & $7 \%$ \\
\hline Clean skin with antiseptic & 105 & $61.2 \%$ & 50 & $29.6 \%$ & 16 & $9.2 \%$ \\
\hline A-septics placing catheter & 80 & $46.8 \%$ & 73 & $42.7 \%$ & 18 & $10.5 \%$ \\
\hline Application dressing & 102 & $69.7 \%$ & 45 & $26.3 \%$ & 24 & $14 \%$ \\
\hline Aseptic during dressing & 97 & $56.3 \%$ & 65 & $38 \%$ & 9 & $5.7 \%$ \\
\hline Horizontal surfaces: & 113 & $66.1 \%$ & 51 & $29.8 \%$ & 7 & $4.1 \%$ \\
\hline Walls & 94 & $55 \%$ & 60 & $35.1 \%$ & 17 & $9.9 \%$ \\
\hline Surfaces of furniture & 87 & $50.9 \%$ & 79 & $46.2 \%$ & 5 & $2.9 \%$ \\
\hline Monitor & 109 & $63.9 \%$ & 57 & $33.2 \%$ & 5 & $2.9 \%$ \\
\hline Chlorhexidine bath & 86 & $50.3 \%$ & 85 & $49.7 \%$ & 0 & $0 \%$ \\
\hline Fumigation & 85 & $49.7 \%$ & 71 & $41.5 \%$ & 15 & $8.7 \%$ \\
\hline
\end{tabular}

\section{Table 5}

Table 6 shows that the statistics (mean, median, mode and standard deviation) of 27 items of checklist regarding knowledge assessment of nurses for the prevention of infection in burn patient and results revealed that the highest mean value is 1.70 of item three and comparatively lowest mean value is 1.26 for item eleven which is "Handling Soiled linen". The mean value for others item is between 1.26-1.70 respectively. Median and mode value of most of items is 1 and highest is 2 . Standard deviation value .771 is highest and comparatively .501 is low.

Checklist regarding prevention of infection in burn patients

\begin{tabular}{|l|c|c|c|c|c|}
\hline Checklist items & $\mathbf{N}$ & Mean & Median & Mode & Std. D \\
\hline Hand washing & 171 & 1.39 & 1.00 & 1 & .545 \\
\hline Mask & 171 & 1.53 & 2.00 & 2 & .501 \\
\hline Gown & 171 & 1.70 & 1.00 & 1 & .720 \\
\hline Gloves & 171 & 1.58 & 1.00 & 1 & .701 \\
\hline No Touch Technique & 171 & 1.63 & 2.00 & 1 & .710 \\
\hline
\end{tabular}




\begin{tabular}{|l|l|l|l|l|l|}
\hline Disinfection Devices & 171 & 1.63 & 2.00 & 1 & .711 \\
\hline Sphygmomanometer: & 171 & 1.63 & 1.00 & 1 & .759 \\
\hline Stethoscope & 171 & 1.45 & 1.00 & 1 & .670 \\
\hline Monitoring equipment & 171 & 1.50 & 1.00 & 1 & .608 \\
\hline Disposal Needle/Sharp & 171 & 1.54 & 1.00 & 1 & .771 \\
\hline Handling Soiled linen & 171 & 1.26 & 1.00 & 1 & .527 \\
\hline Disposal of PPE & 171 & 1.37 & 1.00 & 1 & .622 \\
\hline Disposal Clinical/Waste & 171 & 1.31 & 1.00 & 1 & .607 \\
\hline Hand washing after procedure & 171 & 1.35 & 1.00 & 1 & .577 \\
\hline Patient visitor policy & 171 & 1.34 & 1.00 & 1 & .615 \\
\hline Specific Precautions & 171 & 1.38 & 1.00 & 1 & .679 \\
\hline Hand Washing before procedure & 171 & 1.40 & 1.00 & 1 & .618 \\
\hline clean skin with antiseptic & 171 & 1.48 & 1.00 & 1 & .663 \\
\hline A-septics placing catheter & 171 & 1.64 & 1.00 & & .667 \\
\hline Application dressing & 171 & 1.55 & 1.00 & & .730 \\
\hline Aseptic during dressing & 171 & 1.49 & 2.00 & & \multicolumn{1}{|c|}{.598} \\
\hline Horizontal surfaces: & 171 & 1.38 & 1.00 & 1 & .565 \\
\hline Walls & 171 & 1.55 & 1.00 & 1 & .670 \\
\hline Surfaces of furniture & 171 & 1.52 & 1.00 & 1 & .557 \\
\hline Monitor & 171 & 1.39 & 1.00 & 1 & .546 \\
\hline Chlorhexidine bath & 171 & 1.50 & 1.00 & 1 & .501 \\
\hline Fumigation & 171 & 1.59 & 1.00 & 1 & .648 \\
\hline
\end{tabular}

Table 6

Figure 33 shows that the majority of participants $110(64.3 \%)$ observed as wash their hand $56(32.7 \%)$ did not wash their hand and only $5(2.9 \%)$ were not applicable at the time of patient care.

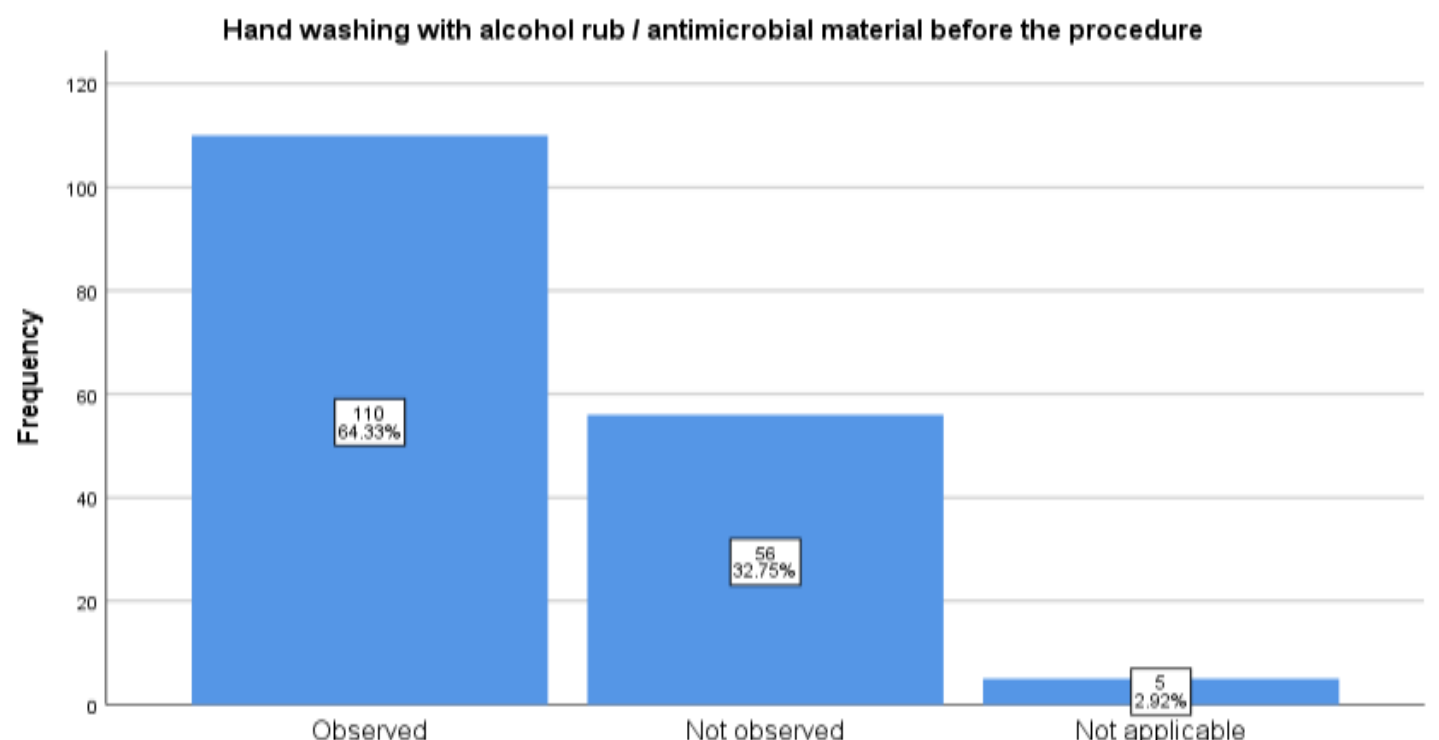

Observed

Not observed

Not applicable

Hand washing with alcohol rub / antimicrobial material before the procedure

Figure 33

Figure 34 shows that the most of participants 81 (47.4\%) observed as wear mask, $90(52.6 \%)$ did not wear mask and only $0(0 \%)$ were not applicable at the time of patient care. 


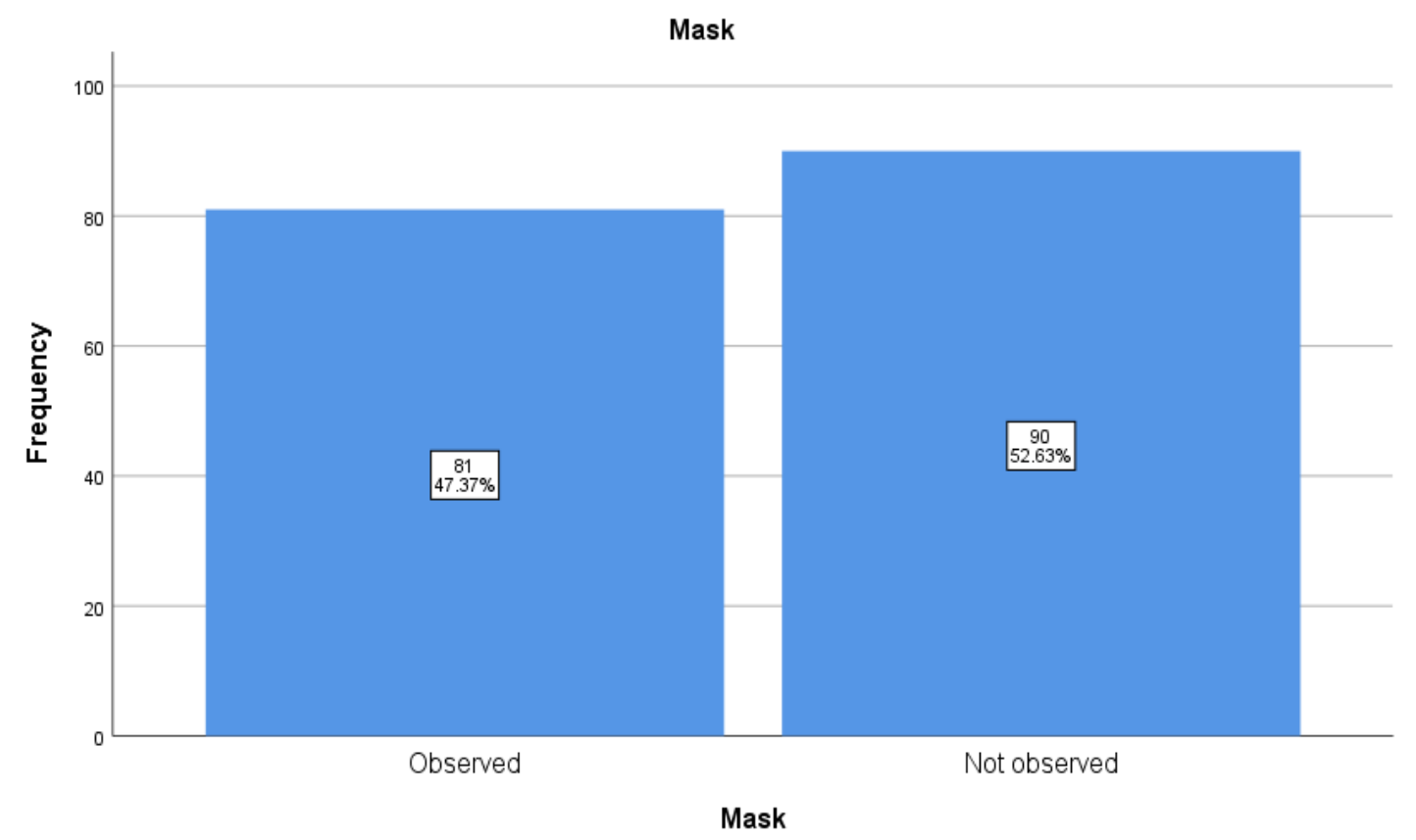

Figure 34

Figure 35 shows that the observation regarding item three was show that 78 (45.2\%) participants wear gown, 67 (39.2\%) did not wear gown and only 26 (15.4\%) were not applicable.

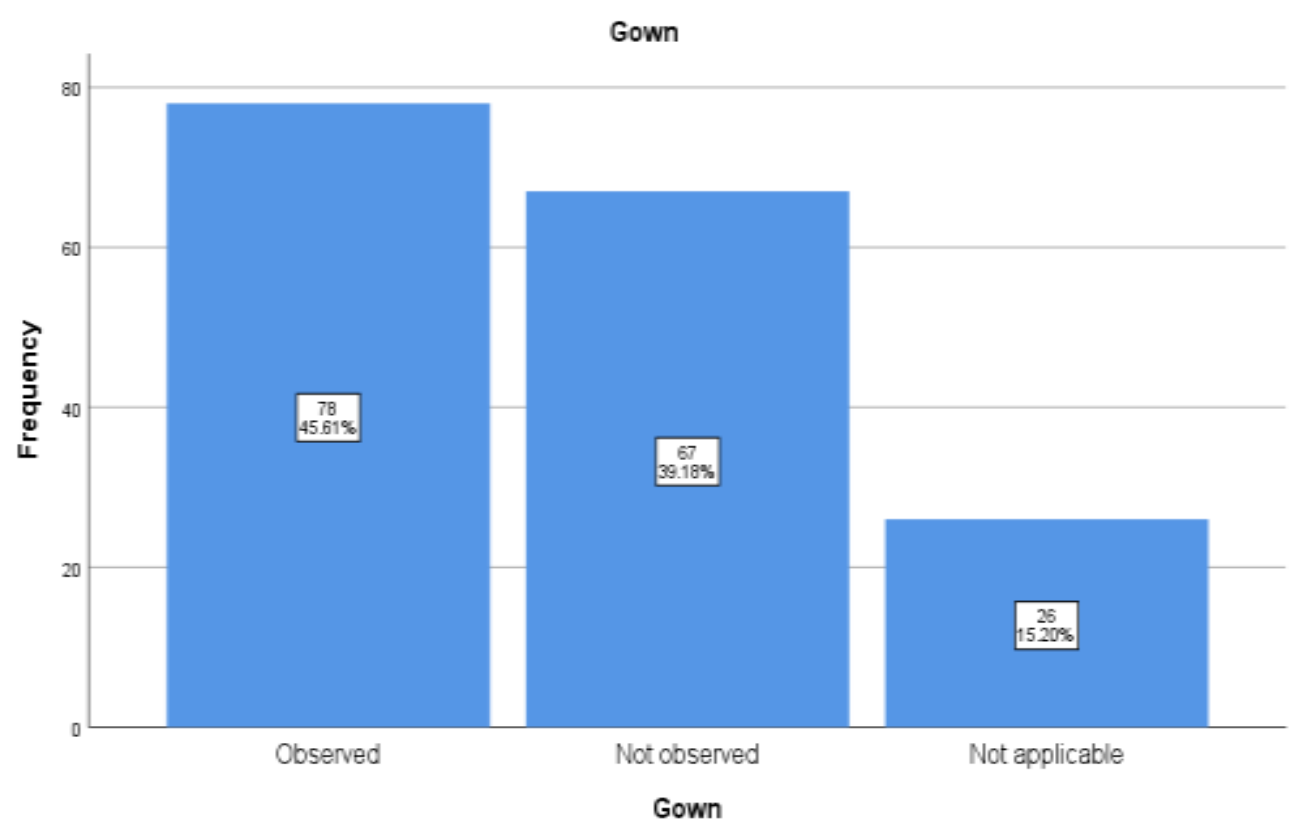

Figure 35

Figure 36 shows that the majority of participants 92 (53.8\%) observed as wear gloves 58 (33.7\%) did not wear gloves and only $21(12.5 \%)$ were not applicable at the time of patient care. 


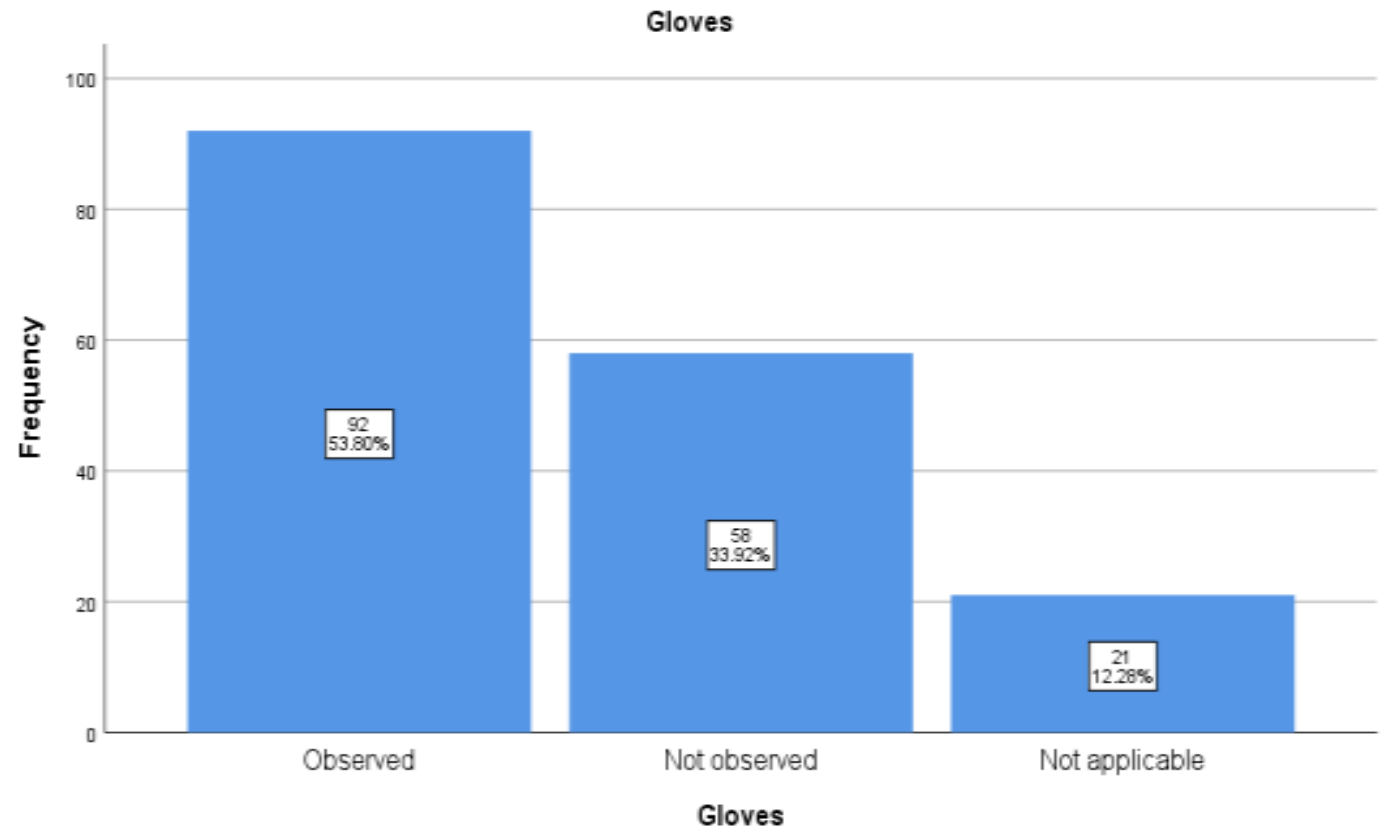

Figure 36

Figure 37 shows that the most of participants 86 (50.3\%) observed as to use no touch technique, $62(36.3 \%)$ did not use no touch technique and only $23(13.4 \%)$ were not applicable at the time of patient care.

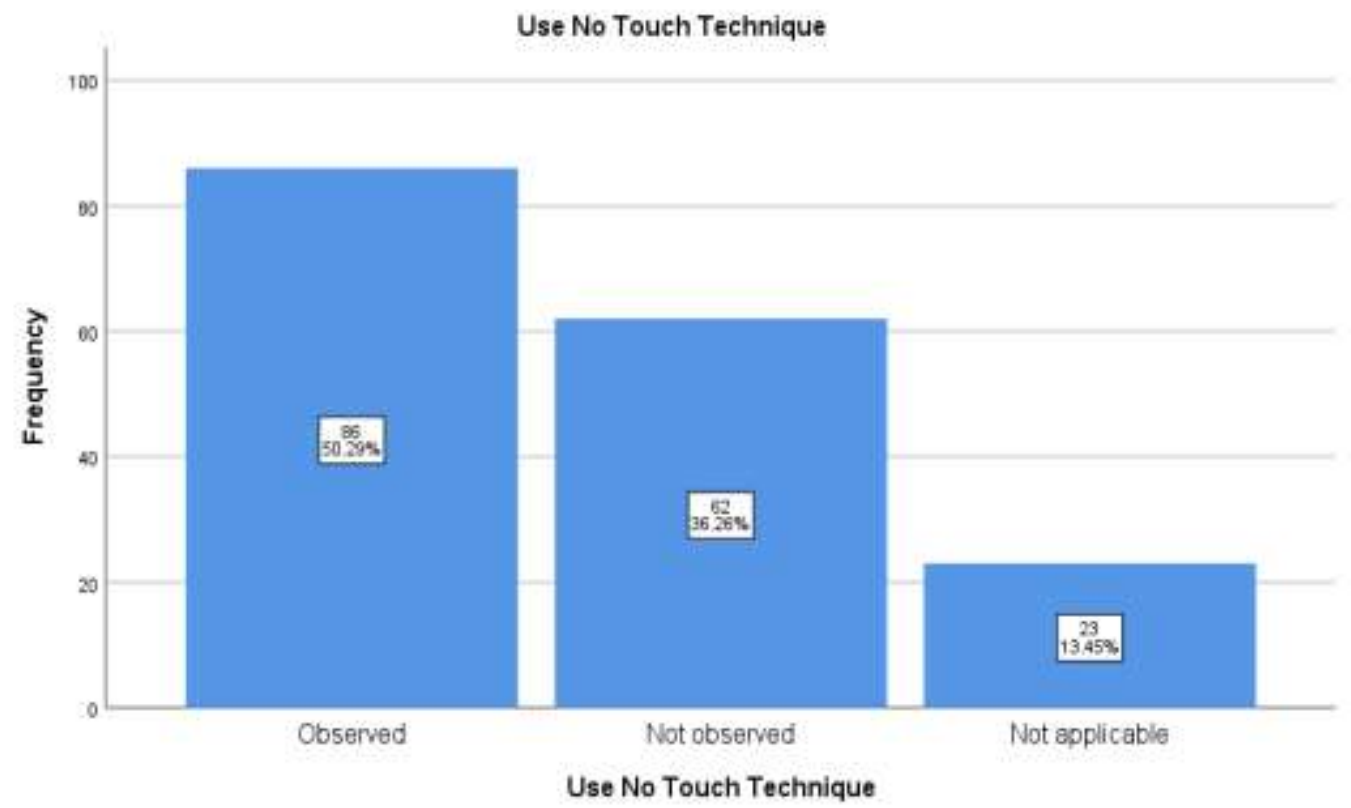

Figure 37

Figure 38 shows that the observation regarding item six was show that 87 (50.9\%) participants were disinfect the devices, $61(35.8 \%)$ did not were disinfect the devices and only $23(13.4 \%)$ were not applicable at the time of patient care. 


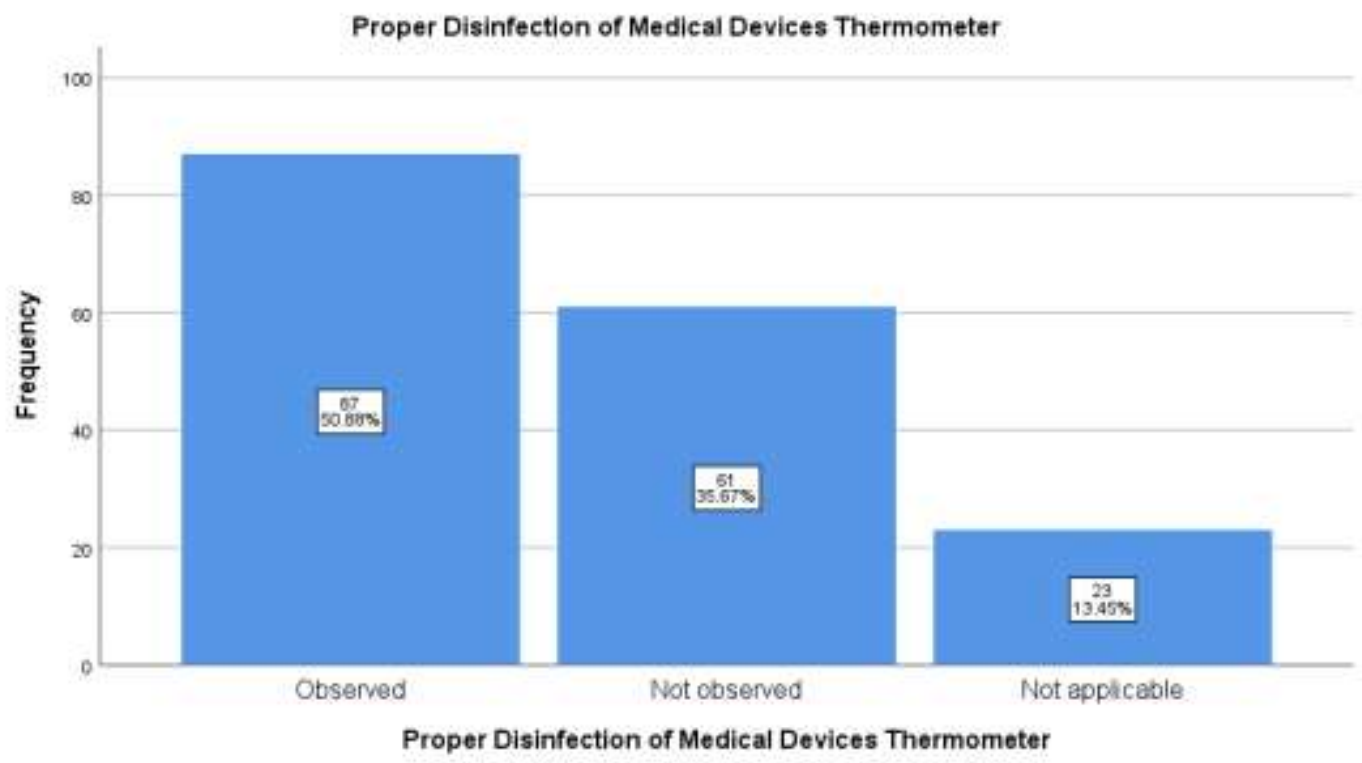

Figure 38

Figure 39 shows that the majority of participants $93(54.4 \%)$ observed as to disinfect the sphygmomanometer, 49 (28.6\%) did not disinfect the sphygmomanometer and only $29(17.6 \%)$ were not applicable at the time of patient care.

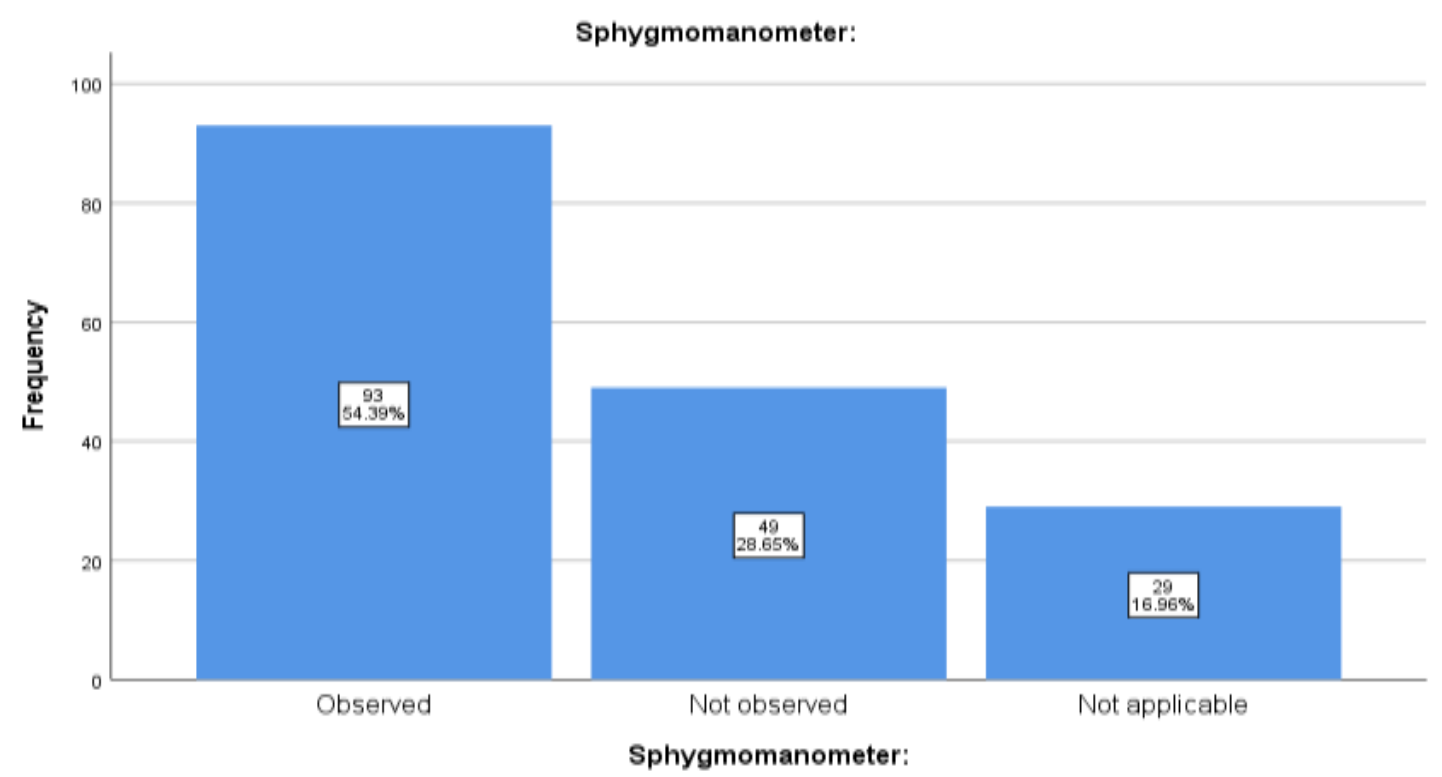

Figure 39

Figure 40 shows that the most of participants 111 (64.9\%) observed as to disinfect the stethoscope, 47 (25.9\%) did not disinfect the stethoscope and only $17(9.2 \%)$ were not applicable at the time of patient care. 


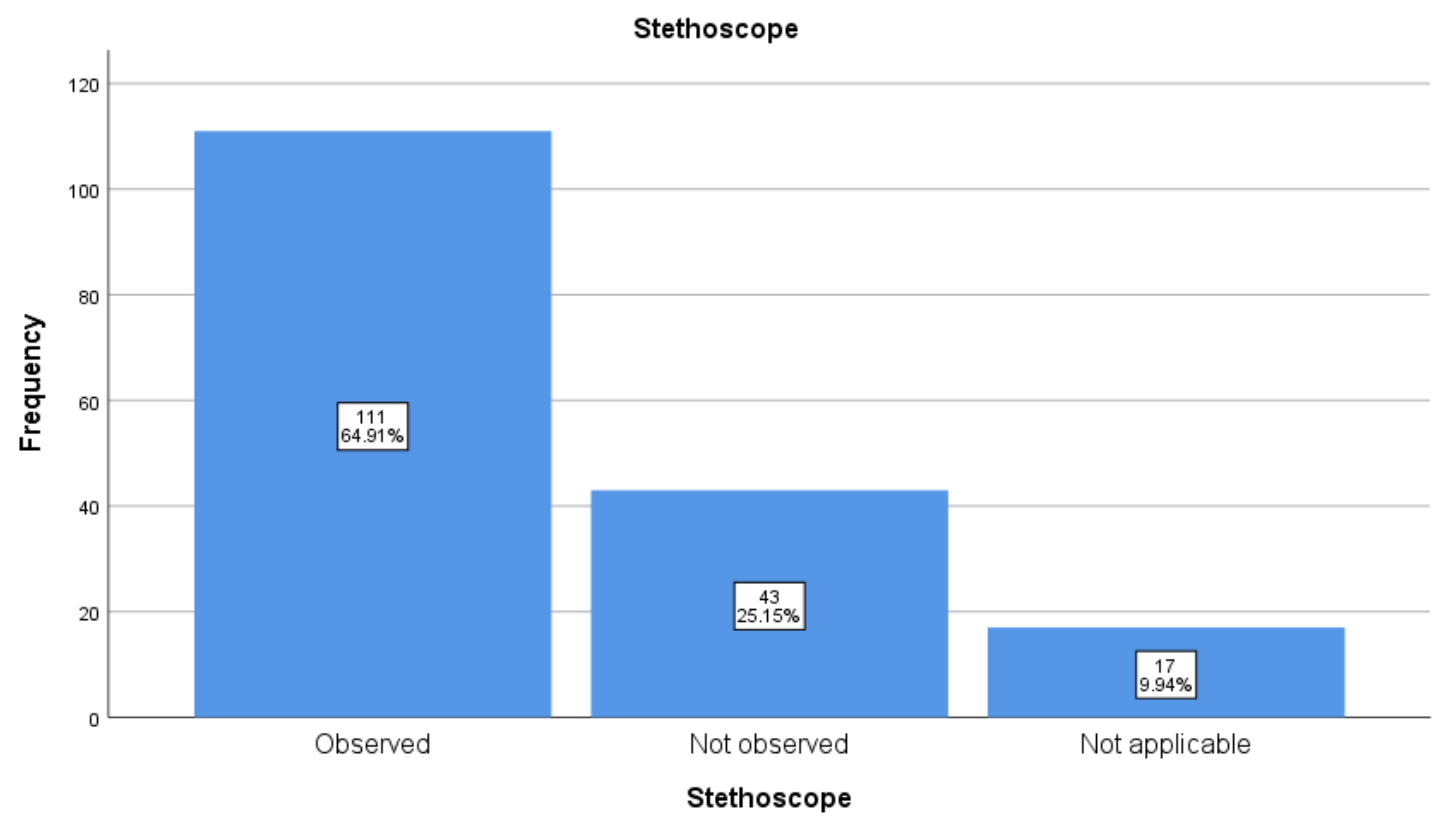

Figure 40

Figure 41 shows that the observation regarding item nine was show that 95 (55.8\%) participants were monitor equipment, 66 (38.8\%) did not monitor equipment and only 10 (5.4\%) were not applicable at the time of patient care.

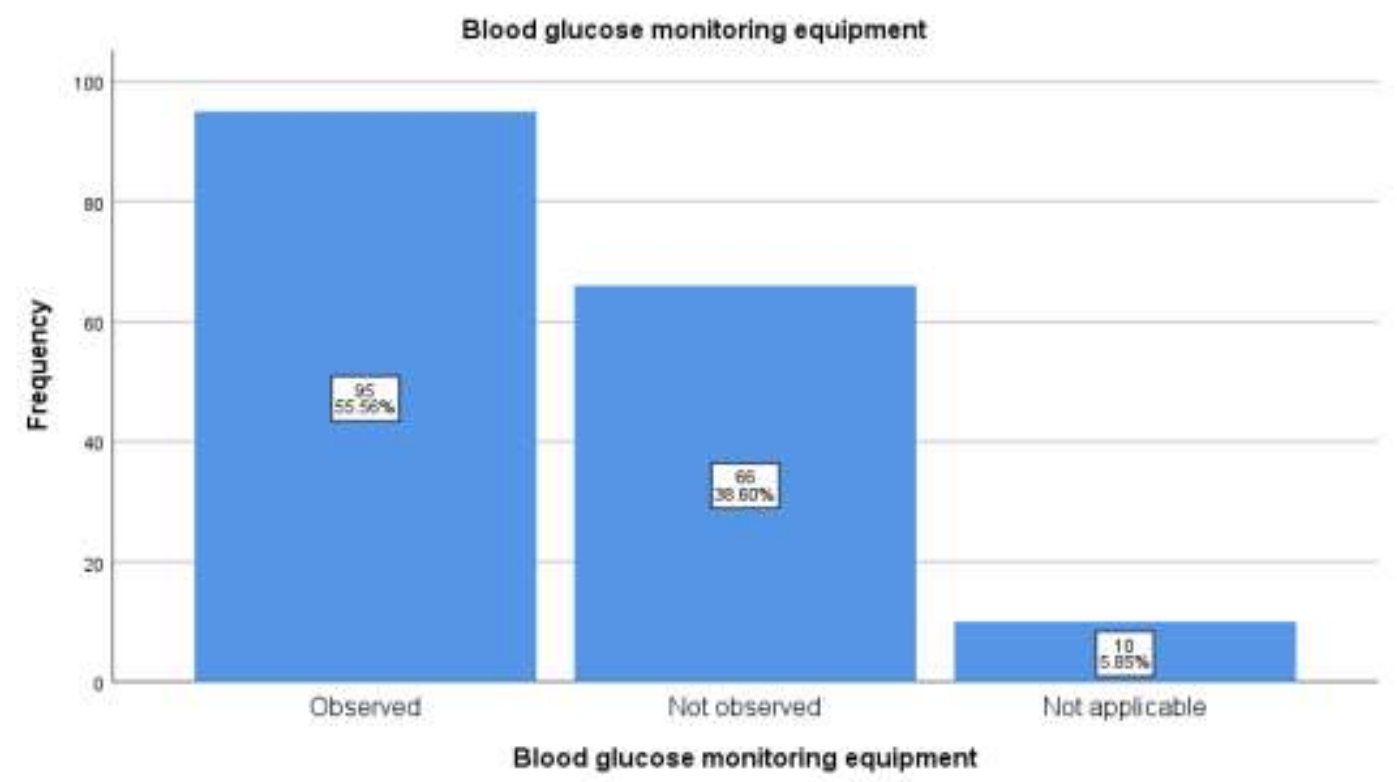

Figure 41

Figure 42 shows that the majority of participants 96 (52.2\%) observed as to dispose needle/sharp properly, 58 (33.9\%) did not dispose needle/sharp properly and only 17 (9.9\%) were not applicable at the time of patient care. 


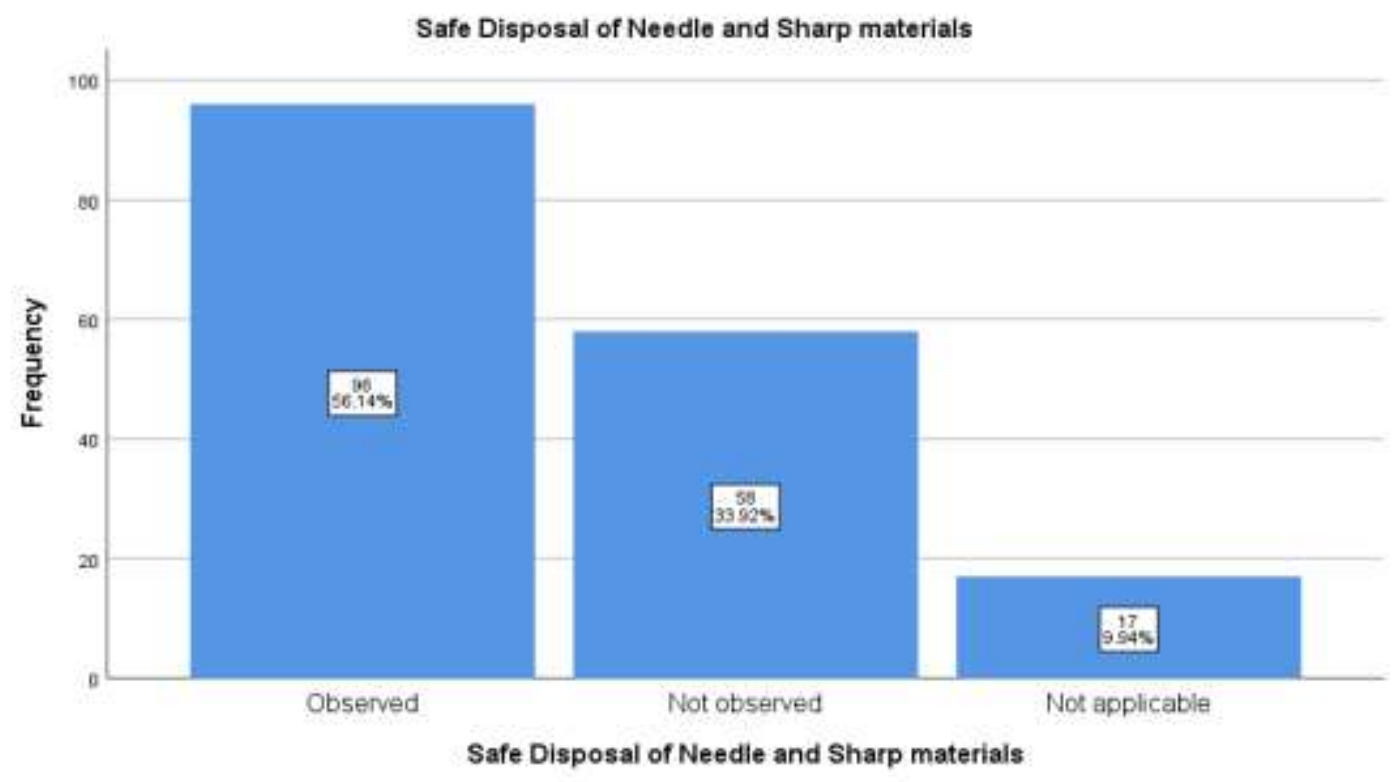

Figure 42

Figure 43 shows that the most of participants 133 (77.8\%) observed as to handle soiled linen properly, 31 (18.1\%) did not handle soiled linen properly and only $7(4.1 \%)$ were not applicable at the time of patient care.

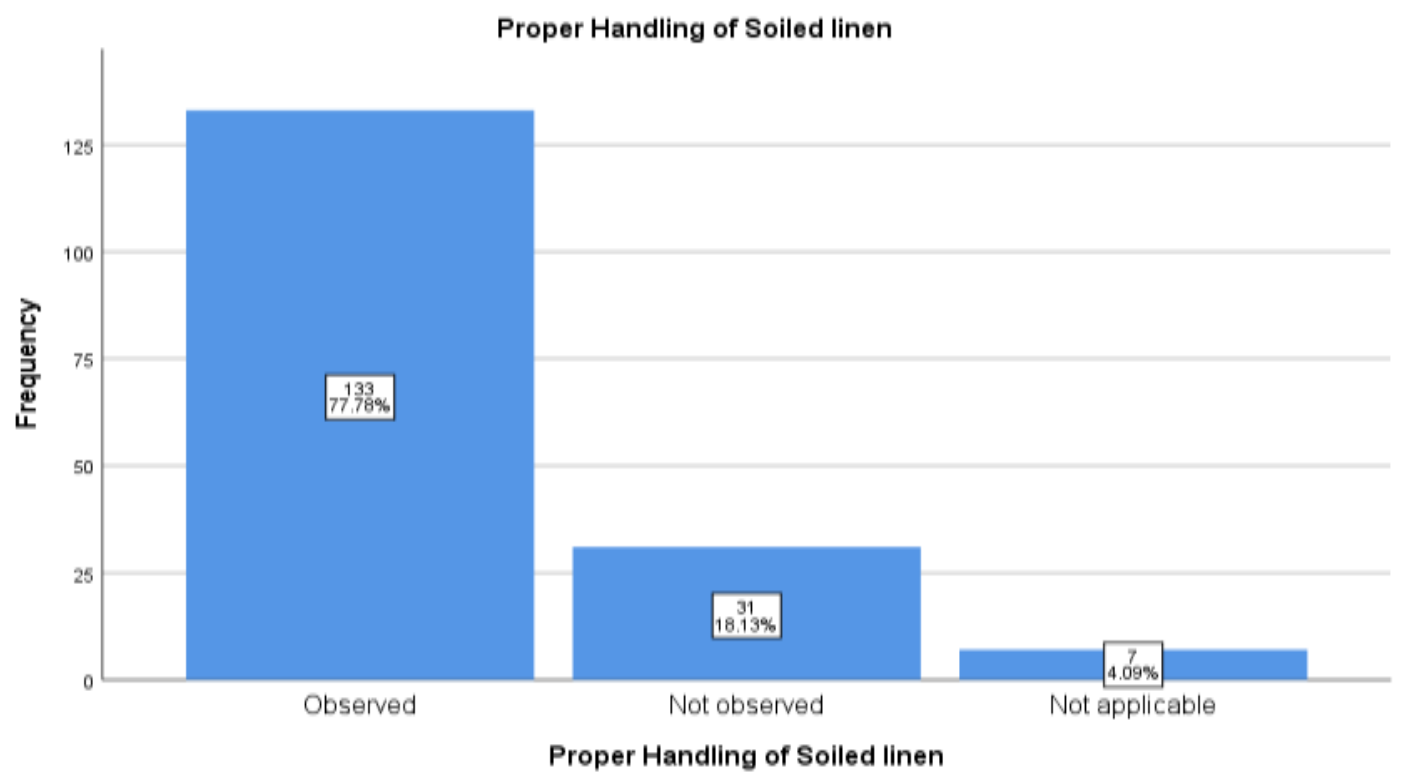

Figure 43

Figure 44 shows that the observation regarding item twelve was show that 121 (77.4\%) participants were dispose PPE properly, 37 (21.6\%) did not dispose PPE properly and only $13(7.8 \%)$ were not applicable at the time of patient care. 


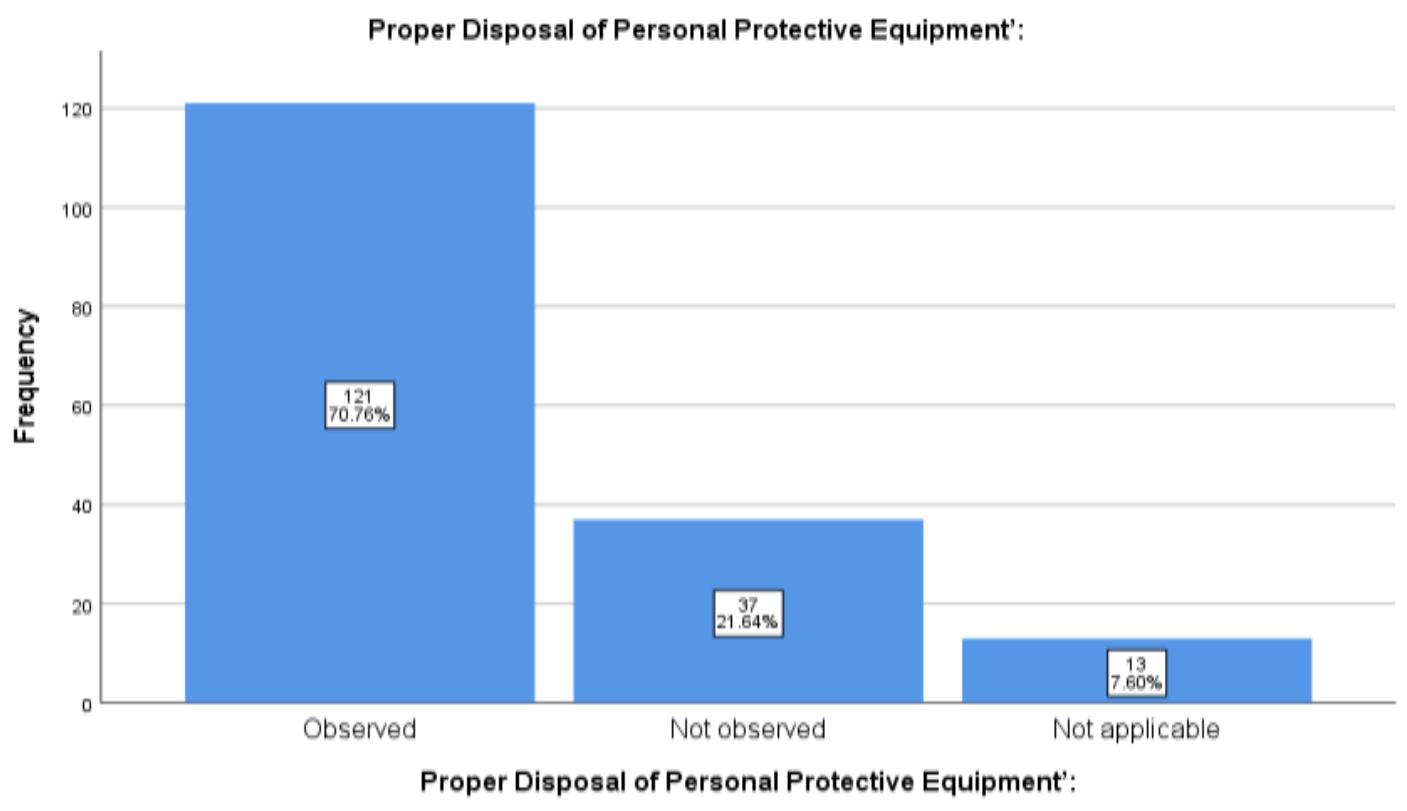

Figure 44

Figure 45 shows that the majority of participants $131(76.6 \%)$ observed as to dispose clinical/waste properly, 27 (15.6\%) did not dispose clinical/waste properly and only $13(7.8 \%)$ were not applicable at the time of patient care.

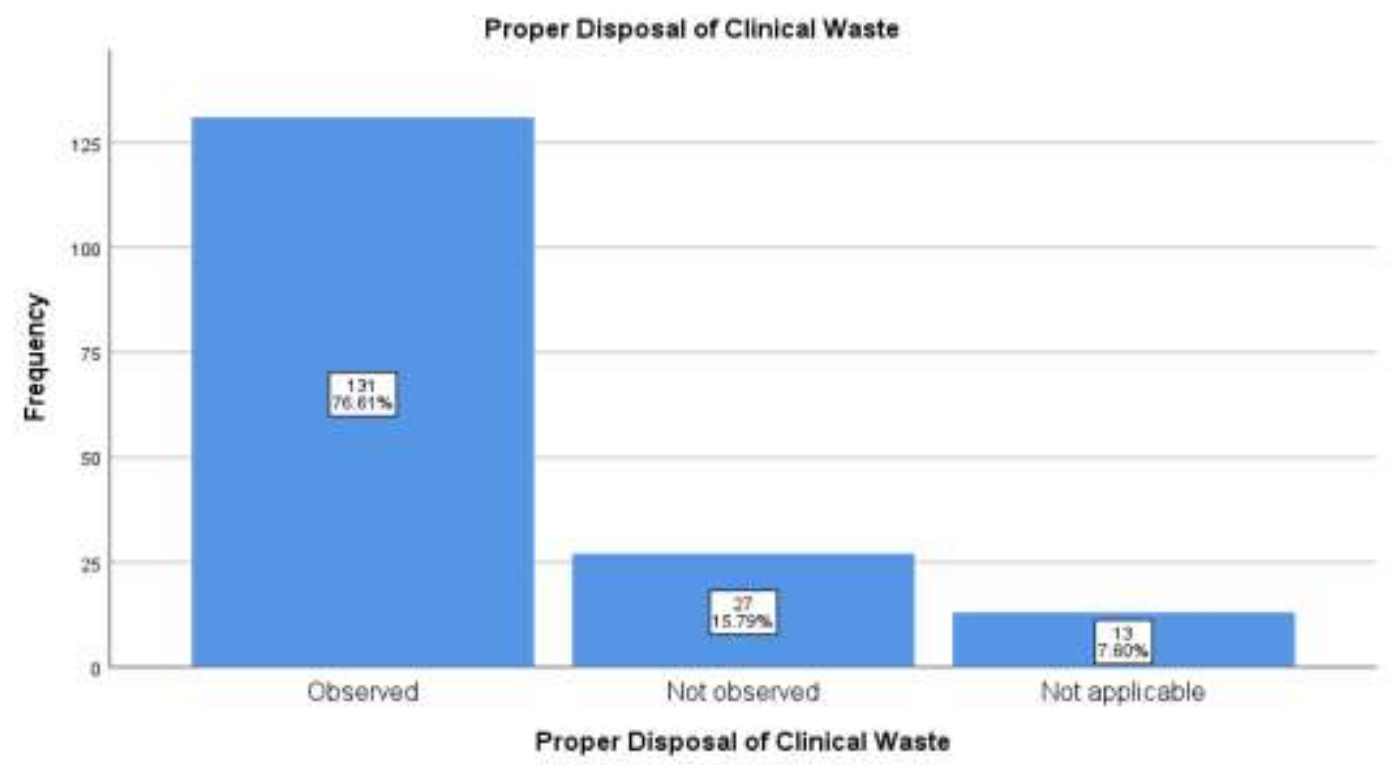

Figure 45

Figure 46 shows that the most of participants 121 (70\%) observed as to wash hand after procedure, $41(24.2 \%)$ did not wash hand after procedure and only $9(5.8 \%)$ were not applicable at the time of patient care. 


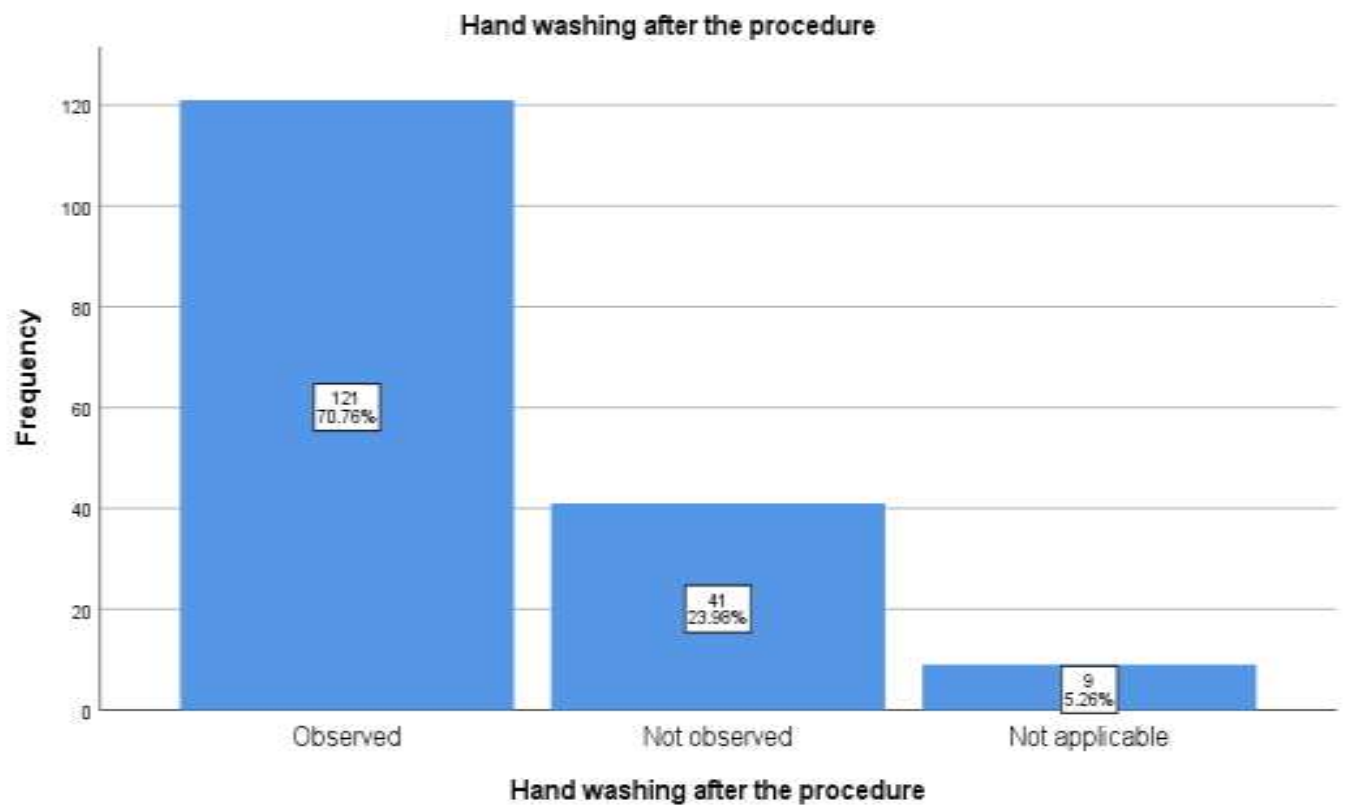

Figure 46

Figure 47 shows that the observation regarding item fifteen was show that $126(73.6 \%)$ participants were follow the patient visitor policy, $32(18.6 \%)$ did not follow the patient visitor policy and only $13(7.8 \%)$ were not applicable at the time of patient care.

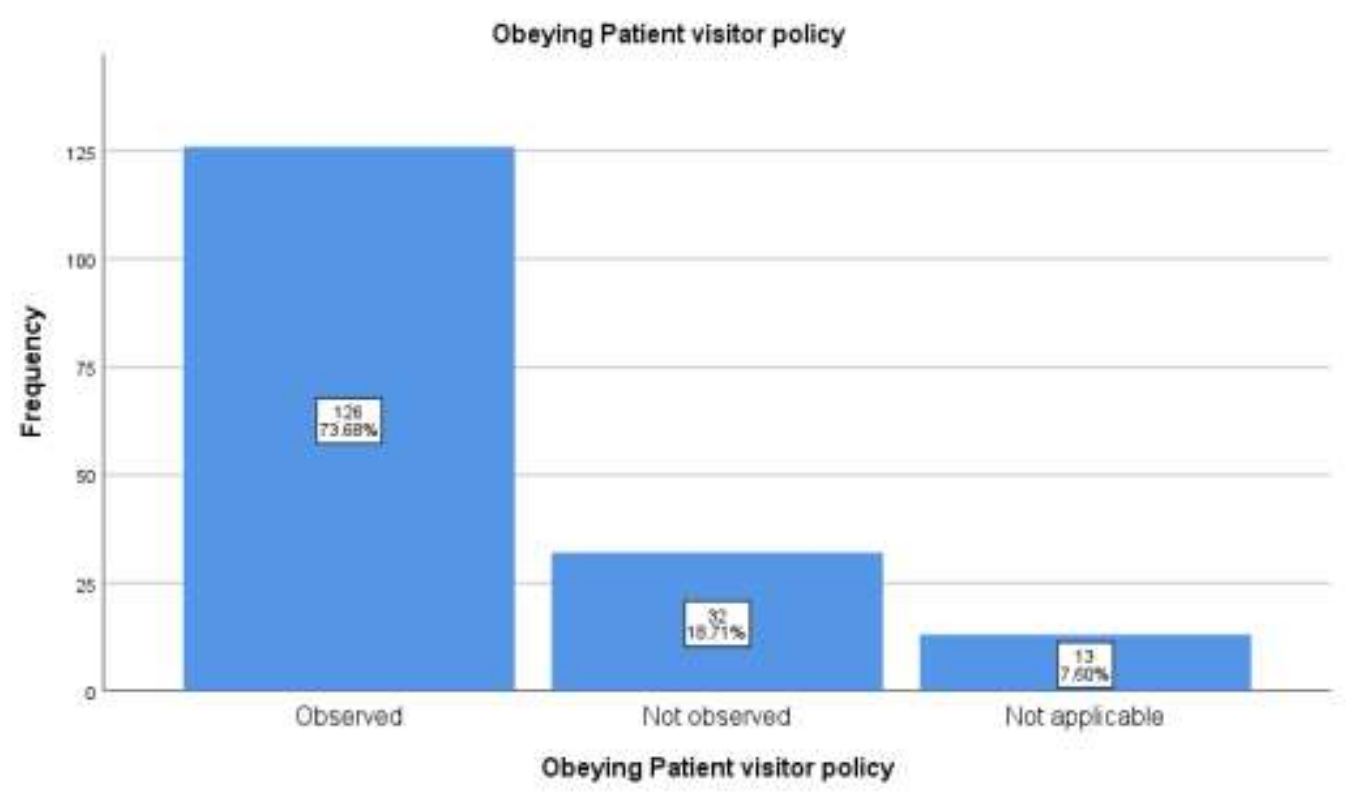

Figure 47

Figure 48 shows that the majority of participants 125 (76.6\%) observed as to take specific precautions, $27(15.8 \%)$ did not take specific precautions and only $19(11.1 \%)$ were not applicable at the time of patient care. 


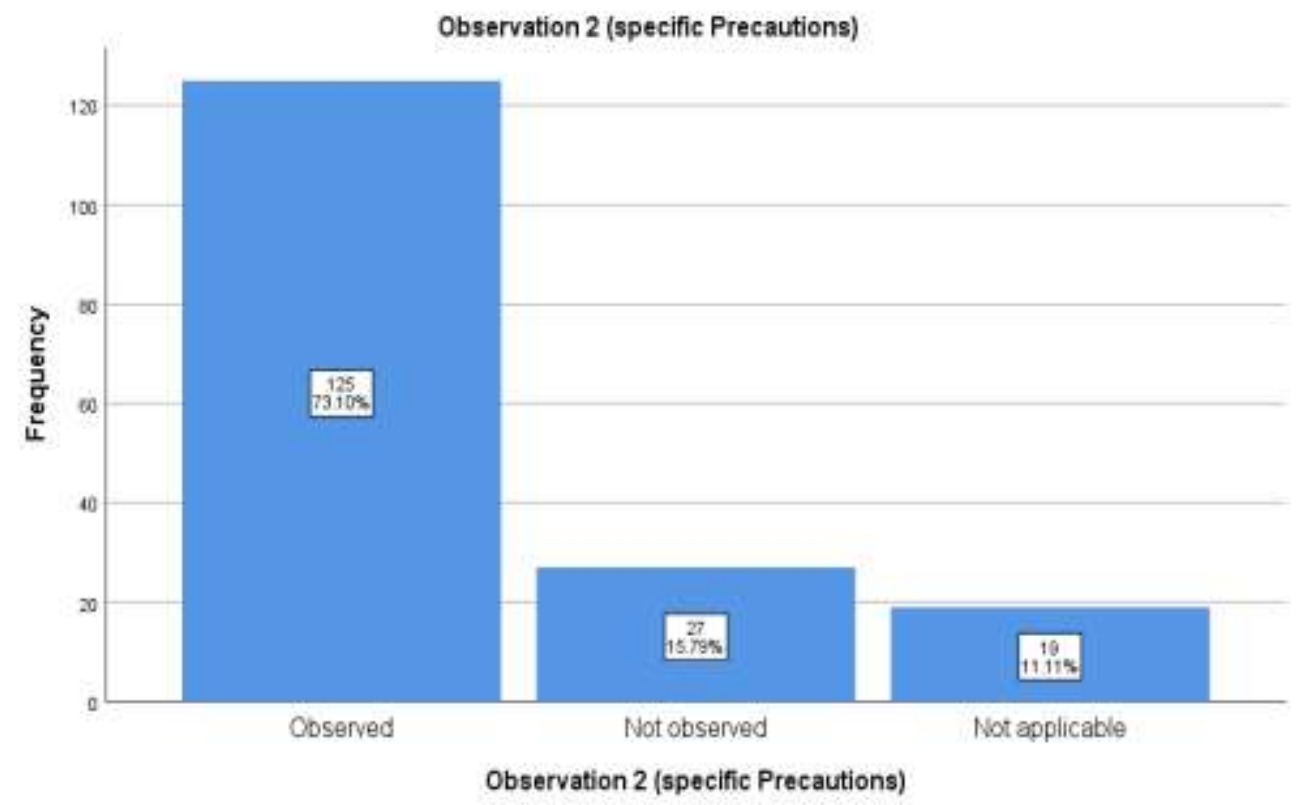

Figure 48

Figure 49 shows that the most of participants 115 (67.3\%) observed as to wash hand before procedure, 44 (25.7\%) did not wash hand before procedure and only $11(7 \%)$ were not applicable at the time of patient care.

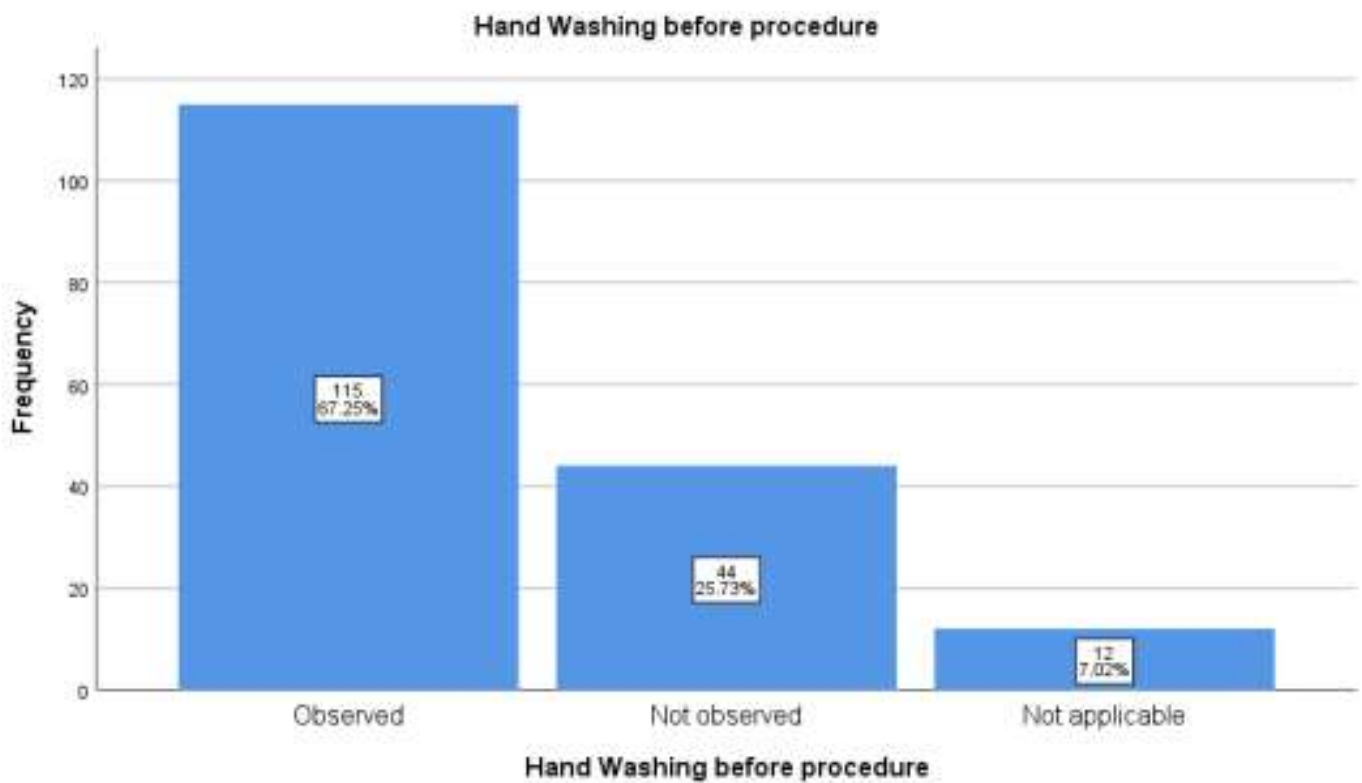

Figure 49

Figure 50 shows that the observation regarding item eighteen was show that $105(61.2 \%)$ participants were clean skin with antiseptic, $50(29.6 \%)$ did not clean skin with antiseptic and only $16(9.2 \%)$ were not applicable at the time of patient care. 


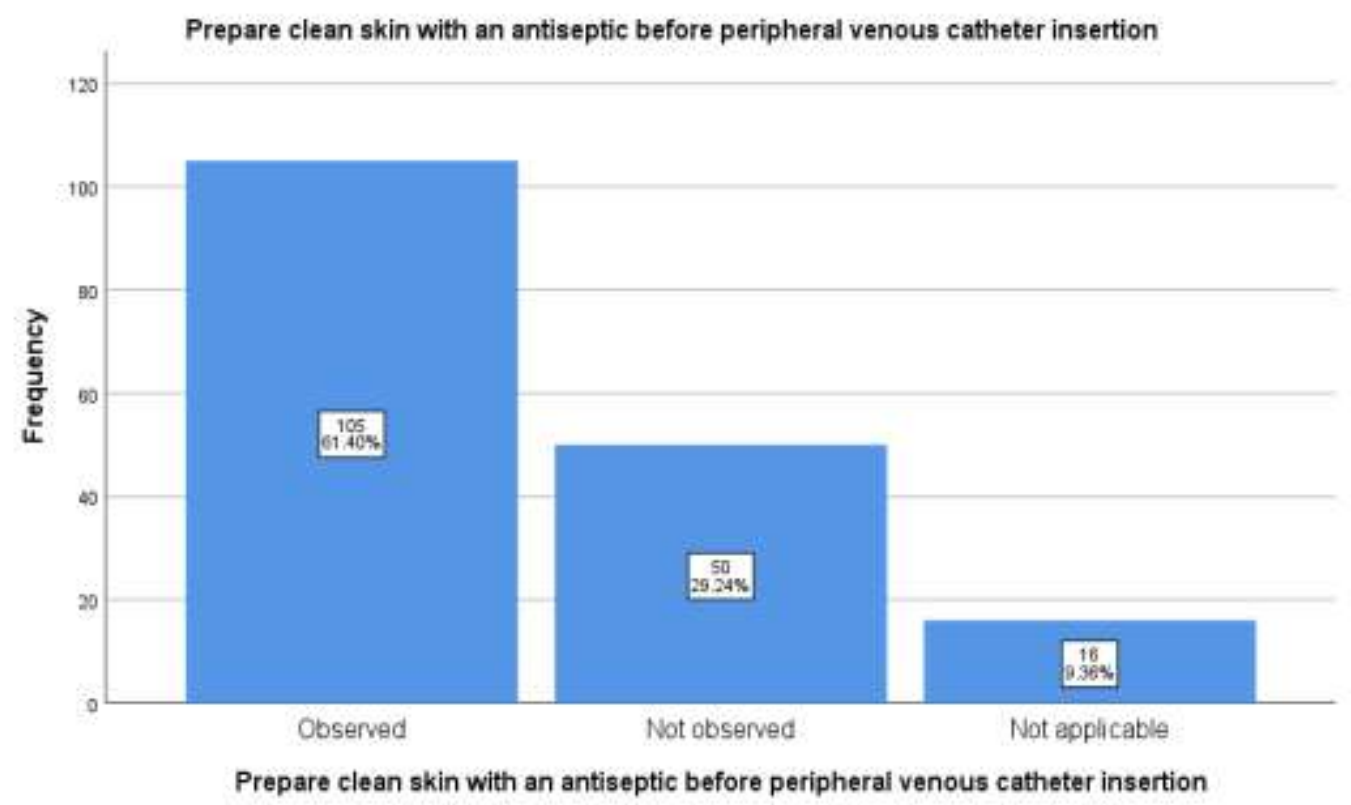

Figure 50

Figure 51 shows that the majority of participants 80 (46.8\%) observed as to use A-septics technique while placing catheter, $73(42.7 \%)$ did not use A-septics technique while placing catheter and only 18 (10.5\%) were not applicable at the time of patient care.

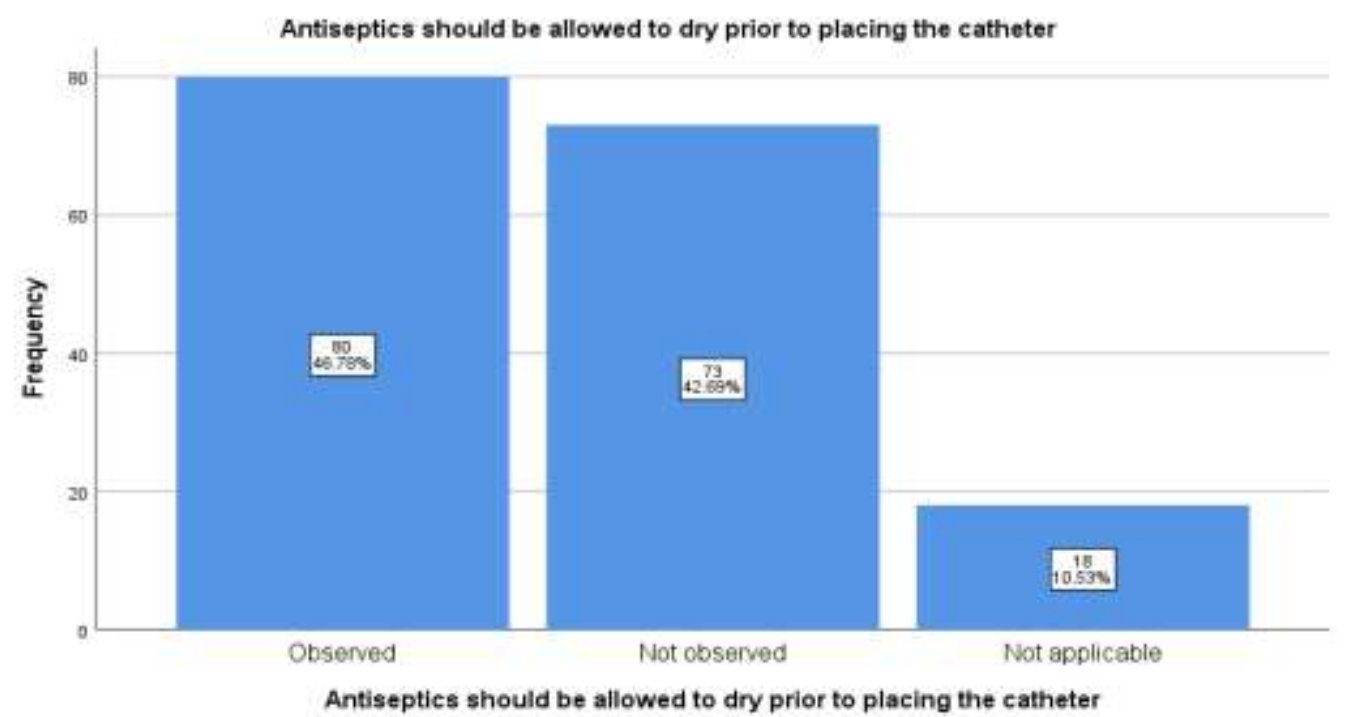

Figure 51

Figure 52 shows that the most of participants 102 (69.7\%) observed as to use standard application for dressing, 46 (25.3\%) did not use standard application for dressing and only 24 (14\%) were not applicable at the time of patient care. 


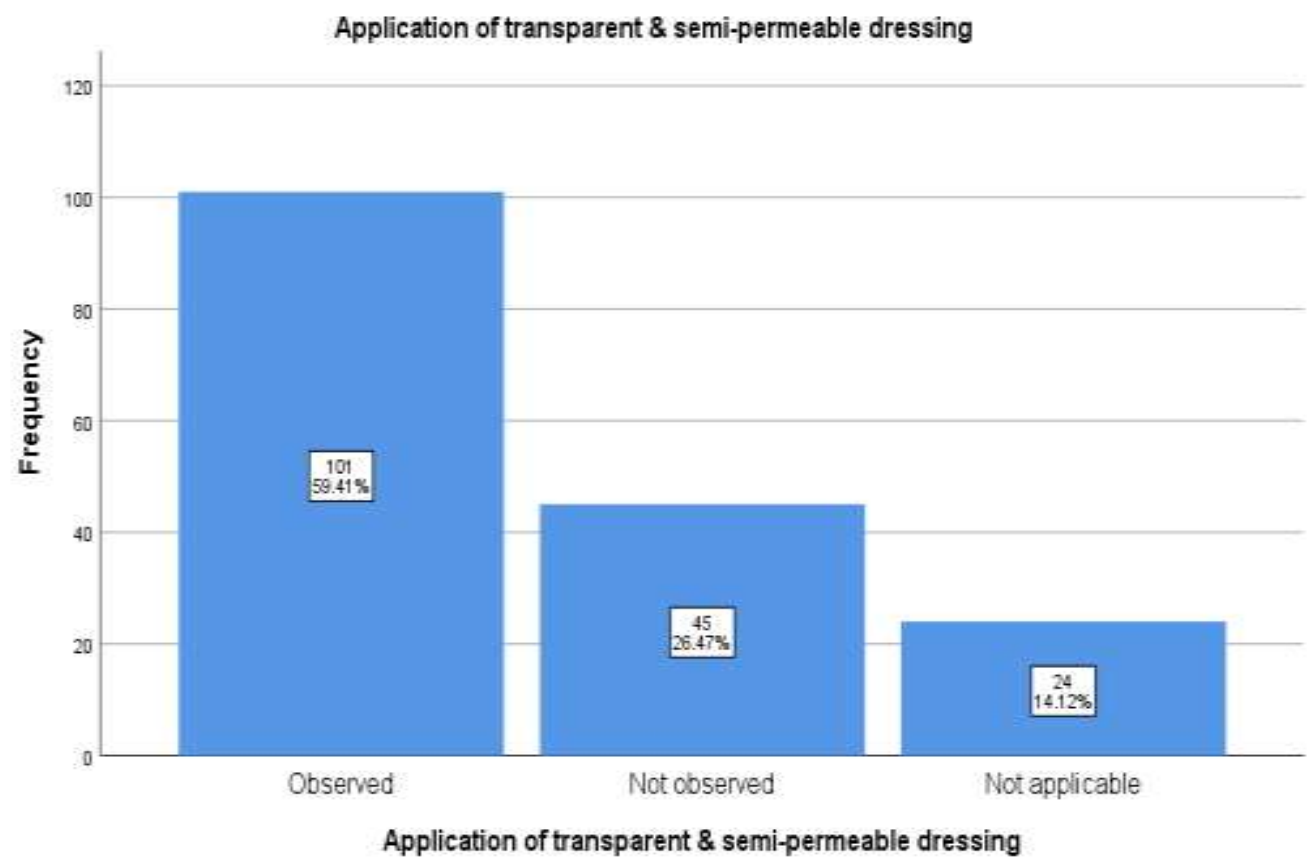

Figure 52

Figure 53 shows that the Observation regarding item twenty-one was show that 97 (56.3\%) participants were use Aseptic techniques during dressing, 65 (38\%) did use Aseptic techniques during dressing and only $9(5.7 \%)$ were not applicable at the time of patient care.

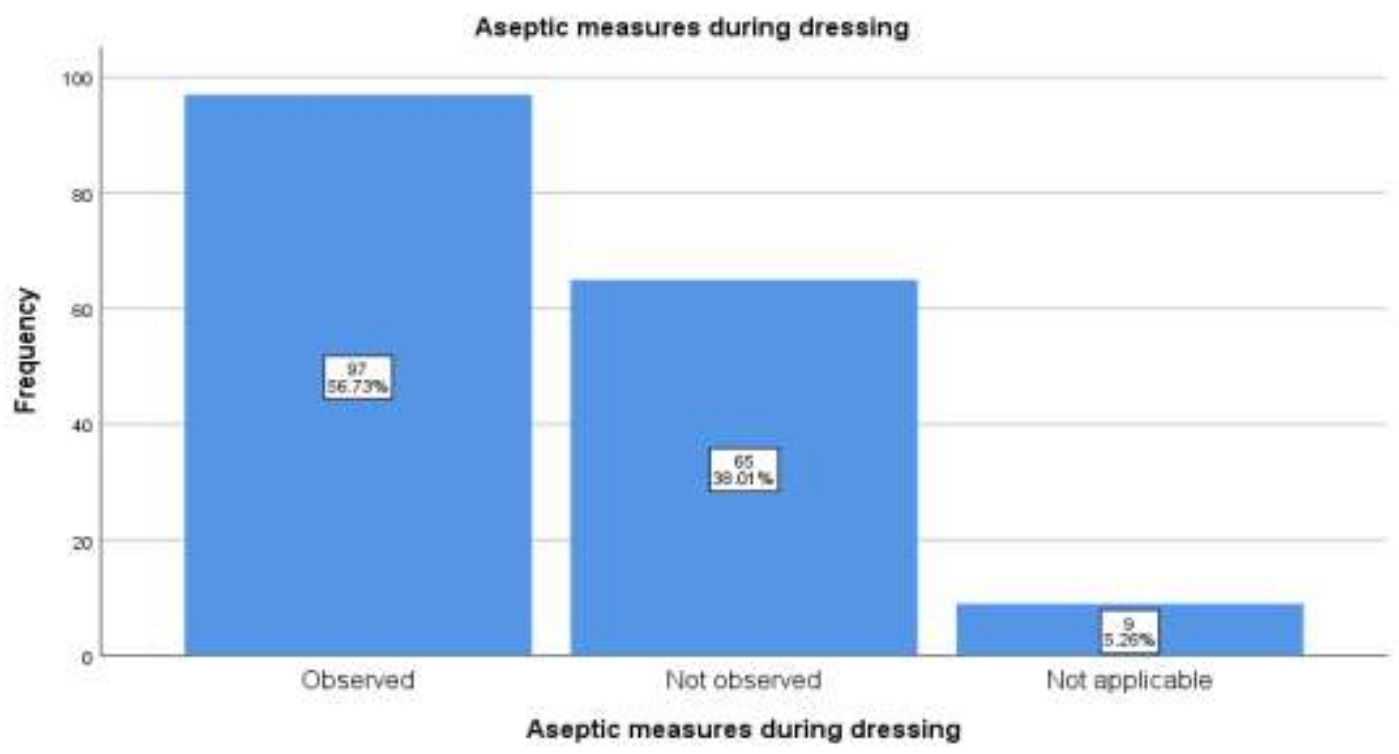

Figure 53

Figure 54 shows that the majority of participants $113(16.1 \%)$ observed as to know horizontal surfaces while cleaner clean the surface, 51 (29.8\%) did not to know horizontal surfaces while cleaner clean the surface and only $7(4.1 \%)$ were not applicable at the time of patient care. 


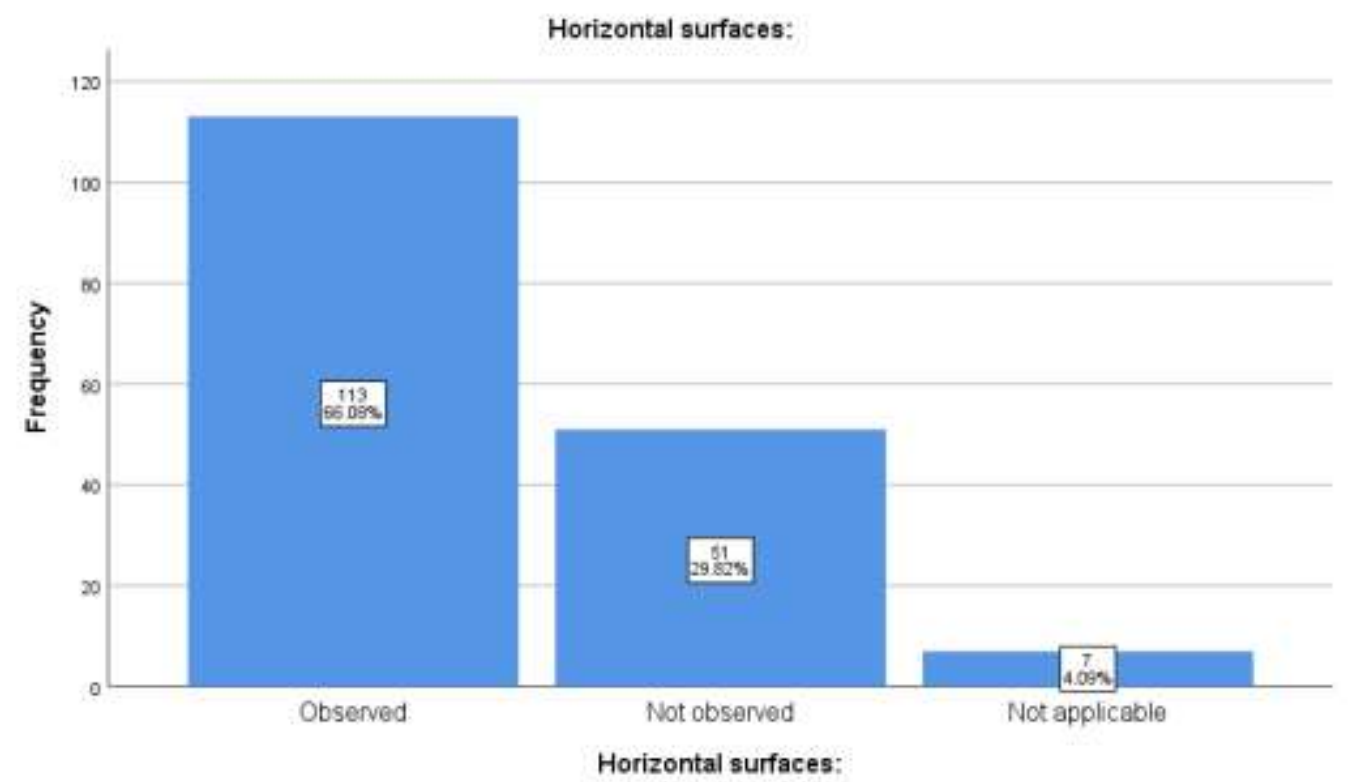

Figure 54

Figure 55 shows that the Most of participants 94 (55\%) observed as to ask the cleaner to clean walls, 60 (35.1\%) did not ask the cleaner to clean walls and only 17 (9.9\%) were not applicable at the time of patient care.

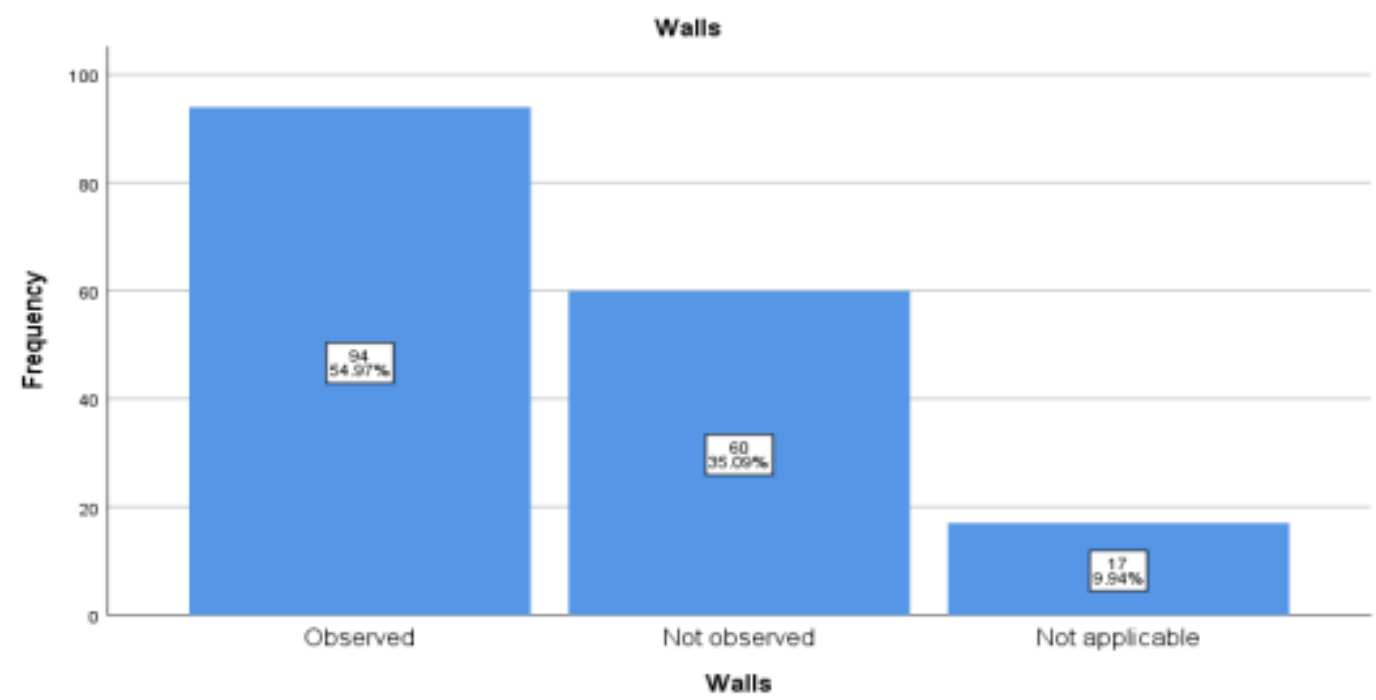

Figure 55

Figure 56 shows that the observation regarding item twenty-four was show that $87(50.9 \%)$ participants were disinfect the surfaces of furniture $79(46.2 \%)$ did not disinfect the surfaces of furniture and only $5(2.9 \%)$ were not applicable at the time of patient care. 


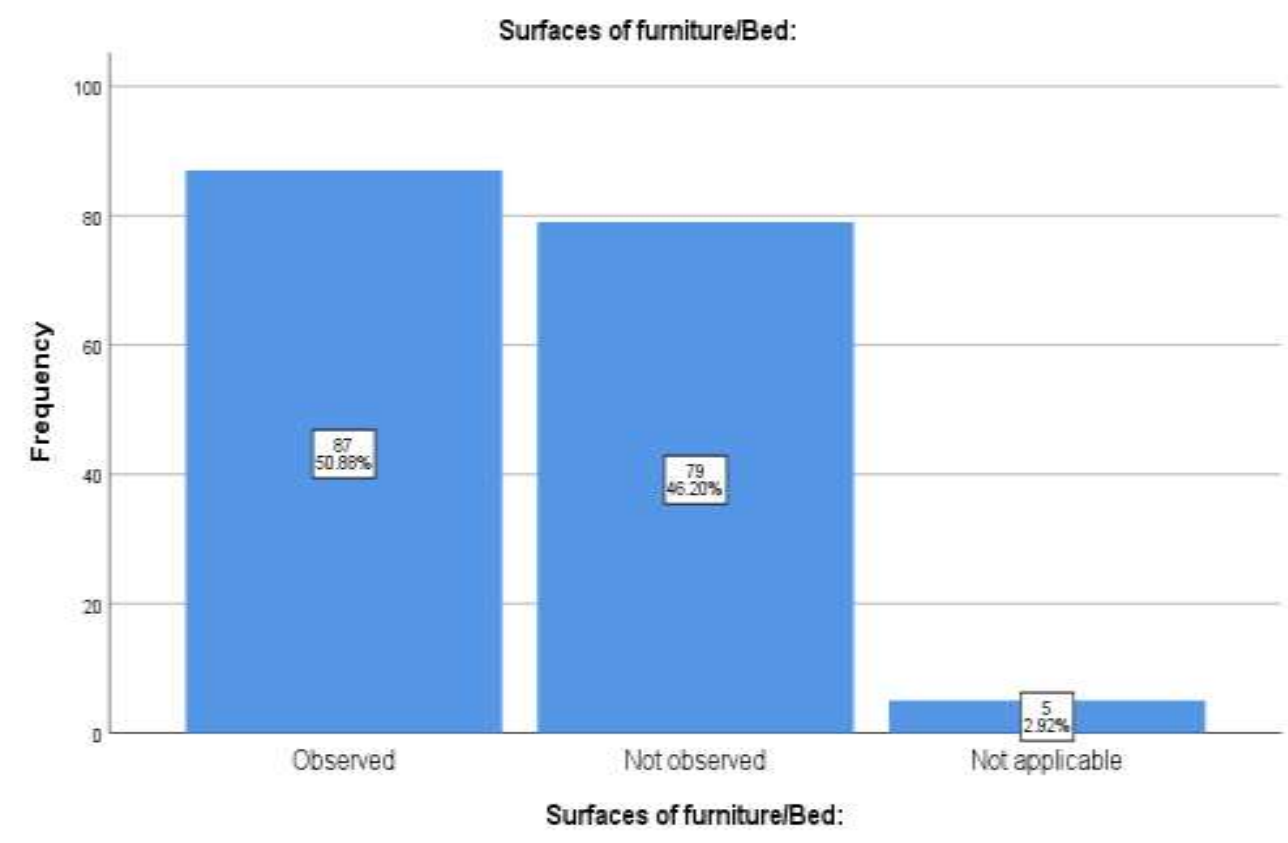

Figure 56

Figure 57 shows that the majority of participants 109 (63.9\%) observed as to disinfect the monitor, $57(32.2 \%)$ did not disinfect the monitor and only $5(2.9 \%)$ were not applicable at the time of patient care.

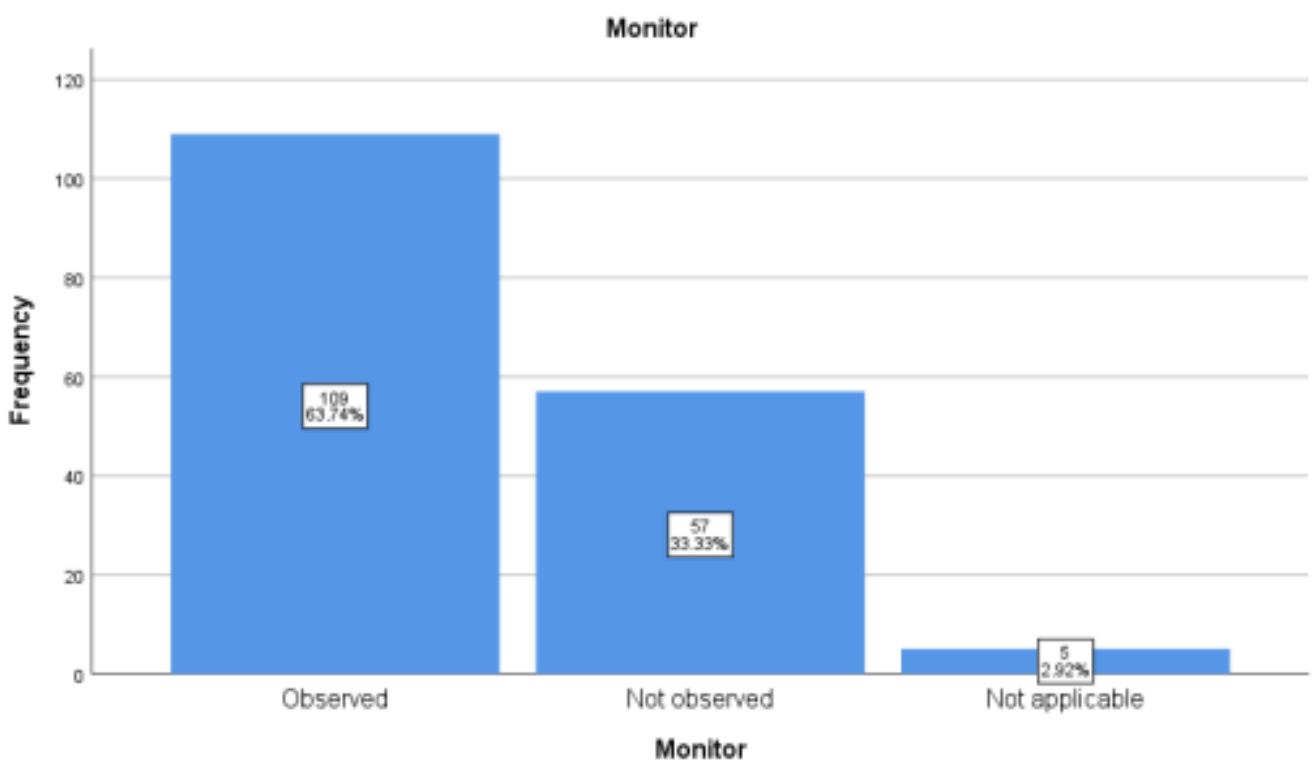

Figure 57

Figure 58 shows that the most of participants 86 (50.3\%) observed as give chlorhexidine bath, 85 (49.7\%) did not give chlorhexidine bath and only $0(0 \%)$ were not applicable at the time of patient care. 


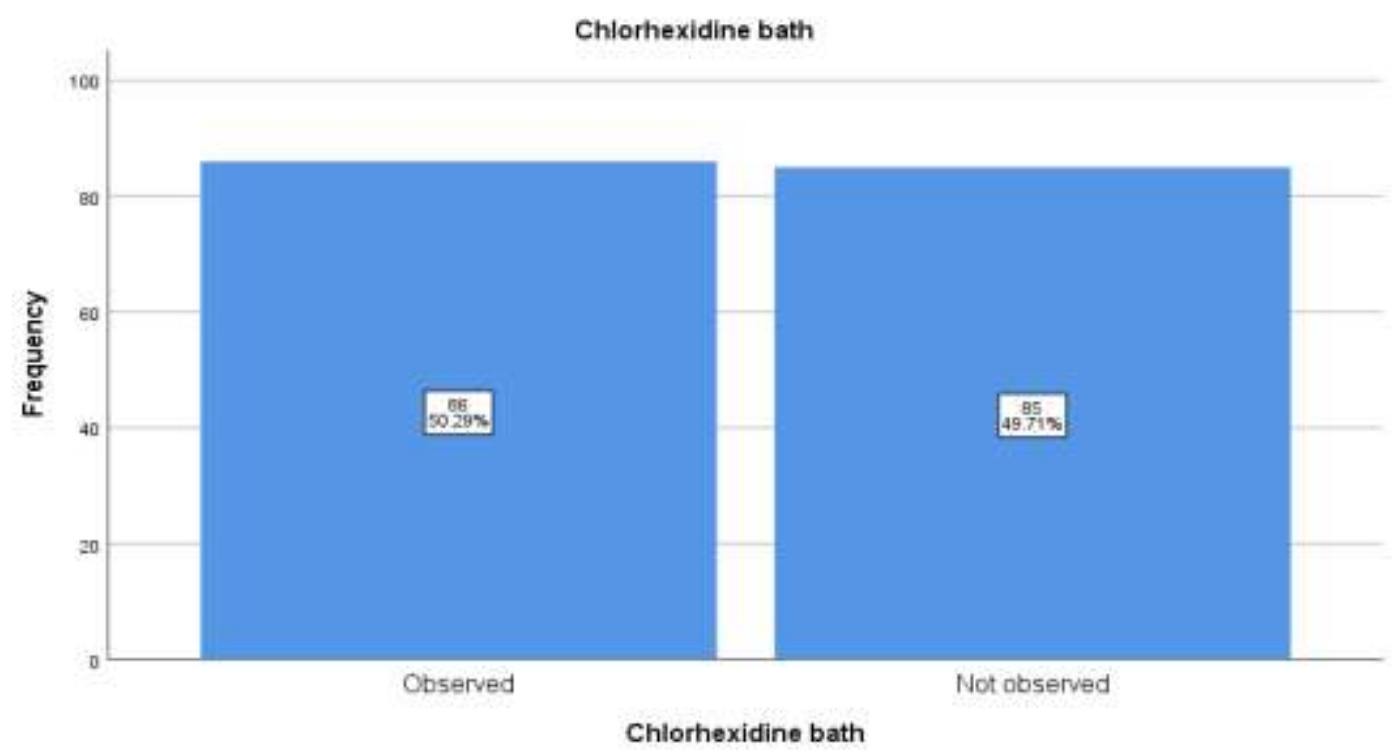

Figure 58

Figure 59 shows that the observation regarding item twenty-seven was show that 85 (49.7\%) participants were prefer to fumigation. $71(41.5 \%)$ did not prefer to fumigation and only $15(8.7 \%)$ were not applicable at the time of patient care

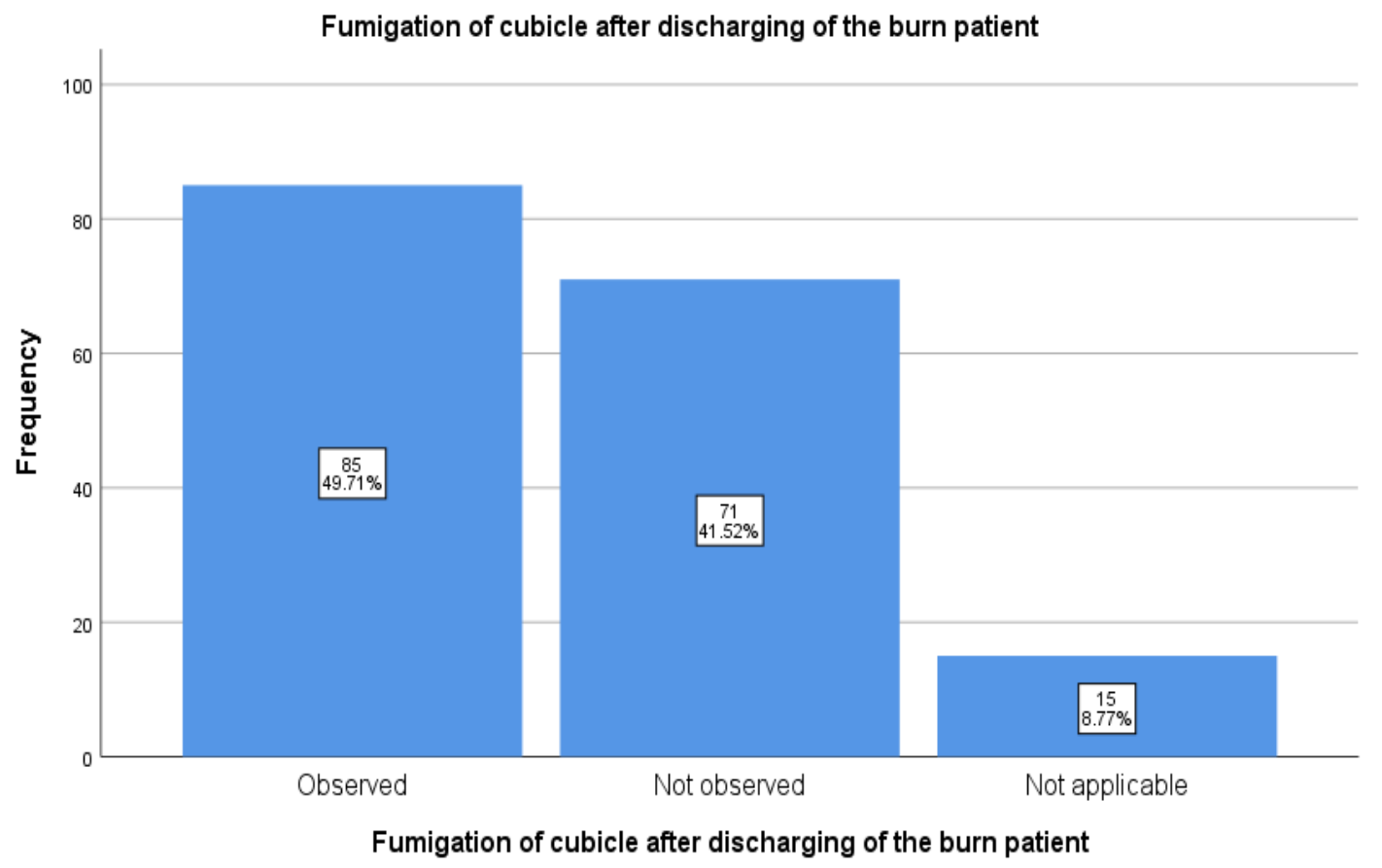

Figure 59

CHAPTER - IV

\section{Discussion}

The findings emerged from the data are that nurses in study areas have insufficient knowledge and practice about infection control in burn patients. However, they received information through practice but in-service education programs need to develop to prepare nurses for prevention of infection. 
Nurses' knowledge of infection control has fundamental role in preventing hospital acquired infections among burn patients. As majority of study participants received information regarding prevention of infection, the finding of current study showed low level of knowledge among nurses as indicated by the low percentages of accurate responses. The finding showed that about $60 \%(\mathrm{n}=171)$ has satisfactory level of knowledge indicated by unsatisfactory knowledge score 40\%. These findings are comparable to Atalla et al. work on compliance of nurses with infection control polices concluded that participants had low-level regarding infection control guidelines (Greenfield, 2010).

Likewise, twice a day chlorhexidine bath protocol is most effective method recommended for burn patients for decreasing hospital acquired infections even up to zero (Popp, Layon, Nappo, Richards, \& Mozingo, 2014). Findings of current study showed very low knowledge regarding this protocol because of unavailability of inservice education regarding prevention of HAI in burn patients. The present study revealed that majority 95 $(55.4 \%)$ of nurses have knowledge about these procedures but the $76(44.6 \%)$ have known knowledge about this. The findings are in agreement with Mohammad Zadeh et al. revealed poor knowledge of health care workers regarding infection control precautions (Mohammadzadeh, Behnaz, \& Parsa, 2013). The findings are contrary to Sorte, who reported that nurses have good $(76 \%)$ knowledge regarding prevention of hospital acquired infection (Joshi et al., 2015).

Burn patients with resistant organisms (for example MRSA) may serve as reservoir for transmission of infection to other patients, so these patients require various precautions specially contact precautions (Emaneini et al., 2018). The present study revealed low knowledge for such precautions especially contact precautions which are more essential for MRSA patients. The fining is consistent with Askarian et al. demonstrated low knowledge of health care workers for standard precautions and also reported that $90 \%$ of participants need extra infection control education (Askarian, Memish, \& Khan, 2007)

Nurses' practices complying with evidence-based guidelines about burn care have a crucial impact on preventing Infections among burn patients. The present study illustrates that not a single nurse has satisfactory level of practice as indicated by total performance scores $65 \%$. These findings may involve many factors such as low nurse to patient ratio, few burn centers, less experience in burn centre, unavailability of in-service training courses, diminished institutional resources and absence of specific protocol etc. Nurses' practices complying with evidencebased guidelines about burn care has crucial impact on preventing Infections among burn patients. All of the nurses showed unsatisfactory level of practice as indicated by total performance scores $<75 \%$. This finding is supported by study conducted by El-Sayed et al. in burn centre of Egypt who reported very low percentage of study sample had satisfactory level of practice for preventing infection in burn patients (El-Sayed et al., 2015).

As nurses' practices for infection control in burn patients mainly involve standard precautions but findings of present study showed very low performance. This may be due to overburden of nurses and unavailability of resources. These consequences are also shared by Abdulraheem et al. who observed poor compliance of health care workers regarding standard precautions during care of patients (Abdulraheem, Amodu, Saka, Bolarinwa, \& Uthman, 2012). 
Hand hygiene is the first initial step towards successful infection control in any healthcare setup including burn Centre. Although the results found that all of nurses had unsatisfactory level of practice but regarding hand washing $110(64.3 \%)$ nurses shows positivity to hand hygiene and $56(32.7 \%)$ did not wash hand or not follow the hand washing steps. Many research studies investigating the compliance to hand hygiene such as Karaaslan et al. also observed only $41 \%$ compliance similar to findings of present study (Karaaslan et al., 2014).

Use of Personal protective equipment (PPE) includes the use of mask, sterile gown and sterile gloves during care of patient. Carrer et al. found reduction in the risk of skin colonization when PPE were implemented (Verbeek et al., 2019). In present study nurses shows unsatisfactory compliance as 81 (75\%) use masks, $92(53.8 \%)$ use masks but very poor compliance for use of gowns (45\%) because they thought that gowns are not necessary during care of patient. Consequently, an overall low performance for PPE was noted because even not wearing gowns can lead to cross contamination between the patients. Findings are agreement with Ganczak and Szych, who reported only low (5\%) compliance to PPE by nurses (Ganczak \& Szych, 2007).

Cleaning and disinfection of medical devices is so important to prevent buildup of various microorganisms onto medical devices, it is highly likely that bacteria will grow if left unchecked or without disinfection properly. Findings of present study showed very low compliance with it. In consistent with Quinn et al. who concluded with that equipment cleaning was observed on approximately one-fourth of the person days for registered nurses (Quinn et al., 2015).

Conclusion: Based on the findings of the study, it is concluded that nurses working in burn units of hospital of Lahore, Punjab region have low knowledge and practices regarding prevention of Infections among burn patients. Therefore, hospitals are required to organize adequate trainings and to develop unit specific clinical infection control guidelines and protocols.

Limitations: There are many limitations found for this study;

$>$ Investigation discoveries will be restricted and can't be summed up on the generalized that the little example and chose from one land region in Pakistan.

$>$ The extent of the examination will be additionally restricted not utilized control group

$>$ The scope of the study will be also limited not used control group.

$>$ The duration for this study was too short.

$>$ Data collection faced lot of issues.

$>$ The participants of the study were careless and non-cooperative regarding to fill the questionnaire.

$>$ Investigation discoveries will be restricted and can't be summed up generally that the little example and chose from one topographical zone in Pakistan.

$>$ The extent of the investigation will be likewise restricted not utilized benchmark group.

\section{Acknowledgement}

This research was biggest step for me and that was not possible without the guidance and enlightenment blessed by God. So, I thank to God for the blessings.

I would like to thank my research supervisor Mr. Muhammad Hussain for his support and guidance throughout the course of this research study and for providing an excellent role model for a novice researcher. 
I would like to thanks authorities of university who gave me permission to collect data from the community. I am also thankful to the participants who actively participated, and gave me their precious time and information in this research.

I would also thanks to my Parents, husband, sisters and my cute children who stood by me and bear my not attending to them in busy days of my research study.

Last but not least, I am very thankful to Mr. Muhammad Sabir who being teacher of English subject supports me and correction without any benefit.

\section{References:}

Abdulraheem, I., Amodu, M., Saka, M., Bolarinwa, O., \& Uthman, M. (2012). Knowledge, awareness and compliance with standard precautions among health workers in north eastearn Nigeria. J Community Med Health Edu, 2(3), 1-5.

Abukhelaif, A. E. (2019). Personal Protective Equipment Knowledge and Practices among Nurses Working at AlBaha King Fahad Hospital, Saudi Arabia. ARCHIVOS DE MEDICINA, 4(1), 2.

Adegboye, M. B., Zakari, S., Ahmed, B. A., \& Olufemi, G. H. (2018). Knowledge, awareness and practice of infection control by health care workers in the intensive care units of a tertiary hospital in Nigeria. African health sciences, 18(1), 72-78.

AL-Salih, S. S. H., Muhbes, F. J., \& Hindi, N. K. K. (2018). Assessment of Nurses' Knowledge about Nosocomial Infection at Burns Units in the Middle Euphrates Teaching Hospitals. Age (years), 20(29), 89.

Alrubaiee, G., Baharom, A., Shahar, H. K., Daud, S. M., \& Basaleem, H. O. (2017). Knowledge and practices of nurses regarding nosocomial infection control measures in private hospitals in Sana'a City, Yemen. Safety in Health, 3(1), 16.

Askarian, M., Memish, Z. A., \& Khan, A. A. (2007). Knowledge, practice, and attitude among Iranian nurses, midwives, and students regarding standard isolation precautions. Infection Control \& Hospital Epidemiology, 28(2), 241-244.

Badran, I. G. (1995). Knowledge, attitude and practice the three pillars of excellence and wisdom: a place in the medical profession.

Buksh, N. A., Ghani, M., Amir, S., Asmat, K., \& Ashraf, S. (2019). Assessment of Nurses' Knowledge and Practice for Prevention of Infection in Burn Patients.

Calandra, T., \& Cohen, J. (2005). The international sepsis forum consensus conference on definitions of infection in the intensive care unit. Critical care medicine, 33(7), 1538-1548.

Cancio, L. C., Barillo, D. J., Kearns, R. D., Holmes IV, J. H., Conlon, K. M., Matherly, A. F., . . Palmieri, T. (2017). Guidelines for burn care under austere conditions: surgical and nonsurgical wound management. Journal of Burn Care \& Research, 38(4), 203-214.

Carrico, R. M., Garrett, H., Balcom, D., \& Glowicz, J. B. (2018). Infection prevention and control core practices: A roadmap for nursing practice. Nursing, 48(8), 28.

Dancer, S. J. (2014). Controlling hospital-acquired infection: focus on the role of the environment and new technologies for decontamination. Clinical microbiology reviews, 27(4), 665-690. 
Davies, H., Bignell, G. R., Cox, C., Stephens, P., Edkins, S., Clegg, S., . . Bottomley, W. (2002). Mutations of the BRAF gene in human cancer. Nature, 417(6892), 949-954.

El-Maghawry, H., El Nem, W., Sherif, N., \& Hagag, S. (2016). An interventional study to decrease healthcare associated burn wound infections in the burn unit of Al Ahrar Hospital in Zagazig city, Sharkia Governorate. Int J Curr Microbiol Appp Sci, 5, 566-578.

El-Sayed, M., Gomaa, M., \& Abdel-Aziz, M. (2015). Nurses' knowledge and practice for prevention of infection in burn unit at a university hospital: suggested nursing guidelines. J Nurs Health Sci, 4(4), 62-69.

Eldeen, A. I. E., Abd-Elaziz, M., Moghazy, A. M., Shahin, E. S., \& El-Ata, A. B. A. (2016). Evaluation of an infection control measures protocol application by nurses on patients' safety at burn units. Journal of Surgery, 4(3-1), 1-9.

Emaneini, M., Beigverdi, R., van Leeuwen, W. B., Rahdar, H., Karami-Zarandi, M., Hosseinkhani, F., \& Jabalameli, F. (2018). Prevalence of methicillin-resistant Staphylococcus aureus isolated from burn patients in Iran: a systematic review and meta-analysis. Journal of global antimicrobial resistance, 12, 202-206.

Ganczak, M., \& Szych, Z. (2007). Surgical nurses and compliance with personal protective equipment. Journal of Hospital Infection, 66(4), 346-351.

Greenfield, E. (2010). The pivotal role of nursing personnel in burn care. Indian Journal of Plastic Surgery, 43(S 01), S94-S100.

JEROTICH, C. J. (2016). Assessment of aseptic technique among nurses in management of burns patients at kenyatta national hospital. UNIVERSITY OF NAIROBI.

Joshi, P., Thakur, B., Rawat, D., Negi, U. M., Bhaisora, M., Sharma, G., . . Sorte, M. D. (2015). Nurses knowledge related to prevention of nosocomial infection. Nursing, 4(7).

Karaaslan, A., Kepenekli Kadayifci, E., Atıcı, S., Sili, U., Soysal, A., Çulha, G., . . Bakır, M. (2014). Compliance of healthcare workers with hand hygiene practices in neonatal and pediatric intensive care units: overt observation. Interdisciplinary perspectives on infectious diseases, 2014.

Lai, N. M., Lai, N. A., O'Riordan, E., Chaiyakunapruk, N., Taylor, J. E., \& Tan, K. (2016). Skin antisepsis for reducing central venous catheter-related infections. Cochrane database of systematic reviews(7).

Ling, M. L., Apisarnthanarak, A., Villanueva, V., Pandjaitan, C., \& Yusof, M. Y. (2015). APSIC Guidelines for environmental cleaning and decontamination. Antimicrobial resistance and infection control, 4(1), 58.

Manning, J. (2018). Field guide to fynbos: Penguin Random House South Africa.

Manning, J. (2018). Sepsis in the burn patient. Critical Care Nursing Clinics, 30(3), 423-430.

Mohammadzadeh, M., Behnaz, F., \& Parsa, S. (2013). Knowledge, practice and attitude towards standard isolation precautions in nurses, auxiliary nurses and midwives of Shahid Sadoughi Hospital, Yazd, Iran. Int J Infect Control, 9(1), 1-8.

Musuuza, J. S., Guru, P. K., O’Horo, J. C., Bongiorno, C. M., Korobkin, M. A., Gangnon, R. E., \& Safdar, N. (2019). The impact of chlorhexidine bathing on hospital-acquired bloodstream infections: a systematic review and meta-analysis. BMC infectious diseases, 19(1), 416.

Norbury, W., Herndon, D. N., Tanksley, J., Jeschke, M. G., Finnerty, C. C., \& Society, S. S. C. o. t. S. I. (2016). Infection in burns. Surgical infections, 17(2), 250-255. 
Organization, W. H. (2015). Water, sanitation and hygiene in health care facilities: status in low and middle income countries and way forward.

Othman, N., \& Kendrick, D. (2010). Epidemiology of burn injuries in the East Mediterranean Region: a systematic review. BMC public health, $10(1), 83$.

Pepin, J., Chakra, C. N. A., Pepin, E., Nault, V., \& Valiquette, L. (2014). Evolution of the global burden of viral infections from unsafe medical injections, 2000-2010. PloS one, 9(6).

Popp, J. A., Layon, A. J., Nappo, R., Richards, W. T., \& Mozingo, D. W. (2014). Hospital-acquired infections and thermally injured patients: chlorhexidine gluconate baths work. American journal of infection control, 42(2), 129-132.

Quinn, M. M., Henneberger, P. K., Braun, B., Delclos, G. L., Fagan, K., Huang, V., . . Le Moual, N. (2015). Cleaning and disinfecting environmental surfaces in health care: toward an integrated framework for infection and occupational illness prevention. American journal of infection control, 43(5), 424-434.

Quirke, S., Coombs, M., \& McEldowney, R. (2011). Suboptimal care of the acutely unwell ward patient: a concept analysis. Journal of Advanced Nursing, 67(8), 1834-1845.

Rowley, S., \& Clare, S. (2019). Right Asepsis with ANTT® for Infection Prevention Vessel Health and Preservation: The Right Approach for Vascular Access (pp. 147-162): Springer.

Rozenbojm, M. D., Nichol, K., Spielmann, S., \& Holness, D. L. (2015). Hospital unit safety climate: relationship with nurses' adherence to recommended use of facial protective equipment. American Journal of Infection Control, 43(2), 115-120.

Tarvadi, P. V. (2018). A Study On Waste Disposal Management In A Tertiary Care Hospital. Journal of Punjab Academy of Forensic Medicine \& Toxicology, 18(1), 54-57.

Unicomb, L., Horng, L., Alam, M.-U., Halder, A. K., Shoab, A. K., Ghosh, P. K., . . Luby, S. P. (2018). Healthcare facility water, sanitation, and health-care waste management basic service levels in Bangladesh: results from a nation-wide survey. The American journal of tropical medicine and hygiene, 99(4), 916923.

Verbeek, J. H., Rajamaki, B., Ijaz, S., Tikka, C., Ruotsalainen, J. H., Edmond, M. B., . . Balci, F. S. K. (2019). Personal protective equipment for preventing highly infectious diseases due to exposure to contaminated body fluids in healthcare staff. Cochrane database of systematic reviews(7). 


\section{QUESTIONNAIRE}

\section{ASSESSMENT OF NURSES' KNOWLEDGE AND PRACTICE FOR PREVENTION OF INFECTION IN BURN PATIENTS IN TERTIARY CARE HOSPITAL LAHORE}

This study is done by Ms. Rukhsana Manzoor in the supervision of respected preceptor, department Nursing. The purpose of this study is to investigate the "ASSESSMENT OF NURSES' KNOWLEDGE AND PRACTICE FOR PREVENTION OF INFECTION IN BURN PATIENTS IN TERTIARY CARE HOSPITAL

LAHORE". Your participation is completely voluntary. You may withdraw at any time for any reason without explanation and without penalty. All records of participation will be kept strictly confidential, such that only I and my supervisor will have access to the information. Your participation in this study will be highly appreciated. This survey is only for the academic purpose and takes maximum 15-20 minutes.

Participants Signature:

Section A: Demographics

Respond by circling (O) or ticking ( ) the most appropriate responses

\begin{tabular}{|c|c|c|c|}
\hline Age & $\begin{array}{l}\text { 21-28 years } \\
\text { 29-36 years } \\
\text { प } 37-44 \text { years } \\
\square \text { 45-52 years }\end{array}$ & Experience & $\begin{array}{l}\text { ㅁ 1-3 year } \\
\text { 4-6 year } \\
\text { } 7-9 \text { year } \\
\text { प 10-12 year }\end{array}$ \\
\hline Qualifications & $\begin{array}{l}\text { Diploma in midwifery } \\
\square \text { Diploma in general nursing } \\
\square \text { Bachelor of science in nursing (Post RN) } \\
\square \text { Bachelor of science in nursing (Generic) }\end{array}$ & $\begin{array}{l}\text { Protocol } \\
\text { availability } \\
\text { regarding } \\
\text { infection } \\
\text { control }\end{array}$ & $\begin{array}{l}\square \text { Yes } \\
\square \text { No }\end{array}$ \\
\hline $\begin{array}{l}\text { Information } \\
\text { received regarding } \\
\text { infection control }\end{array}$ & $\begin{array}{l}\text { 口Yes } \\
\square \text { No }\end{array}$ & & \\
\hline
\end{tabular}

Section B: assessment regarding nursing knowledge

\begin{tabular}{|c|c|c|c|}
\hline SN & Self-assessment questions & Yes & No \\
\hline 1 & Burn patients are unique due to propensity to disperse microbes in environment & & \\
\hline 2 & Did you know that the about referral criteria of American Burn Association? & & \\
\hline 3 & Did you know that which zone is located in the center of burn wound? & & \\
\hline 4 & $\begin{array}{l}\text { Did you know that the soak the burn in cool water, then treat it with a skin care product like } \\
\text { aloe vera cream or an antibiotic ointment? }\end{array}$ & & \\
\hline 5 & Did you know that the one of major burn infection is burn wound cellulitis? & & \\
\hline 6 & $\begin{array}{l}\text { Did you know that the common cause of fever in burn patients is systemic inflammatory } \\
\text { response not a pathogenic action of microorganisms? }\end{array}$ & & \\
\hline 7 & Did you know that the burn wound cellulitis is most common infection in burn patients? & & \\
\hline 8 & Did you know that the burn wounds initially colonized with gram-positive organisms? & & \\
\hline 9 & $\begin{array}{l}\text { Did you know that the sepsis syndrome clinically manifested by following, bloodstream } \\
\text { infection, Fluid loss, including low blood volume, Dangerously low body temperature? }\end{array}$ & & \\
\hline 10 & $\begin{array}{l}\text { Did you know that the exogenous microorganisms are more resistant as compared to } \\
\text { endogenous }\end{array}$ & & \\
\hline
\end{tabular}




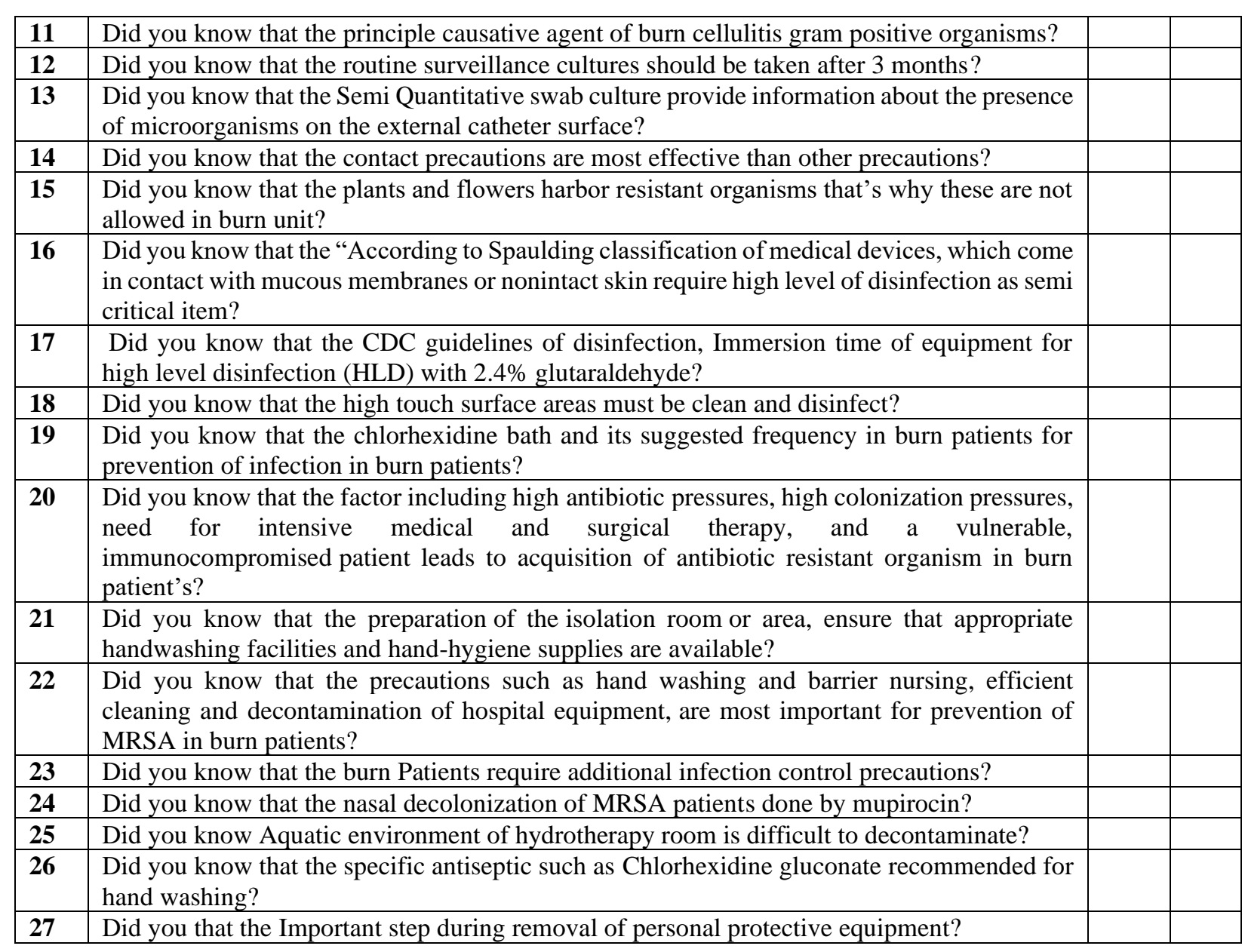

Checklist regarding prevention of infection in burn patients

\begin{tabular}{|l|l|l|l|l|}
\hline \multirow{2}{*}{$\begin{array}{c}\text { Sr } \\
\text { No }\end{array}$} & \multicolumn{1}{|c|}{ Preventive measure } & \multicolumn{2}{c|}{ observations } \\
\cline { 4 - 5 } & Observed & $\begin{array}{c}\text { Not } \\
\text { observed }\end{array}$ & $\begin{array}{c}\text { Not } \\
\text { applicable }\end{array}$ \\
\hline $\mathbf{0 1}$ & $\begin{array}{l}\text { Hand washing with alcohol rub / antimicrobial material before } \\
\text { the procedure }\end{array}$ & & & \\
\hline $\mathbf{0 2}$ & Mask & & & \\
\hline $\mathbf{0 3}$ & Gown & & & \\
\hline $\mathbf{0 4}$ & Gloves & & & \\
\hline $\mathbf{0 5}$ & Use No Touch Technique & & & \\
\hline $\mathbf{0 6}$ & Proper Disinfection of Medical Devices Thermometer & & \\
\hline $\mathbf{0 7}$ & Sphygmomanometer: & & & \\
\hline $\mathbf{0 8}$ & Stethoscope & & & \\
\hline $\mathbf{0 9}$ & Blood glucose monitoring equipment & & \\
\hline $\mathbf{1 0}$ & Safe Disposal of Needle and Sharp materials & & \\
\hline $\mathbf{1 1}$ & Proper Handling of Soiled linen & & \\
\hline $\mathbf{1 2}$ & Proper Disposal of Personal Protective Equipment': & & \\
\hline $\mathbf{1 3}$ & Proper Disposal of Clinical Waste & & & \\
\hline $\mathbf{1 4}$ & Hand washing after the procedure & & & \\
\hline $\mathbf{1 5}$ & Obeying Patient visitor policy & & & \\
\hline $\mathbf{1 6}$ & Observation 2 (specific Precautions) & & \\
\hline $\mathbf{1 7}$ & Hand Washing before procedure & & & \\
\hline $\mathbf{1 8}$ & Prepare clean skin with an antiseptic before peripheral venous \\
& catheter insertion & & & \\
\hline
\end{tabular}




\begin{tabular}{|l|l|l|l|l|}
\hline $\mathbf{1 9}$ & $\begin{array}{l}\text { Antiseptics should be allowed to dry prior to placing the } \\
\text { catheter }\end{array}$ & & \\
\hline $\mathbf{2 0}$ & Application of transparent \& semi-permeable dressing & & & \\
\hline $\mathbf{2 1}$ & Aseptic measures during dressing & & & \\
\hline $\mathbf{2 2}$ & Horizontal surfaces: & & & \\
\hline $\mathbf{2 3}$ & Walls & & & \\
\hline $\mathbf{2 4}$ & Surfaces of furniture/Bed: & & & \\
\hline $\mathbf{2 5}$ & Monitor & & & \\
\hline $\mathbf{2 6}$ & Chlorhexidine bath & & & \\
\hline $\mathbf{2 7}$ & Fumigation of cubicle after discharging of the burn patient & & \\
\hline
\end{tabular}

